\begin{tabular}{|c|c|c|}
\hline Beitr. Ent. & Keltern & ISSN 0005-805X \\
\hline $\mathbf{6 1}(2011) 1$ & S. $89-148$ & 16.05 .2011 \\
\hline
\end{tabular}

\title{
A revision of the genus Neosclerus CAMERon
}

\section{(Coleoptera: Staphylinidae: Paederinae)}

With 188 figures

Volker Assing

\section{Summary}

Neosclerus Cameron, 1924 is closely related to Sunius Stephens, 1829 of the Medonina and is distributed in the Oriental and southern East Palaearctic regions. The genus is redescribed; its intra- and intergeneric phylogenetic affiliations are discussed. The types of all previously described species and additional material are revised. Twenty-six species are recognized, (re-)described, and illustrated, 19 of them for the first time: Neosclerus armatus sp. n. (Taiwan), N. barbatulus sp. n. (Thailand, Myanmar, China), N. barbatus sp. n. (Thailand), N. bicarinatus sp. n. (Vietnam), N. bifidus sp. n. (Taiwan), N. carinatus sp. n. (Taiwan), $N$. configens sp. n. (Taiwan), $N$. dupleseriatus sp. n. (N. India), N. erubescens sp. n. (Borneo), N. glaber sp. n. (S. China, Hongkong, Thailand, Malaysia), N. hlavaci sp. n. (China: Fujian, Jiangxi), N. inarmatus sp. n. (Taiwan), $N$. incisus sp. n. (China: Guangxi), $N$. praeacutus sp. n. (China: Yunnan), N. rimatus sp. n. (China: Guangxi), N. rougemonti sp. n. (Thailand), N. schillhammeri sp. n. (Myanmar), N. schuelkei sp. n. (China: Yunnan), N. smetanai sp. n. (Taiwan). Several additional species are listed, but not described, since they are represented only by females. The secondary homonym Lobochilus brachypterus Cameron, 1943 is replaced with Sunius cameroni nom. n. Two synonymies are proposed: Neosclerus brevipennis (Cameron, 1943) = Lobochilus houlberti (CoIffaIt, 1987), syn. n.; N. granulicollis CAMERon, $1924=N$. frater CAMERon, 1924, syn. n. Four new combinations are established: Neosclerus assamensis (CAmeron, 1931), comb. n. (ex Lobochilus), N. javanus (Bernhauer, 1920); comb. n. (ex Lobochilus), N. nigerrimus (KraAtz, 1859); comb. n. (ex Lobochilus), and "Medon" labralis (CAmeron, 1943), comb. n. (ex Neosclerus). Lectotypes are designated for Neosclerus fortepunctatus Cameron, 1924, N. granulicollis Cameron, 1924, N. frater Cameron, 1924, Lobochilus assamensis Cameron, 1931, and Lithocharis nigerrima Kraatz, 1859. Data on the distribution and natural history of the Neosclerus species are compiled. Some of them are apparently active flyers and widespread. Micropterous species with low dispersal power and restricted distributions are known only from southern China and Taiwan, the regions with the highest species diversity. Neosclerus species apparently live in - usually moist - leaf litter and moss in forests, shrub habitats, and on banks of streams. A key to species and a catalogue are provided.

\section{Key words}

Coleoptera, Staphylinidae, Paederinae, Medonina, Neosclerus, Sunius, Palaearctic region, Oriental region, taxonomy, new species, new synonymies, new combinations, replacement name, lectotype designations, key to species, additional records

\section{New species}

Neosclerus armatus sp. n., N. barbatulus sp. n., N. barbatus sp. n., N. bicarinatus sp. n., N. bifidus sp. n., $N$. carinatus sp. n., $N$. configens sp. n., $N$. dupleseriatus sp. n., $N$. erubescens sp. n., $N$. glaber sp. n., $N$. hlavaci sp. n., $N$. inarmatus sp. n., $N$. incisus sp. n., $N$. praeacutus sp. n., $N$. rimatus sp. n., $N$. rougemonti sp. n., N. schillhammeri sp. n., N. schuelkei sp. n., N. smetanai sp. n. 


\section{Zusammenfassung}

Neosclerus Cameron, 1924 ist nah verwandt mit der Gattung Sunius Stephens, 1829 (Subtribus Medonina); die derzeit bekannte Verbreitung ist auf die Orientalis und die südliche Ostpaläarktis beschränkt. Die Gattung wird redeskribiert; die phylogenetischen Beziehungen zu anderen Gattungen sowie innerhalb der Gattung werden diskutiert. Die Typen aller bisher beschriebenen Arten sowie weiteres Material werden revidiert. Nach Revision umfasst die Gattung 26 Arten, die sämtlich beschrieben und abgebildet werden; 19 davon sind neu für die Wissenschaft: Neosclerus armatus sp. n. (Taiwan), N. barbatulus sp. n. (Thailand, Myanmar, China), N. barbatus sp. n. (Thailand), N. bicarinatus sp. n. (Vietnam), N. bifidus sp. n. (Taiwan), $N$. carinatus sp. n. (Taiwan), N. configens sp. n. (Taiwan), N. dupleseriatus sp. n. (N-Indien), N. erubescens sp. n. (Borneo), N. glaber sp. n. (S-China, Hongkong, Thailand, Malaysia), N. hlavaci sp. n. (China: Fujian, Jiangxi), N. inarmatus sp. n. (Taiwan), N. incisus sp. n. (China: Guangxi), N. praeacutus sp. n. (China: Yunnan), N. rimatus sp. n. (China: Guangxi), N. rougemonti sp. n. (Thailand), N. schillhammeri sp. n. (Myanmar), N. schuelkei sp. n. (China: Yunnan), N. smetanai sp. n. (Taiwan). Einige weitere Arten werden aufgeführt, aber nicht beschrieben, da bislang ausschließlich Weibchen bekannt sind. Das sekundäre Homonym Lobochilus brachypterus Cameron, 1943 wird durch Sunius cameroni nom. n. ersetzt. Zwei Namen werden synonymisiert: Neosclerus brevipennis (CAMERon, 1943) = Lobochilus houlberti (CoIfFAIT, 1987), syn. n.; N. granulicollis CAmeron, $1924=N$. frater CAMEron, 1924, syn. n. Für vier Arten ändert sich das Binomen bzw. die Gattungszugehörigkeit: Neosclerus assamensis (CAMEron, 1931), comb. n. (ex Lobochilus), N. javanus (Bernhauer, 1920); comb. n. (ex Lobochilus), N. nigerrimus (KraATZ, 1859); comb. n. (ex Lobochilus), and "Medon" labralis (Cameron, 1943), comb. n. (ex Neosclerus). Für Neosclerus fortepunctatus Cameron, 1924, N. granulicollis Cameron, 1924, N. frater CAmeron, 1924, Lobochilus assamensis Cameron, 1931 und Lithocharis nigerrima KraATZ, 1859 werden Lectotypen designiert. Die verfügbaren Daten zur Verbreitung und Ökologie der Neosclerus-Arten werden zusammengestellt. Viele davon sind flugfähig und z.T. sehr weit verbreitet. Flugunfähige, endemische Arten sind derzeit nur aus Südchina und Taiwan bekannt, den Gebieten mit der höchsten Artendiversität. Offenbar leben die Arten dieser Gattung in der feuchten Bodenstreu und im Moos von Wald- und Strauchbiotopen sowie an Ufern von Fließgewässern. Eine Bestimmungstabelle und ein Katalog werden erstellt.

\section{Introduction and taxonomic history}

Bernhauer (1920) described the genus Lobochilus to accommodate the new species L. javanus from Java, the type species by monotypy. Four years later, CAmeron (1924) erected the genus Neosclerus to include three new species from northern India, $N$. fortepunctatus (type species by original designation), N. granulicollis, and $N$. frater. In his synopsis of the Paederinae of India and adjacent regions, CAMERon (1931) synonymized Neosclerus with Lobochilus and keyed five species, the three species described by him seven years earlier, as well as a new species, $N$. assamensis from Assam, and N. nigerrimus (KRAATZ, 1859) from Ceylon, which had originally been placed in Lithocharis DejeAn, 1833. Subsequently, three additional Lobochilus species from northern India were described by CAMERon (1943): L. brachypterus, L. brevipennis, and L. labralis.

BLACKWELder (1952) noticed the homonymy of Lobochilus BeRnHAUER, 1920 with Lobochilus Boulenger, 1882 and revalidated Neosclerus, with Lobochilus Bernhauer as a junior synonym. Since then, two further species have become known. Apparently unaware of the reversed synonymy proposed by Blackwelder (1952), CoIfFAIT (1978) described Lobochilus brevipennis from Bhutan. Subsequently noticing the primary homonymy with L. brevipennis CAMERon, however, he replaced the name with the nomen novum L. houlberti (CoIfFAIT 1987). The latest species, Neosclerus atsushii, was described from Taiwan by Shibata (1992).

Thus, prior to the present revision, eleven Neosclerus species had become known, all of them distributed in the south of the Eastern Palaearctic and the Oriental regions. 
The systematic affiliations of Neosclerus have remained unresolved. In the original description of Lobochilus, BERnhauer (1920) noted the similarity of the genus with species allied to Sunius melanocephalus (FABriciUs, 1793). CAMERON (1931), too, placed the taxon near genera today attributed to the Medonina, whereas Smetana (2004) lists it as Paederini, incertae sedis.

The present revision was initiated by material from China and Taiwan made available to me by various colleagues (Guillaume de Rougemont, Peter Hlavač, Aleš Smetana, Stanislav Vít). A preliminary examination of this material revealed not only a much higher diversity than previously known, but also remarkable similarities both in external and sexual characters with species of the genus Sunius Stephens, 1829, a genus revised earlier in several instalments (see Assing 2008a, 2008 b, in press, and references therein).

\section{Material and methods}

The material referred to in this study is deposited in the following public institutions and private collections:

$\begin{array}{ll}\text { AMNH } & \text { American Museum of Natural History, New York (L. H. Herman) } \\ \text { BMNH } & \text { The Natural History Museum, London (R. Booth) } \\ \text { FMNH } & \text { Field Museum of Natural History, Chicago (J. Boone, A. F. Newton; via L. H. Herman) } \\ \text { MNHNP } & \text { Muséum National d'Histoire Naturelle, Paris (A. Taghavian) } \\ \text { NHMW } & \text { Naturhistorisches Museum Wien (H. Schillhammer) } \\ \text { OUMNH } & \text { Oxford University Museum of Natural History (via G. de Rougemont) } \\ \text { NME } & \text { Naturkundemuseum Erfurt (M. Hartmann, W. Apfel) } \\ \text { SDEI } & \text { Senckenberg Deutsches Entomologisches Institut, Müncheberg (L. Behne, L. Zerche) } \\ \text { cAss } & \text { author's private collection } \\ \text { cPüt } & \text { private collection Andreas Pütz, Eisenhüttenstadt } \\ \text { cRou } & \text { private collection Guillaume de Rougemont, London } \\ \text { cSch } & \text { private collection Michael Schülke, Berlin } \\ \text { cShi } & \text { private collection Yasutoshi Shibata, Tokyo } \\ \text { cSme } & \text { private collection Aleš Smetana, Ottawa } \\ \text { cWun } & \text { private collection Paul Wunderle, Mönchengladbach }\end{array}$

The morphological studies were conducted using a Stemi SV 11 microscope (Zeiss Germany) and a Jenalab compound microscope (Carl Zeiss Jena). For the photographs a digital camera (Nikon Coolpix 995) was used.

Head length was measured from the anterior margin of the frons to the posterior margin of the head, elytral length at the suture from the apex of the scutellum to the posterior margin of the elytra.

\section{The genus Neosclerus CAMERoN}

Neosclerus Cameron, 1924: 188 f. [type species: N. fortepunctatus Cameron, 1924]

Lobochilus Bernhauer, 1920: 179 [preocc.; type species: L. javanus Bernhauer, 1920]

\section{Redescription:}

Species of rather small and uniform size, body length $2.8-4.1 \mathrm{~mm}$; habitus similar to that of Sunius (e.g., Figs 1, 7, 15, 21). Body in most species of dark (dark-brown to black) coloration, rarely partly or completely reddish; legs and antennae yellowish to reddish. 
Head (e.g., Figs 2, 8, 16, 22) across eyes distinctly transverse, 1.1-1.3 times as broad as long; eyes enormous and strongly bulging, similar to those of Stenus LATREILle, occupying the whole side of the head, and with relatively long pubescence; postocular region obsolete or extremely short, at most approximately as long as width of antennomere I; punctation of dorsal surface usually rather coarse and moderately to extremely dense, often distinctly sparser in posterior portion; interstices with or without microsculpture; neck not conspicuously slender, similar to that of Sunius. Antenna 0.7-1.2 mm long, slender, of similar morphology as in Sunius. Gular sutures rather widely separated. Mouthparts: labrum with anterior margin notched in the middle, but not dentate (Fig. 83); ligula truncate and with approximately six short stout setae; maxilla and mandible similar to those of Sunius (Figs 82, 84).

Pronotum (e.g., Figs 2, 8, 16) distinctly narrower than head (including eyes), weakly oblong to weakly transverse; of similar shape as in Sunius; punctation usually coarse, rarely fine and granulose, moderately dense to dense; impunctate midline of variable width, often weakly defined; interstices without microsculpture and glossy.

Elytra of variable length and width, in some species di- or polymorphic; in micropterous species distinctly shorter than pronotum (e.g., Figs 74, 81); in macropterous species usually approximately as long as or longer than pronotum (e.g., Fig. 2), rarely shorter than pronotum (e.g., Figs 28, 134); humeral angles in micropterous species often weakly marked; punctation usually moderately fine and very dense, often shallow and weakly defined. Hind wings completely reduced (micropterous species), fully developed (macropterous species), or of reduced length (di- and polymorphic species). Legs similar to those of Sunius; protarsi without sexual dimorphism; all tarsi slender, not dilated; metatarsomere I somewhat longer than II.

Abdomen subparallel, widest at segment VI; punctation fine and moderately dense, usually more or less distinctly sparser on posterior than on anterior tergites; interstices with more or less distinct microsculpture; posterior margin of tergite VII with or without palisade fringe; tergite VIII usually with sexual dimorphism.

$0^{\star}$ : tergite VIII usually with broadly and weakly convex posterior margin; sternite VII often with more or less distinctly concave posterior margin, in one species dentate on either side of the median concavity, and often with a cluster of dense setae posteriorly (e.g. Fig. 10); sternite VIII with moderately deep to deep, $\mathrm{V}$-shaped to U-shaped posterior excision and often with additional modifications (anteriorly elevated in the middle, with median carina posteriorly extending into an acute and apically bifid process, or with pair of carinae; posteriorly with extensive impression or depression without pubescence); aedeagus of similar general morphology as in Sunius, ventral process often dorso-ventrally (e.g., Figs 5-6) or laterally (e.g., Figs 32-33) compressed, often subapically notched and/or dentate; internal sac with long series of spines (e.g., Figs 5-6), or with pairs of sclerotized structures basally (e.g., Figs 78-79), in median, or in apical portion (e.g., Figs 138-139).

+ : tergite VIII usually with more strongly convex posterior margin than in $\sigma^{*}$ (Fig. 91); sternite VIII with broadly convex posterior margin.

\section{Systematics:}

Based on external characters, the mouthparts, and the male sexual characters, Neosclerus undoubtedly belongs to the subtribe Medonina. As can be inferred from the description above, Neosclerus is highly similar to Sunius, not only in external morphology, but also in the male primary and secondary sexual characters. In fact the only constant morphological differences found between the two genera are the shape of the anterior margin of the labrum (Sunius: dentate on either side of median notch) and the size of the eyes. Even in micropterous species they are enormous and not smaller than in macropterous ones. There are Sunius species with rather large eyes, too, but 
these are always distinctly smaller and much less bulging than in Neosclerus (see Fig. 159). These observations suggest that the derived morphology of the eyes is a synapomorphy shared by all Neosclerus species, so that there is little doubt that the taxon is monophyletic. Nevertheless, an external character such as eye size, which is often subject to considerable intrageneric variation in Paederinae, is by itself a rather weak argument for the hypothesis that Neosclerus should be distinct at the genus level and not placed within Sunius. However, further evidence comes from biogeography. Sunius probably has a Holarctic distribution; the Nearctic species have not been revised, but it seems likely that at least some of them actually belong to this genus. In the Old World, Sunius is strictly confined to the Palaearctic region with few scattered species distributed as far south as Yunnan, where they inhabit high-altitude habitats (Assing 2010); true Sunius from the Oriental region are unknown. The distribution of Neosclerus, in contrast, is predominantly Oriental, with some species reaching the extreme south of the Eastern Palaearctic region. In consequence, based on both morphological and biographic evidence, Neosclerus appears to represent as distinct genus, possibly the adelphotaxon of Sunius.

\section{Intrageneric affiliations:}

Within the genus, several species groups may be distinguished, but the affiliations of some species remain uncertain, either because the male sexual characters are unknown $(N$. javanus, $N$. granulicollis, $N$. assamensis) or because it is difficult to identify clear synapomorphies ( $N$. nigerrimus). Based on the internal structures of the aedeagus, the genus falls into two groups. One of them has long series of small spines in the internal sac and is additionally characterized by the following characters: modified pubescence of the male sternite VII (exception: $N$. erubescens); sternite VIII without modifications besides the posterior excision; ventral process of aedeagus slender and subapically neither notched nor acutely dentate. This group is here referred to as the fortepunctatus group and includes $N$. fortepunctatus, $N$. dupleseriatus, $N$. barbatus, and $N$. erubescens. The remainder of the genus has a pair of larger internal structures (plus additional membranous structures) in the basal, median, or apical portion of the internal sac. Among these species $N$. glaber and $N$. bicarinatus form an isolated group (glaber group) which is distinguished from other groups by the following characters: ventral process curved, subapically neither dentate nor notched, dorso-ventrally more or less compressed, and apically abruptly narrowed towards the acute apex (ventral aspect). The brevipennis group, which includes nine species ( $N$. brevipennis, N. schillhammeri, $N$. praeacutus, $N$. inarmatus, $N$. rougemonti, $N$. barbatulus, $N$. rimatus, $N$. incisus, $N$. schuelkei), is characterized as follows: ventral process of aedeagus somewhat spear-shaped (straight, apically very acute, subapically acutely dentate); sclerotized internal structures situated in basal or median portion of internal sac; male sternite VII with modified pubescence posteriorly; male sternite VII anteriorly with median elevation or pair of carinae (exception: $N$. praeacutus), posteriorly depressed or impressed and extensively devoid of pubescence. Finally, the hlavaci group, which exclusively includes micropterous species from southern China and Taiwan (N. hlavaci, N.atsushii, N. armatus, N. smetanai, N. configens, $N$. carinatus, $N$. bifidus), shares two obvious synapomorphies: the male sternite VIII has a median carina with a bifid posterior extension anteriorly and the ventral process of the aedeagus is obliquely notched and very finely acutely dentate at some distance from apex (best visible in lateral view).

\section{Distribution and diversity:}

The genus is widespread in the Oriental and the southern East Palaearctic regions, its distribution ranging from the southern slopes of the Himalaya southwards to Sri Lanka, Malaysia and Indonesia. Owing to the scarcity of material available from these regions, the distributions of individual species are poorly known. Two species ( $N$. brevipennis, $N$. dupleseriatus) are evidently widespread in the southern Himalaya and adjacent regions. The range of $N$. glaber extends from southern China to Malaysia, thus spanning almost 24 degrees of latitude. Neosclerus barbatulus is 
known from Myanmar, Thailand, and southern China. Several additional species may be widespread, too, as can be inferred from their fully developed hind wings and their collection data (some caught in interception traps), but are currently known only from one or two localities.

At least ten micropterous species without a palisade fringe at the posterior margin of the abdominal tergite VII undoubtedly have very restricted distributions, seven of them in Taiwan ( $N$. atsushii, $N$. armatus, $N$. smetanai, $N$. configens, $N$. carinatus, $N$. bifidus, $N$. inarmatus) and three in southern China ( $N$. hlavaci, $N$. incisus, $N$. rimatus). The same may be true of $N$. praeacutus (southern China), whose hind wings are apparently of reduced length, but which still has a palisade fringe at the posterior margin of tergite VII.

The regions with the highest diversity are southern China (7 species), Taiwan (7), northern India (5), and Thailand (5). The fact that the Neosclerus fauna of Taiwan is composed of representatives of two species groups $(N$. inarmatus of the brevipennis group and six species of the hlavaci group) suggests that it has originated from two colonization events.

\section{Natural history:}

As can be inferred from the collection data, Neosclerus species live in - usually moist - leaf litter, moss, and other debris of forests, shrub habitats, and on banks of streams. The altitudes range from near sea-level to almost $2600 \mathrm{~m}$. Due to lack of material, little is known about the phenology of the species. Teneral adults were collected in May and August. Some species were repeatedly collected with flight interception traps, suggesting that they are active flyers.

Remarkably, several males of different species dissected in the course of the present study had teratologically deformed aedeagi. In one male the aedeagus was completely missing and one additionally had a sternite VIII without posterior excision. Teratologically deformed aedeagi are quite common in Medonina (Assing 2006), a phenomenon that is difficult to explain in view of the high selective pressure that should work against conditions that impair reproduction.

\section{The species of Neosclerus ${ }^{1}$}

\section{Neosclerus fortepunctatus CAMERON, 1924 (Figs 1-6)}

Neosclerus fortepunctatus Cameron, 1924: 189 f.; partim.

Lobochilus fortepunctatus: CAMERON (1931: 124).

Neosclerus fortepunctatus: SMETANa (2004: 622).

\section{Type material:}

Lectotype $0^{\star}$ : "Kemti Falls, Mussoorie, U. P. / Dr. Cameron, 29.V.21 / Syntype / M. Cameron. Bequest. B.M. 1955-147. / Syntype Neosclerus fortepunctatus Cameron, 1924, det. R.G. Booth 2010 / Lectotypus o Neosclerus fortepunctatus Cameron, desig. V. Assing 2010 / Neosclerus fortepunctatus Cameron, det. V. Assing 2010" (BMNH). Paralectotypes [see also the type material of Neosclerus dupleseriatus]: 1 : : same data as holotype (BMNH); 1 : : Arni Gad. Mussoorie. / Dr. Cameron, 28.V.21 / Syntype / M. Cameron. Bequest. B.M. 1955-147" (BMNH); 1 \%: "Arni Gad. Mussoorie. Dr. Cameron. 16.X.21 / Syntype / M. Cameron. Bequest. B.M. 1955147" (BMNH); 1 ㅇ: "Arni Gad. Mussoorie. Dr. Cameron, 16.X.21 / Blackwelder Collection / Lobochilus fortepunctatus" (AMNH).

\footnotetext{
${ }^{1}$ For additional paratypes of two newly described species, as well as additional records of two other species see the supplement to this revision (Assing, 2011 p. 149-153) in the same issue. New country records reported in the supplement are included in the key and in the catalogue, but not in the species sections.
} 


\section{Comment:}

The original description is based on an unspecified number of syntypes from "Mussorie District; Arni Gad, Kemti Falls. Chakrata District; Khedar Khud" (CAmeron 1924). Five syntypes were located in the collections of the BMNH, one male and three females from Mussoorie District, and one male from Chakrata District. Additional four syntypes, two males and two females, were found in the collections of the AMNH and FMNH. An examination of the male sexual characters revealed that the type series is composed of two similar and evidently closely related species. In order to define the identity of the $N$. fortepunctatus, the male from Kemtie Falls is designated as the lectotype.

Additional material examined:

India: 1 \% [identification uncertain], Uttarakhand, Kumaun ["Kumaon"; 2950'N, 79³0'E], leg. Champion (BMNH); 1 + [identification uncertain], Mossy Falls, Mussoorie, stream moss, 20.III.1921, leg. Cameron $(\mathrm{AMNH})$.

\section{Redescription:}

Body length 3.0-3.5 mm. Habitus as in Fig. 1. Coloration: body blackish-brown to blackish, with the elytra and the abdominal apex indistinctly paler; legs yellowish; antennae yellowish-brown.

Head across eyes 1.15-1.20 times as wide as long; postocular region very short, approximately as long as width of antennomere II; punctation coarse and rather dense; interstices on average narrower than diameter of punctures, without microsculpture and glossy (Fig. 2); antenna approximately $0.9 \mathrm{~mm}$ long.

Pronotum approximately as long as wide or indistinctly oblong, approximately 0.85 times as wide as head; punctation very coarse and dense; midline narrowly impunctate, sometimes only in posterior half; interstices without microsculpture and glossy (Fig. 2).

Elytra relatively long, approximately 1.03-1.07 times as long and 1.15-1.20 times as wide as pronotum; humeral angles marked; punctation much finer than that of head and pronotum, very dense and often partly ill-defined. Hind wings present.

Abdomen approximately 0.9 times as wide as elytra; punctation fine and sparse; tergites III-V with almost obsolete, tergites VI-VIII usually with more distinct transverse microsculpture; posterior margin of tergite VII with palisade fringe.

$\sigma^{*}$ : sternite VII posteriorly with a cluster of moderately dense, long and dark setae; posterior margin very weakly concave in the middle (Fig. 3); sternite VIII with deep V-shaped posterior excision, its depth approximately $1 / 5$ the length of sternite, otherwise unmodified (Fig. 4); aedeagus with long, slender, and apically weakly hooked ventral process, with long dorsal plate, and with two long series of moderately sclerotized spines (Figs 5-6).

\section{Comparative notes:}

From other macropterous species with similarly coarse punctation of the forebody, $N$. fortepunctatus is reliably distinguished only by the morphology of the aedeagus, from many of them also by the male secondary sexual characters.

\section{Distribution and bionomics:}

Confirmed records of this species are known only from Mussoorie district in Uttarakhand, northern India. In view of the similarity to other species, the previous records from other regions such as Nepal (Coiffait 1975, 1982), Darjiling, and Assam (Biswas \& Biswas 1995) should be considered highly doubtful. According to CAMEron (1924, 1931), the species was collected from stream moss. 

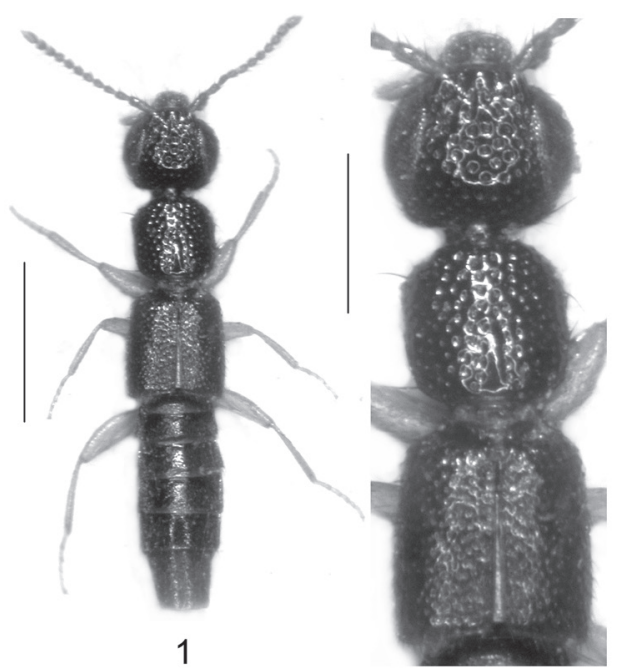

2

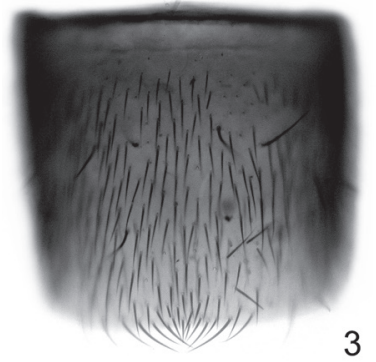

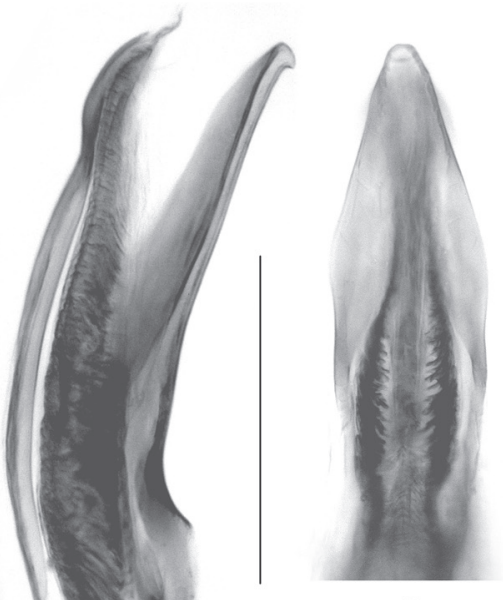

6

Figs 1-6: Neosclerus fortepunctatus CAMERon (lectotype): habitus (1); forebody (2); male sternite VII (3); male sternite VIII (4); aedeagus in lateral view (5); apical portion of aedeagus in ventral view (6). Scale bars: 1: $1.0 \mathrm{~mm} ; 2: 0.5 \mathrm{~mm}$; 3-6: $0.2 \mathrm{~mm}$.

Neosclerus dupleseriatus sp. n. (Figs 7-14)

Neosclerus fortepunctatus CAMERoN, 1924: 189 f.; partim.

\section{Type material:}

Holotype ơ: "India; Himachal Pradesh, Kullu Valley, 25 km S Kullu, 3 km SW Aut, 600 m, 4.X.1996, leg. Schulz \& Vock / Holotypus ơ Neosclerus dupleseriatus sp. n., det. V. Assing 2010" (cAss). Paratypes: $10^{7}$ : "Chakrata Dist. Khedar Khud 7500 / Dr. Cameron, 11.V.22 / Syntype / M. Cameron. Bequest. B.M. 1955-147. / Syntype Neosclerus fortepunctatus Cameron, 1924, det. R.G. Booth 2010 / Paralectotypus o Neosclerus fortepunctatus Cameron, desig. V. Assing 2010 / Paratypus ơ Neosclerus dupleseriatus sp. n., det. V. Assing 2010" (BMNH); 1 o": "Chakrata Dist., Khedar Khud / 7500' / Dr. Cameron, 11.V.22 / Neosclerus fortepunctatus / fortepunctatus Cam. Cotypus. don. Cameron / Chicago NHMus M.Bernhauer Collection / Paralectotypus ơ Neosclerus fortepunctatus Cameron, desig. V. Assing 2010 / Paratypus o Neosclerus dupleseriatus sp. n., det. V. Assing 2010" (FMNH); 1 ơ: "Arni Gad. Mussoorie. / Dr. Cameron, 16.X.1921 / Lobochilus fortepunctatus Cam. / Chicago Nat. Hist. Mus. (ex. M. Cameron Colln. by exchange with Brit. Mus. Nat. Hist.) / Paralectotypus Neosclerus fortepunctatus Cameron, desig. V. Assing 2010 / Paratypus Neosclerus dupleseriatus sp. n., det. V. Assing 2010" (cAss); 1 \%: "Chakrata Dist. 
Khedar Khud 7500 / Dr. Cameron, 11.V.22 / Chicago Nat. Hist. Mus. (ex. M. Cameron Colln. by exchange with Brit. Mus. Nat. Hist.) / Paralectotypus Neosclerus fortepunctatus Cameron, desig. V. Assing 2010 / Paratypus Neosclerus dupleseriatus sp. n., det. V. Assing 2010" (FMNH); 1 \%: "Mohna, 5000. Chakrata, U.P. / Dr. Cameron, 2.V.21 / Neosclerus fortepunctatus Cam. / ex coll. Scheerpeltz / Cotypus Neosclerus fortepunctatus Cameron. / fortepunctatus Cam" (NHMW).

\section{Comment:}

Most of the paratypes originally belonged to the type series of $N$. fortepunctatus Cameron, 1924 , but are not conspecific with the lectotype of that species (see comment in the preceding section).

\section{Description:}

Body length 3.0-3.3 mm. Habitus as in Fig. 7. External morphology as in N. fortepunctatus, except as follows:

Head across eyes approximately 1.15 times as wide as long; postocular region extremely short, shorter than width of antennomere II; punctation coarse and rather dense (Figs 8-9).

Pronotum relatively broader and shorter, approximately 1.03 times as wide as long and 0.9 times as wide as head.

Elytra of very variable length and width (dimorphic?), either approximately 0.9 times as long and 1.05 times as wide as pronotum, or approximately 1.05 times as long and 1.15-1.20 times as wide as pronotum (Figs 8-9); punctation extremely dense, shallow, and partly ill-defined.

Abdomen approximately 0.95 times as wide as elytra; tergites III-V with shallow, but distinct transverse microsculpture.

$\sigma^{\text {t }}$ : sternite VII posteriorly with a more extensive cluster of rather dense, long and dark setae, posterior margin distinctly concave in the middle (Fig. 10); sternite VIII shorter and less slender, V-shaped posterior excision approximately 1/4 the length of sternite (Fig. 11); aedeagus with relatively shorter, less slender, and apically more strongly hooked ventral process, with shorter dorsal plate, and with two long series of strongly sclerotized spines (Figs 12-14).

\section{Etymology:}

The specific epithet (Latin, adjective) alludes to the presence of two long series of spines in the internal sac of the aedeagus.

\section{Comparative notes:}

Based on the similar external characters, the similar chaetotaxy of the male sternite VII, and the similarly derived morphology of the aedeagus, particularly the presence of two long series of spines in the internal sac, $N$. dupleseriatus is closely allied to $N$. fortepunctatus, with which it was previously confounded. For characters separating the two species see the description above. From other macropterous species with similarly coarse punctation of the forebody, $N$. dupleseriatus is reliably distinguished by the morphology of the aedeagus, from many of them also by the male secondary sexual characters.

\section{Distribution and bionomics:}

The species is currently known from several localities in Himachal Pradesh and Uttarakhand, northern India. The habitat is probably similar to that of $N$. fortepunctatus. The holotype was collected at an altitude of approximately $2300 \mathrm{~m}$ in October. 

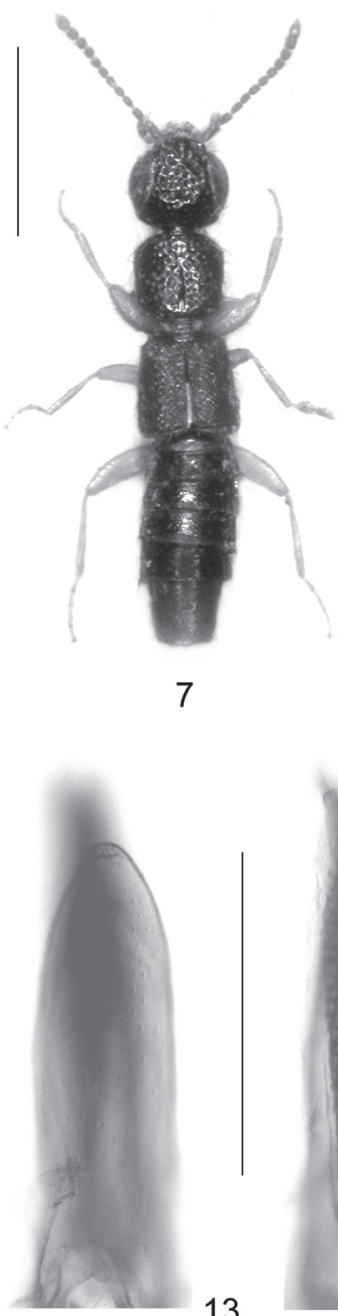

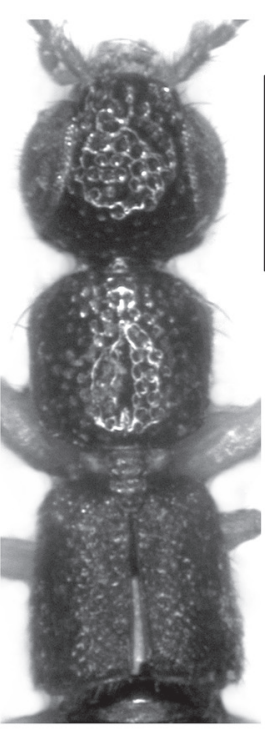

8

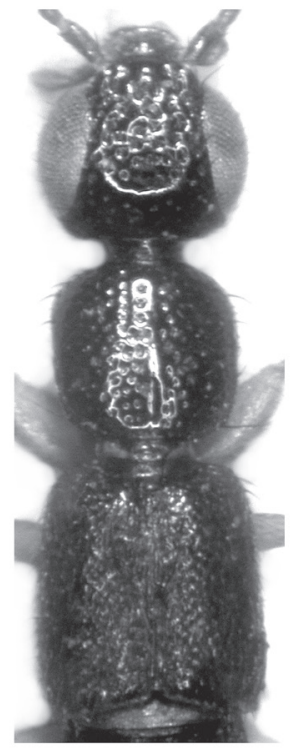

9
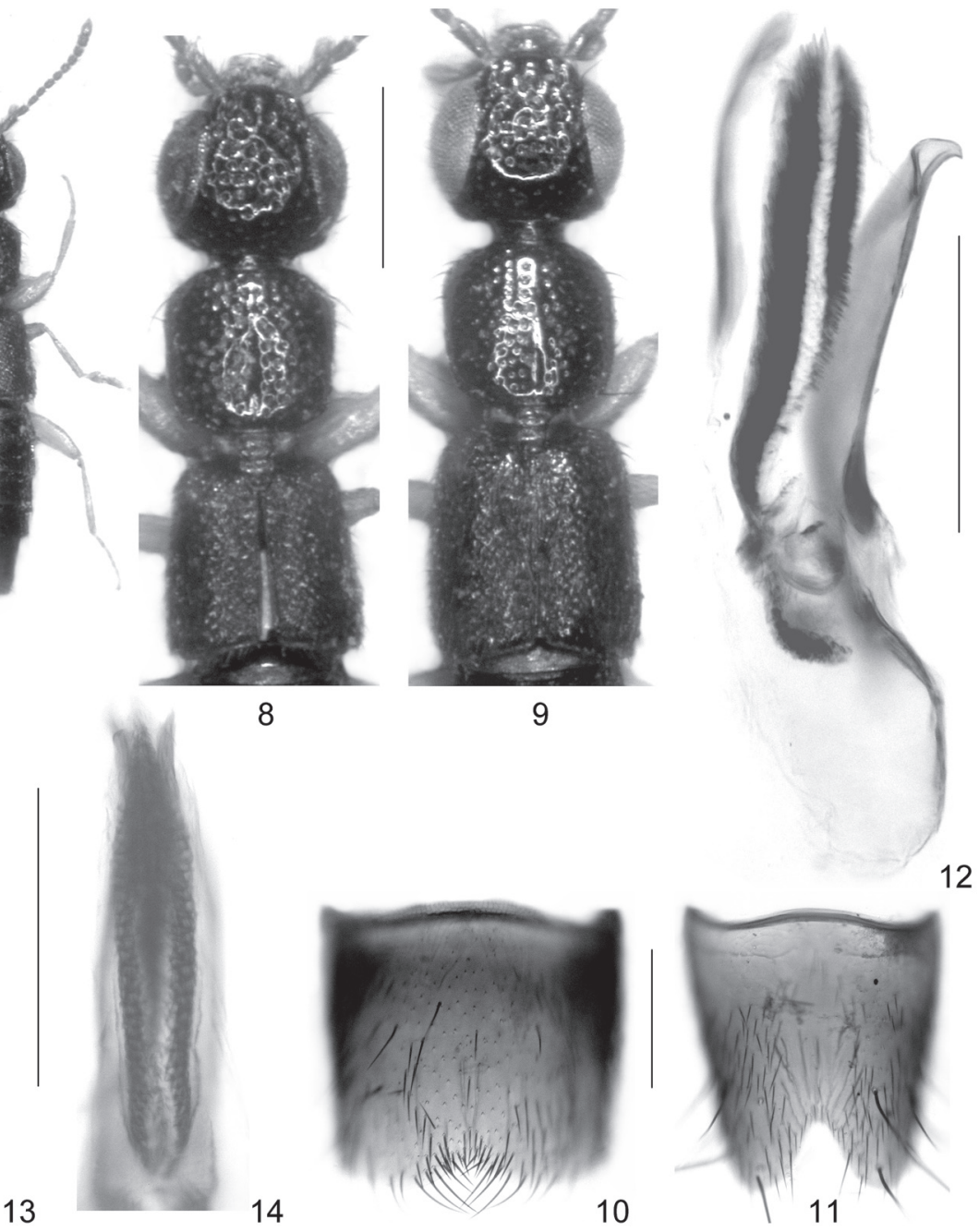

Figs 7-14: Neosclerus dupleseriatus sp. n. (paralectotypes of $N$. fortepunctatus CAMERoN): habitus (7); forebody (8-9); male sternite VII (10); male sternite VIII (11); aedeagus in lateral view (12); ventral process of aedeagus in ventral view (13); internal structures of aedeagus in ventral view (14). Scale bars: 7: $1.0 \mathrm{~mm}$; 8-9: 0.5 mm; 10-14: $0.2 \mathrm{~mm}$.

Neosclerus barbatus sp. n. (Figs 15-20)

\section{Type material:}

Holotype ơ: "Thailand, Ban Sai Yok, 9:III:1982, G. de Rougemont / Lobochilus sp. ?, det. 198 [sic], G. de Rougemont / Holotypus ơ Neosclerus barbatus sp. n. det. V. Assing 2010" (cAss).

\section{Description:}

Body length $3.0 \mathrm{~mm}$. Habitus as in Fig. 15. Coloration: head blackish; pronotum blackish-brown; elytra dark-brown, with the humeral angles and the posterior margin reddish-yellow; abdomen dark-brown with paler apex; legs yellowish; antennae reddish-yellow. 


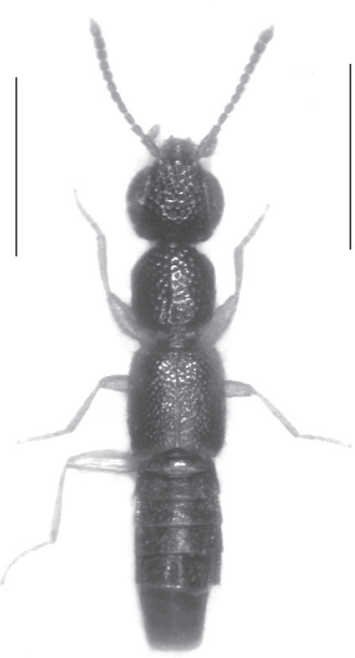

15

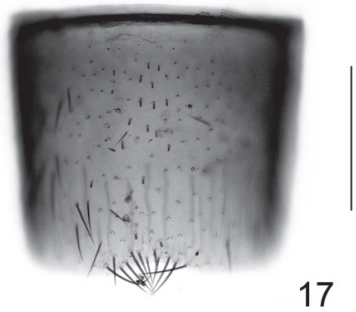

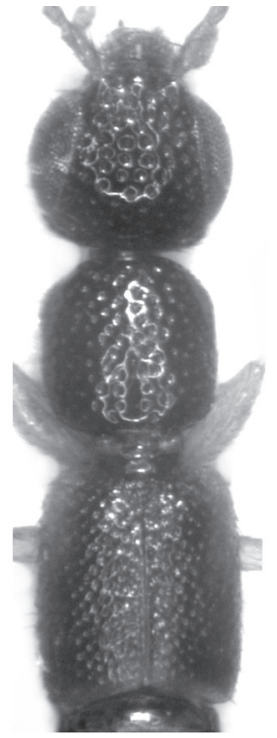

16

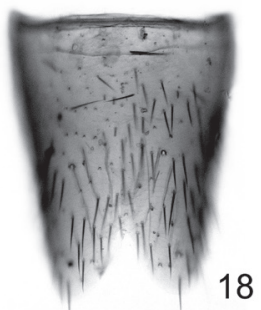

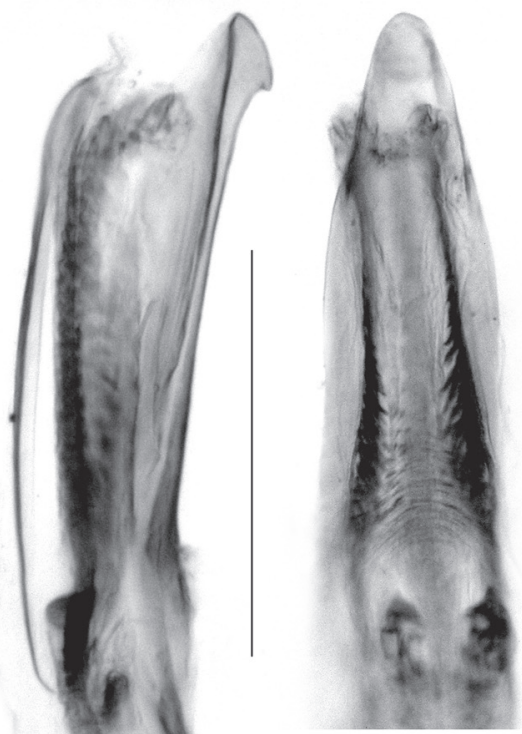

20

Figs 15-20: Neosclerus barbatus sp. n. (holotype): habitus (15); forebody (16); male sternite VII (17); male sternite VIII (18); aedeagus in lateral view (19); apical portion of aedeagus in ventral view (20). Scale bars: 15: $1.0 \mathrm{~mm}$; 16: $0.5 \mathrm{~mm}$; 17-20: $0.2 \mathrm{~mm}$.

Head across eyes approximately 1.15 times as wide as long; postocular region approximately as long as width of antennomere II in dorsal view (Fig. 16); punctation very coarse and dense, not distinctly sparser in posterior portion of dorsal surface; interstices without microreticulation and glossy; antenna approximately $0.95 \mathrm{~mm}$ long.

Pronotum indistinctly oblong, approximately 1.03 times as wide as long, and approximately 0.85 times as wide as head; punctation as coarse and dense as that of head; impunctate midline ill-defined, reduced to short and narrow patch in posterior half; interstices without microsculpture and glossy (Fig. 16).

Elytra relatively long and large, 1.03 times as long and approximately 1.15 times as wide as pronotum; humeral angles marked (Fig. 16); punctation dense and moderately fine; interstices glossy. Hind wings fully developed.

Abdomen distinctly narrower than elytra; punctation fine and moderately dense on anterior tergites, sparser on posterior tergites; interstices with distinct microsculpture; posterior margin of tergite VII with palisade fringe.

$\mathrm{O}^{\star}$ : sternite VII with posterior margin moderately concave, near this concavity with cluster of long dark submarginal setae (Fig. 17); sternite VIII anteriorly unmodified, posterior excision acute, 
deep, and V-shaped, its depth approximately $1 / 4$ the length of sternite (Fig. 18); aedeagus small, barely $0.5 \mathrm{~mm}$ long, with long, slender, and apically weakly hooked ventral process, internal sac with two long series of small sclerotized structures (Figs 19-20).

\section{Etymology:}

The specific epithet (Latin, adjective: with beard) alludes to the cluster of setae near the posterior margin of the male sternite VII.

\section{Comparative notes:}

Based on the morphology of the aedeagus (ventral process slender in lateral view, not compressed laterally, and apically weakly hooked; internal sac with two long series of small sclerotized structures), the shape and chaetotaxy of the male sternites VII (posterior margin concave in the middle and with cluster of dark setae) and VIII (anteriorly unmodified), N. barbatus is closely allied to $N$. fortepunctatus and $N$. dupleseriatus. It is distinguished from all its congeners particularly by the shape of the ventral process of the aedeagus, as well as by the conspicuously coarse and dense punctation of the whole dorsal surface of the head and of the pronotum.

\section{Distribution and bionomics:}

The species is currently known only from the type locality in Thailand, where it was collected in March.

\section{Neosclerus erubescens sp. n. (Figs 21-26)}

\section{Type material:}

Holotype $0^{*}$ : "Malaysia: Sabah, Lahad Datu, Ulu Segama For. Res., Danum Valley Forest Centre, $04^{\circ} 57.9^{\prime} \mathrm{N}, 117^{\circ} 48.1^{\prime} \mathrm{E}, 200 \mathrm{~m}$ alt / xi.2005, $1^{\circ}$ Forest, baited PF, coll. Mann, Slade \& Villanueva, OUMNH-2006-051 / Holotypus ơ Neosclerus erubescens sp. n. det. V. Assing 2010" (OUMNH). Paratypes: $2 \sigma^{\star} \sigma^{\star}$ [1 $\sigma^{\star}$ teratological, without aedeagus], 4 우 + : same data as holotype (OUMNH, cAss); 1 \%: "Malaysia: Borneo: Sabah. Ulu Segama Forest Reserve. Yayasan Sabah Logging Concession. ca. 21 km from Danun Valley F. C. / Near Malua Biodiversity Experiment, 30.iii.2005, F. I. Trap, Secondary forest, ca N0505.73', E 117³7.61', Malua 2 Plot 5, Leg., E. Slade + J. Villanueva" (cRou); $10^{\star}$ [without apex of abdomen], 1 q: "Sabah, Danum Valley, B.R.L., f.i.t., 14.-16.II.2007, G. de Rougemont" (cRou); 1 ㅇ: "Malaysia: Sabah, Lahad Datu, Ulu Segama For. Res., Borneo Rainforest Lodge, 250 m, 0502.682'N, 11745.553'E, iii-iv.2005, FIT, $1^{\circ}$ Forest, Coll. E. Slade \& J. Villanueva / Flight Interception Trap, Dipterocarp Forest, Danum Valley Conservation Area, OUMNH-2005-062" (cAss).

\section{Description:}

Body length 3.0-3.5 mm. Habitus as in Fig. 21. Coloration characteristic: whole body dark reddish; legs yellowish; antennae reddish-yellow.

Head across eyes approximately 1.15 times as wide as long; postocular region not particularly short, approximately as long as width of antennomere I; punctation relatively fine, relatively shallow, and extremely dense on whole dorsal surface; interstices reduced to narrow rides and with microreticulation; dorsal surface matt (Fig. 22); antenna approximately 0.9-1.0 mm long.

Pronotum approximately 1.05 times as wide as long, and approximately 0.85-0.90 times as wide as head; punctation similar to that of head, but less shallow; impunctate midline very narrow or ill-defined (Fig. 22); interstices without microsculpture and glossy. 

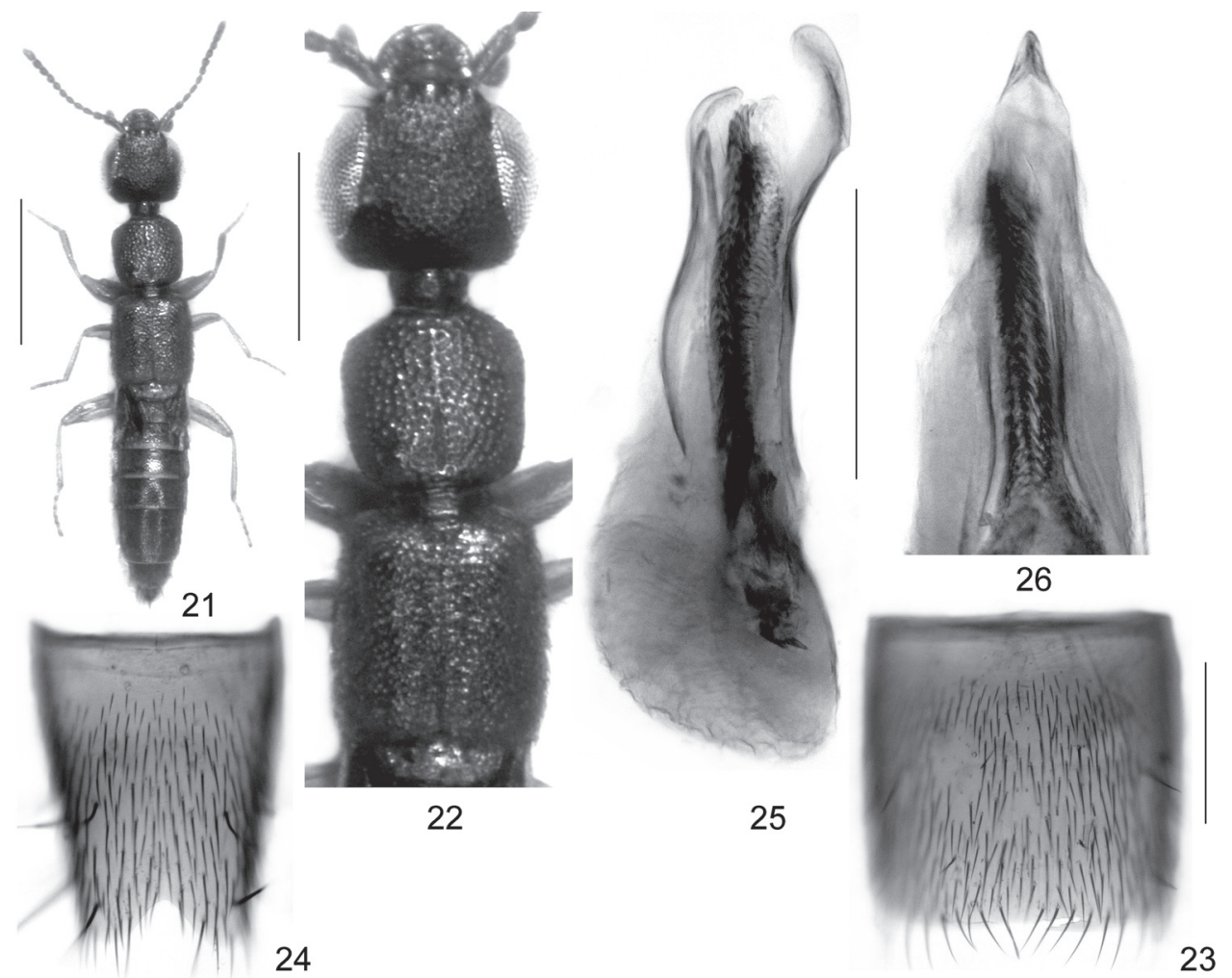

Figs 21-26: Neosclerus erubescens sp. n.: habitus (21); forebody (22); male sternite VII (23); male sternite VIII (24); aedeagus in lateral view (25); apical portion of aedeagus in ventral view (26). Scale bars: 21: $1.0 \mathrm{~mm}$; 22: $0.5 \mathrm{~mm}$; 23-26: $0.2 \mathrm{~mm}$.

Elytra relatively long, 1.05-1.10 times as long and approximately 1.15 times as wide as pronotum; humeral angles marked (Fig. 22); punctation dense and relatively fine; interstices glossy. Hind wings fully developed.

Abdomen 0.85-0.90 times as wide as elytra; punctation fine and relatively dense, also on tergite VII; interstices with shallow microsculpture; posterior margin of tergite VII with palisade fringe. $\sigma^{\star}$ : sternite VII with posterior margin indistinctly concave, with row of long dark submarginal setae, otherwise unmodified (Fig. 23); sternite VIII slender, oblong, anteriorly unmodified, densely pubescent, posterior excision broadly $\mathrm{V}$-shaped, its depth approximately $1 / 6$ the length of sternite (Fig. 24); aedeagus with ventral process of characteristic shape, internal sac with two long series of short spines (Figs 25-26).

\section{Etymology:}

The specific epithet (Latin, present participle of erubescere: to blush) refers to the uniformly reddish coloration of the body.

\section{Comparative notes:}

This species is readily distinguished from all its congeners by the uniformly reddish coloration, the characteristic punctation of the head and pronotum, as well as by the highly distinctive shape of the ventral process of the aedeagus. 


\section{Distribution and bionomics:}

The known distribution is confined to Danum Valley in Sabah (Malaysia: Borneo). The type specimens were collected with flight interception and pitfall traps in forest habitats at low elevations during the period from November to April.

\section{Neosclerus brevipennis (CAMERON, 1943) (Figs 27-33, 176-178)}

Lobochilus brevipennis CAMERon, 1943: 33.

Neosclerus brevipennis: SMETANA (2004: 622).

Lobochilus brevipennis CoIFFAIT, 1978: 129; primary homonym.

Lobochilus houlberti CoIfFAIT, 1987: 497; replacement name; syn. $\mathbf{n}$.

\section{Type material:}

N. brevipennis (Cameron): Holotype o: "Ghum dist., Mangpo, v.31, Dr. Cameron / L. brevipennis Cam. Type / M. Cameron. Bequest. B.M. 1955-147. / Holotype Lobochilus brevipennis Cameron, 1943, det. R.G. Booth 2010 / Holotypus Lobochilus brevipennis Cameron, rev. V. Assing 2010 / Neosclerus brevipennis (Cameron), det. V. Assing 2010" (BMNH).

N. houlberti (CoIffait): Paratype + : "Thimphu, $20 \mathrm{~km} \mathrm{S,} \mathrm{18.5.} \mathrm{/} \mathrm{Nat.-Hist.} \mathrm{Museum} \mathrm{Basel} \mathrm{-}$ Bhutan Expedition 1972 / Paratypus / Lobochilus brevipennis H. Coiffait 1976" (MNHNP).

Additional material examined:

India: $1 \sigma^{\star}$, Assam, Patkai Mts., leg. Doherty (BMNH); $2 \sigma^{\star} \sigma^{\star}$, Arunachal Pradesh, Along, 30.V.2006, leg. de Rougemont (cRou, cAss).

Nepal: 1 ㅇ, Phakump $a$ [?], 2300 m, IV.1984, leg. Morvan (cRou); 1 ㅇ, Arun valley, near Num, 1000 m, V.1989, leg. Morvan (cRou); 1 \& , Khandbari District, Arun Valley at Num main bridge, 1150 m, 21.IV.1984, leg. Smetana \& Löbl (cSme).

\section{Comment:}

Lobochilus brevipennis CAMERON was described from a single specimen, a female, from "Ghum district: Mangpu" (CAMERON 1943). The original description of Lobochilus brevipennis CoIfFAIT is based on a female holotype and five female paratypes from "20 km sud de Thimphu, $2300 \mathrm{~m}$ " deposited in the natural history museum in Basel and in the Coiffait collection in the MNHNP. The name is a primary homonym of L. brevipennis CAMERON, 1943 and was subsequently replaced with the nomen novum L. houlberti by CoIfFaIT (1987).

A comparison of the type material of both name yielded no evidence suggesting that they represent different species; in external characters, both specimens are extremely similar. Consequently, $N$. houlberti (COIFFAIT) is placed in synonymy with $N$. brevipennis.

The male from Assam listed as additional material above is apparently fully winged and has longer elytra than the type specimens, but is similar in other external characters.

\section{Redescription:}

Body length 3.3-3.4 mm. Habitus as ihn Fig. 27. Coloration: head blackish; pronotum blackishbrown; elytra reddish-brown to brown; abdomen dark-brown; legs and antennae yellowish.

Head across eyes 1.20-1.25 times as wide as long; postocular region very short, shorter than the width of antennomere II; punctation very coarse and very dense in anterior two thirds, sparse in posterior third of dorsal surface; interstices in anterior two thirds very narrow, mostly reduced to narrow ridges, without microsculpture and glossy (Fig. 28); antenna approximately $0.9 \mathrm{~mm}$ long. 

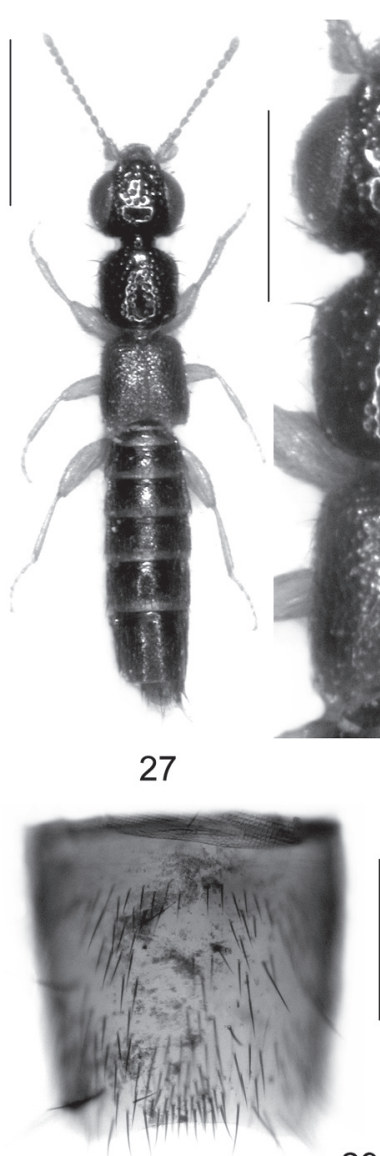

29

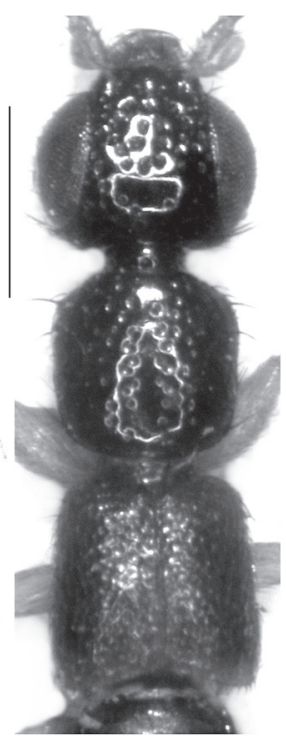

28

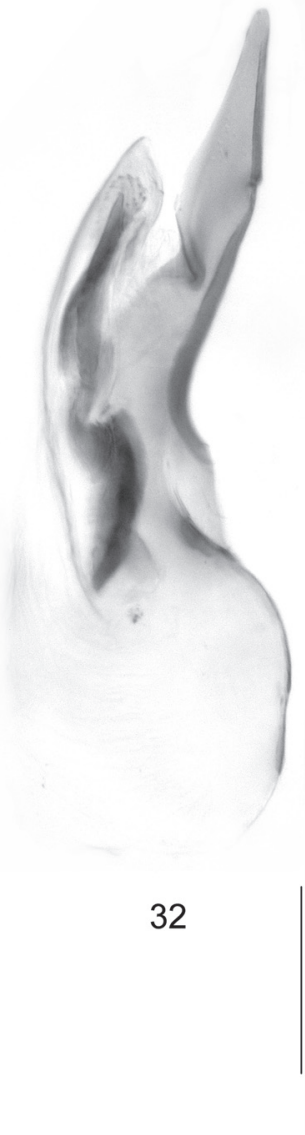

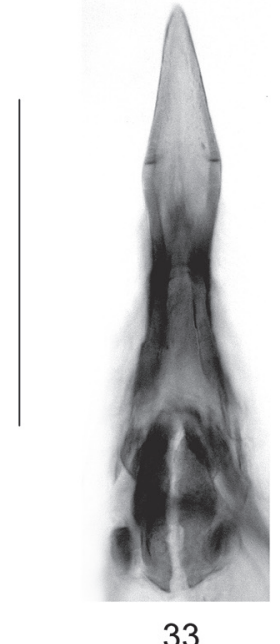

33

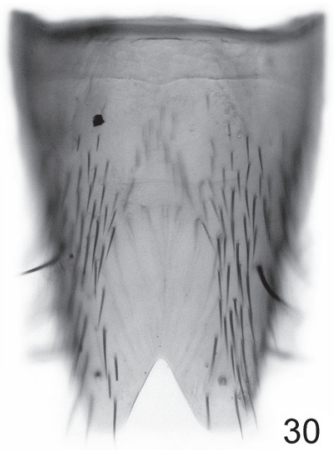

Figs 27-33: Neosclerus brevipennis (CAMERon) (27-28: holotype; 29-33: male from Assam): habitus (27); forebody (28); male sternite VII (29); male sternite VIII in ventral view (30); male sternite VIII in lateral view (31); aedeagus in lateral view (32); apical portion of aedeagus in ventral view (33). Scale bars: 27: $1.0 \mathrm{~mm}$; 28: $0.5 \mathrm{~mm}$; 29-33: $0.2 \mathrm{~mm}$.

Pronotum indistinctly oblong and approximately 0.85-0.90 times as wide as head (Fig. 28); punctation less coarse than that of head and moderately sparse; interstices on average approximately as wide as diameter of punctures, or nearly so; midline impunctate.

Elytra possibly dimorphic, approximately $0.85-0.95$ times as long and 1.10-1.15 times as wide as pronotum; humeral angles marked (Fig. 28); punctation fine, very dense and mostly welldefined. Hind wings present, but possibly of reduced length in specimens with shorter elytra.

Abdomen approximately as wide as elytra; punctation fine and moderately sparse, somewhat sparser on posterior than on anterior tergites; microsculpture shallow, but distinct; posterior margin of tergite VII with palisade fringe.

$0^{\text {t }}$ : sternite VII with posterior margin broadly and shallowly concave, in the middle with slightly denser submarginal cluster of dark setae (Figs 29, 176); sternite VIII slender, anteriorly with two short carinae, middle of posterior half extensively without pubescence, posterior excision distinctly V-shaped, its depth approximately $1 / 5$ the length of sternite (Figs 30, 177); aedeagus with slender, laterally compressed, and apically more or less acute ventral process and with pair of sclerotized structures in internal sac (Figs 32-33, 178). 


\section{Comparative notes:}

Neosclerus brevipennis is distinguished from other geographically close Neosclerus species by the following character combination: elytra reddish-brown to brown, often distinctly contrasting with the darker head and pronotum; head with very coarse and dense punctation in the anterior two thirds of the dorsal surface (similar to $N$. fortepunctatus); hind wings present, but elytra shorter than pronotum. It is additionally separated from $N$. fortepunctatus by the less coarse and sparser punctation of the pronotum.

\section{Distribution and bionomics:}

The species is currently known only from the type locality in West Bengal, northern India, two localities in eastern Assam and in Arunachal Pradesh in the very northeast of India, from two localities near Thimphu in Bhutan, and three localities in Nepal. The specimens were collected at altitudes of 1000-2300 m in April and May. One specimen collected in May is teneral.

\section{Neosclerus schillhammeri sp. n. (Figs 169-175)}

\section{Type material:}

Holotype o': "Myanmar: Shan State (MBS 81D), ca. $35 \mathrm{~km}$ N Aungban, 2055.20'N, 96 33.60'E, 31.5.-8.6.2002, ca. $1320 \mathrm{~m} /$ leg. Schillhammer / Holotypus ơ Neosclerus schillhammeri sp. n., det. V. Assing 2010" (cAss). Paratypes: 3 ㅇ 우 : same data as holotype (NHMW).

\section{Description:}

Body length 3.1-3.5 mm. Habitus as in Fig. 169. In external and male sexual characters highly similar to $N$. brevipennis, but distinguished as follows:

Coloration: pronotum and elytra similarly dark-brown, i.e., elytra not distinctly paler than pronotum.

Elytra monomorphic, 0.90-0.95 times as long as pronotum (Fig. 170). Hind wings present.

$0^{\text {t }}$ : sternite VII similar to that of $N$. brevipennis (Fig. 171); sternite VIII shorter and less slender, posterior median portion less extensively devoid of pubescence (Figs 172-173); aedeagus with ventral process not angled in the middle (lateral view) and with differently shaped apex (lateral view); apical internal structures stouter and shorter (Figs 174-175).

\section{Etymology:}

The species is dedicated to Harald Schillhammer (NHMW), specialist of Staphylininae, who collected the type series.

\section{Comparative notes:}

Based on the similar external morphology and the similar sexual characters, N. schillhammeri is undoubtedly closely related to, and probably the adelphotaxon of $N$. brevipennis. For characters separating the two species see the description above and Figs 27-33, 169-178. From other congeners, $N$. schillhammeri is best distinguished by the shape of the aedeagus.

\section{Distribution and bionomics:}

The type locality is situated in Shan state, central Myanmar, at an altitude of approximately $1350 \mathrm{~m}$. 
Neosclerus praeacutus sp. n. (Figs 34-39)

\section{Type material:}

Holotype $\sigma^{\star}$ : "China (N-Yunnan), Lijiang Naxi Aut. Co., 3 km NW Yongsheng, $53 \mathrm{~km}$ WSW Lijiang, $1950-2000 \mathrm{~m}, 26^{\circ} 41.8^{\prime} \mathrm{N}, 100^{\circ} 43.1^{\prime} \mathrm{E}$ (SE-slope, secondary broadleaved forest) 14.VIII.2003, Wrase [03] / Holotypus ơ Neosclerus praeacutus sp. n. det. V. Assing 2010" (cAss). Paratypes: 3 exs.: "China: N-Yunnan [C03-03], Lijiang Naxi Aut. Co., 3 km NW Yongsheng, $53 \mathrm{~km}$ WSW Lijiang, 26² $41^{\prime} .8^{\prime} \mathrm{N}, 100^{\circ} 43.1^{\prime} \mathrm{E}, 1950-2000 \mathrm{~m}$, SE slope, secondary broadleaved forest, 14.VIII.2003, leg. M. Schülke" (cSch, cAss); 10 exs.: "China: Yunnan [CH07-31], Dali Bai Auton. Pref., mtn. range N Er Hai, 42 km N Dali, 2604'53"N, 10009'39"E, 2500-2550 m, NE slope with oaks, litter sifted, 12.VI.2007, M. Schülke" (cSch, cAss); 1 o : "China: N-Yunnan, Dali Bai Nat. Aut. Pref., $1 \mathrm{~km}$ W Dali, foothill of Diancang Shan, $25^{\circ} 41.9^{\prime} \mathrm{N}, 100^{\circ} 08.4^{\prime} \mathrm{E}$, 2170 m, 3.IX.2003, A. Smetana [C146]" (cSme); 1 o : "China (Yunnan), Nujiang Lisu Aut. Pref., Salween side valley $5 \mathrm{~km}$ S Fugong, road SS $228 \mathrm{~km} 223$ (creek bank, litter sifted), 8.VI.2007, D.W. Wrase [25]" (cSch); 3 ㅇ, "China: Yunnan, (CH07-25), Nujiang Lisu Aut. Pref., Salween

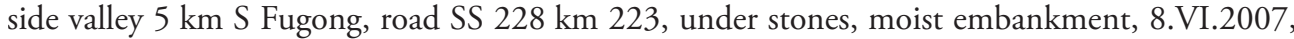

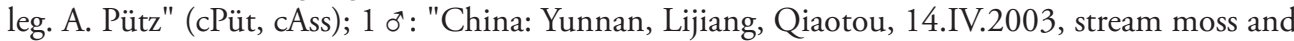
litter, G. de Rougemont leg." (cRou); 1 ㅇ: "China: N-Yunnan, Diqing Tibet Aut. Pr., Deqin Co., gully W Jinsha Jiang river, $33 \mathrm{~km}$ WNW Zhongdian, $27^{\circ} 56.75^{\prime} \mathrm{N}, 99^{\circ} 24.42 \mathrm{E}, 2300 \mathrm{~m}$, 4.VI.2005, A. Smetana [C151]" (cAss).

\section{Description:}

Body length 3.0-3.7 mm. Habitus as in Fig. 34. Coloration: body blackish, pronotum and elytra sometimes indistinctly paler; legs and antennae yellowish.

Head across eyes approximately 1.2 times as wide as long; postocular region very short, shorter than width of antennomere IV; punctation moderately coarse and moderately dense, sparser in posterior portion of dorsal surface (Fig. 35); interstices in anterior and median dorsal portion without microsculpture and glossy, in posterior portion often with shallow traces of microreticulation; antenna approximately $0.9 \mathrm{~mm}$ long.

Pronotum approximately as long as wide or indistinctly oblong, and 0.80-0.85 times as wide as head; punctation similar to that of head (Fig. 35); impunctate midline of variable width, often narrow or ill-defined (particularly in anterior half); interstices without microsculpture and glossy.

Elytra short, approximately 0.85 times as long, and 1.05-1.15 times as wide as pronotum, slightly widened posteriad; humeral angles relatively weakly marked (Fig. 35); punctation fine, dense, shallow, and relatively ill-defined. Hind wings present, but probably of reduced length.

Abdomen approximately as wide as elytra; punctation fine, moderately dense, somewhat sparser on tergite VII than on anterior tergites; interstices with shallow microsculpture; posterior margin of tergite VII with palisade fringe.

$\sigma^{\star}$ : sternite VII with posterior margin weakly and broadly convex in the middle, in posterior median portion with cluster of slightly modified (stouter and darker) setae (Fig. 36); sternite VIII anteriorly unmodified, with sparse pubescence, in posterior median portion without pubescence, posterior excision V-shaped, its depth approximately $1 / 6$ the length of sternite (Fig. 37); aedeagus with long, straight, subapically weakly dentate, and apically very acute ventral process; internal sac with pair of elongate sclerotized structures (Figs 38-39). 

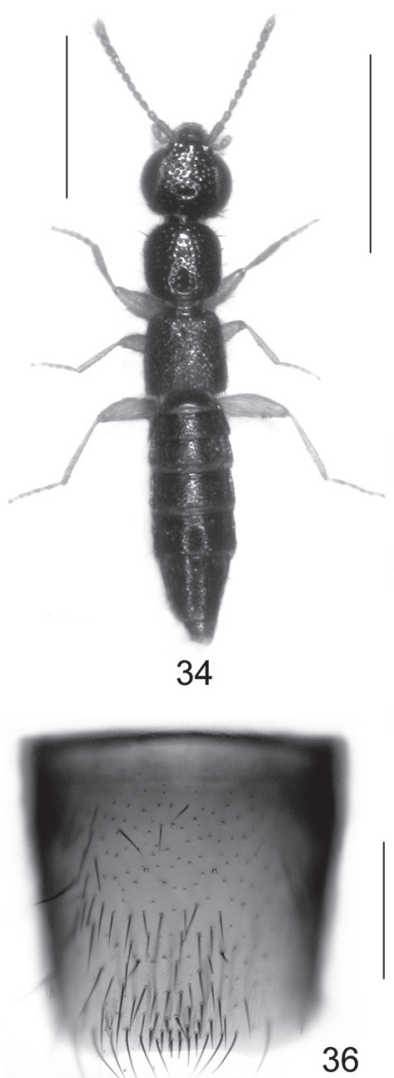

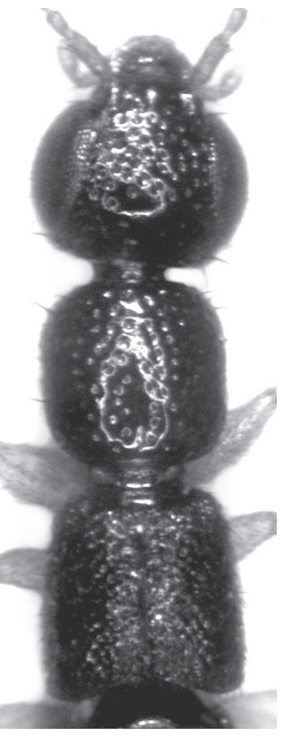

35

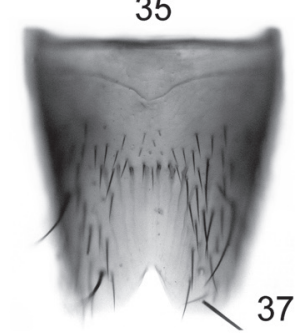

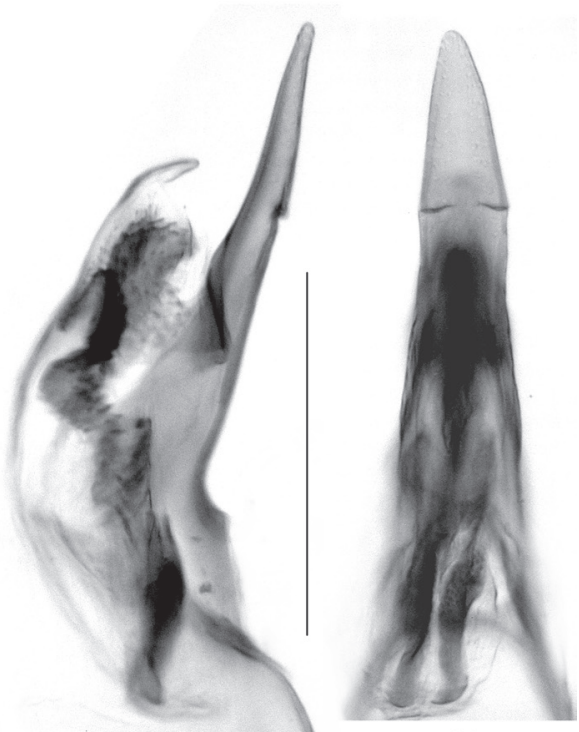

39

Figs 34-39: Neosclerus praeacutus sp. n.: habitus (34); forebody (35); male sternite VII (36); male sternite VIII (37); aedeagus in lateral view (38); apical portion of aedeagus in ventral view (39). Scale bars: 34: $1.0 \mathrm{~mm}$; 35: $0.5 \mathrm{~mm}$; 36-39: $0.2 \mathrm{~mm}$.

\section{Etymology:}

The name (Latin, adjective: pointed, sharpened) refers to the apically acute ventral process of the aedeagus.

\section{Comparative notes:}

This species is best distinguished from its congeners by the morphology of the aedeagus, particularly the shape of the ventral process. It is separated from the similar N. glaber, which is apparently widespread in southern China, by the shorter and more slender elytra, as well as by the shape and chaetotaxy of the male sternites VII and VIII.

\section{Distribution and bionomics:}

The known distribution is confined to four localities in Yunnan, China, where the type specimens were sifted from leaf litter and moss in forests and on stream banks at altitudes of 1950$2550 \mathrm{~m}$ in April, June, and August. 


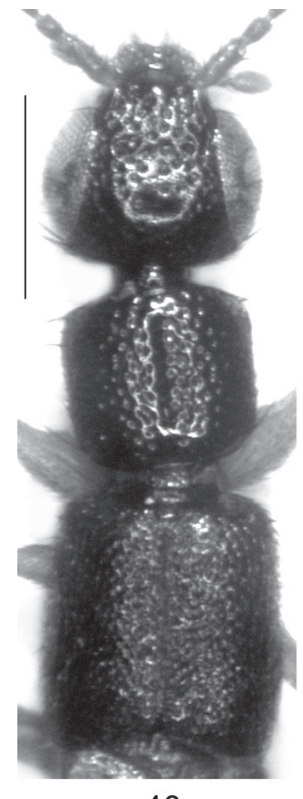

40

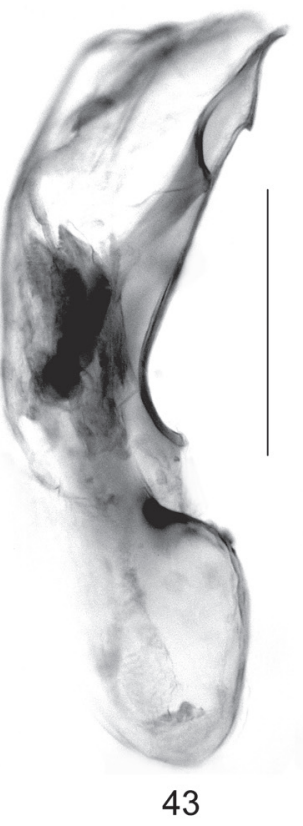

43

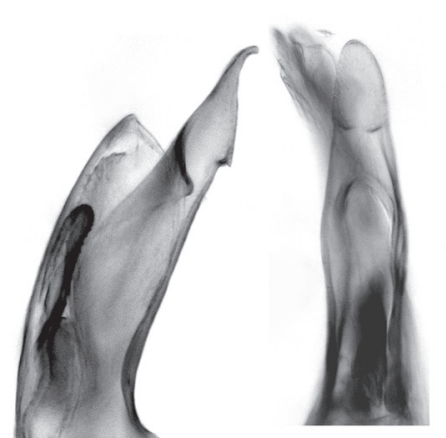

45

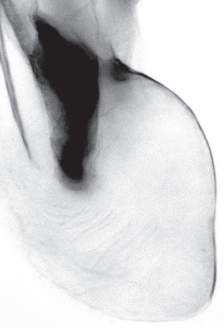

44

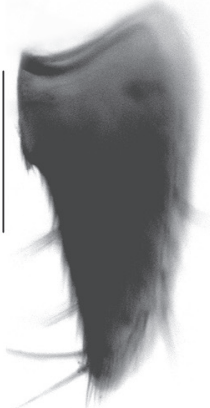

42

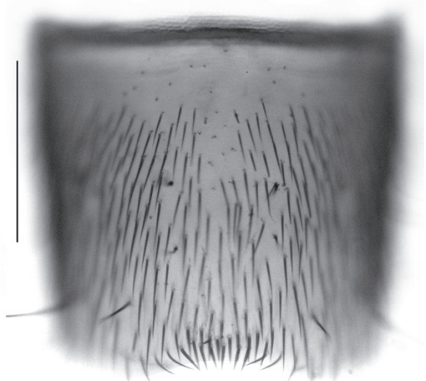

41

Figs 40-45: Neosclerus barbatulus sp. n.: forebody (40); male sternite VII (41); male sternite VIII in lateral view (42); aedeagus in lateral view (43-44; 43: Thailand, 44: Yunnan); apical portion of aedeagus in ventral view (45). Scale bars: 40: $0.5 \mathrm{~mm}$; 41-45: $0.2 \mathrm{~mm}$.

Neosclerus barbatulus sp. n. (Figs 40-46)

\section{Type material:}

Holotype ơ: "W. Thailand: $300 \mathrm{~m}$, Thung Yai Wildlife Sanctuary, $15^{\circ} 28^{\prime} \mathrm{N}-98^{\circ} 48^{\prime} \mathrm{E} / \mathrm{Tak}$ Province, Umphang District, Song Bae Stream.18-27.iv.1988. / Evergreen rain forest. M.J.D. Brendell. B.M. 1988-183. / flight interception trap / Lobochilus sp. cf. fortepunctatus, det. 1989, G. de Rougemont / Holotypus o Neosclerus barbatulus sp. n. det. V. Assing 2010" (BMNH). Paratypes: 2 ㅇ 우 : same data as holotype (BMNH, cAss); 1 ㅇ: "Burma, Wetwun, 30.I.1982, de Rougemont" (cRou); 1 ơ, 1 \%: "Burma, Taunggyi, 1.I.1980, de Rougemont" (cRou, cAss); 5 exs.: "Thailand, r. Kwae Noi, Ban Sai Yok, III.1987, G. de Rougemont (cRou, cAss); 2 ㅇ ㅇ: "Myanmar: Mandalay Division, $8 \mathrm{~km} \mathrm{~S}$ Pyin Oo Lwin, $1040 \mathrm{~m}, 21^{\circ} 58.199^{\prime} \mathrm{N}, 96^{\circ} 25.840$ 'E, Paungdaw vill., 20.10.1998, leg. Schillhammer" (NHMW, cAss); 3 exs.: "China, Yunnan, Xishuangbanna, 20.I.1993, G. de Rougemont" (cRou, cAss); 1 ex.: "China, Yunnan, Xishuangbanna, 22.I.1993, G. de Rougemont" (cRou).

\section{Description:}

Body length 3.0-3.7 mm. Forebody as in Fig. 40. Coloration: head blackish-brown to black; pronotum dark-brown to blackish-brown; elytra brown to dark-brown; abdomen dark-brown with dark-reddish apex; legs and antennae yellowish.

Head across eyes approximately 1.15 times as wide as long; eyes large, postocular region approximately as long as width of antennomere II in dorsal view; punctation coarse and dense in anterior 
portion, sparse and finer in posterior portion of dorsal surface (Fig. 40); interstices with microreticulation (sometimes very superficial and visible only in posterior portion) and moderately glossy or with subdued shine; antenna approximately 0.9-1.0 $\mathrm{mm}$ long.

Pronotum approximately as wide as long or indistinctly transverse, and approximately 0.85 times as wide as head; punctation moderately coarse and moderately dense, distinctly finer than that of anterior portion of head (Fig. 40); midline moderately broadly impunctate; interstices without microsculpture and glossy.

Elytra long and large, 1.10-1.15 times as long and approximately 1.25 times as wide as pronotum; humeral angles marked (Fig. 40); punctation dense and moderately fine; interstices glossy. Hind wings fully developed.

Abdomen distinctly narrower than elytra; punctation fine and moderately dense; interstices with shallow microsculpture; posterior margin of tergite VII with palisade fringe.

$0^{\star}$ : sternite VII with posterior margin broadly and shallowly concave, near this concavity with a transverse cluster of somewhat condensed setae (Fig. 41); sternite VIII anteriorly with elevation (best visible in lateral view), tip of this elevation with a cluster of a few short setae, median portion extensively depressed and without pubescence, posterior excision acute, its depth approximately $1 / 5$ the length of sternite (Figs 42, 46); aedeagus with long and apically acute ventral process, internal sac basally with pair of distinctly sclerotized structures (Figs 44-45).

\section{Etymology:}

The specific epithet (Latin, adjective derived from barbatula, diminutive of barba = beard) alludes to the cluster of setae near the posterior margin of the male sternite VII.

\section{Comparative notes:}

Based on the morphology of the aedeagus (shape of ventral process, shape of internal structures), the synapomorphically derived shape and chaetotaxy of the male sternites VII and VIII, as well as on the presence of microreticulation on the head, $N$. barbatulus is closely allied to $N$. inarmatus from Taiwan. It is, however, readily distinguished from this species by the much longer and broader elytra, the fully developed hind wings, the paler coloration of the elytra, the presence of a palisade fringe at the posterior margin of the abdominal tergite VII, as well as by the slightly different shape of the apex of the ventral process and the shape and position of the internal structures of the aedeagus.

\section{Distribution and bionomics:}

The species is currently known from two localities in Thailand, three localities in Myanmar, and one in the Chinese province Yunnan, suggesting that it is widespread in the Oriental and southern East Palaearctic regions. The specimens from Thailand were partly collected on the wing in an evergreen forest at an altitude of $300 \mathrm{~m}$, one of the specimens from Myanmar was found at an altitude of $1040 \mathrm{~m}$. The months indicated are January, March, April, and October.

Neosclerus rougemonti sp. n. (Figs 47-53)

\section{Type material:}

Holotype $0^{*}$ : "Thailand, Doi Inthanon, 15:III:1982, G. de Rougemont / Holotypus ơ Neosclerus rougemonti sp. n. det. V. Assing 2010" (cRou). Paratypes: $10^{*}, 1$ : same data as holotype (cRou, cAss); 1 ㅇ: "Thailand, Doi Southeb, Chiang Mai, 11.I.80, Osella" (cRou). 


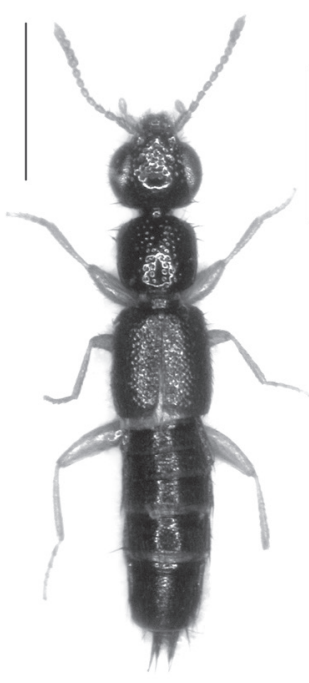

47

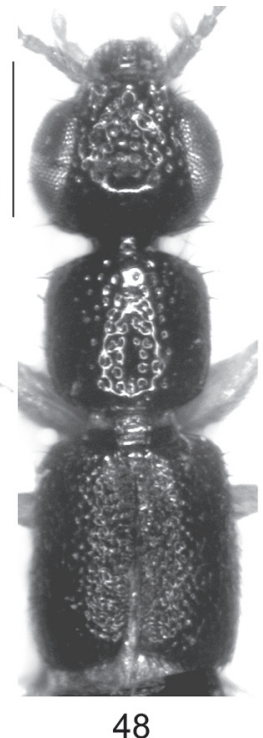

48

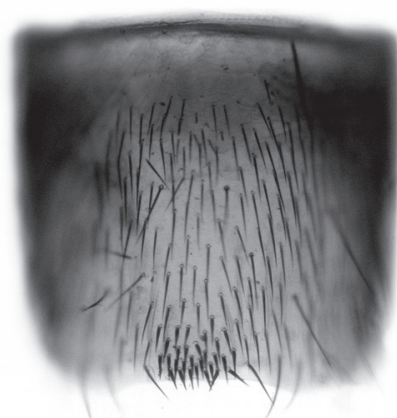

49

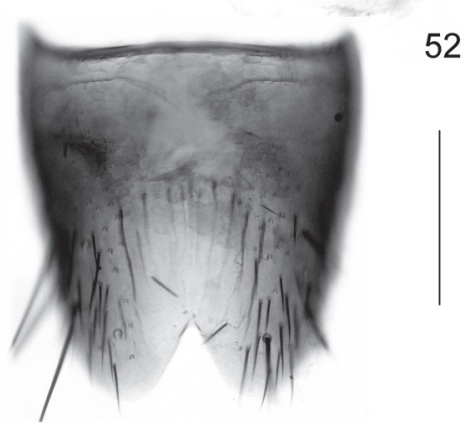

50
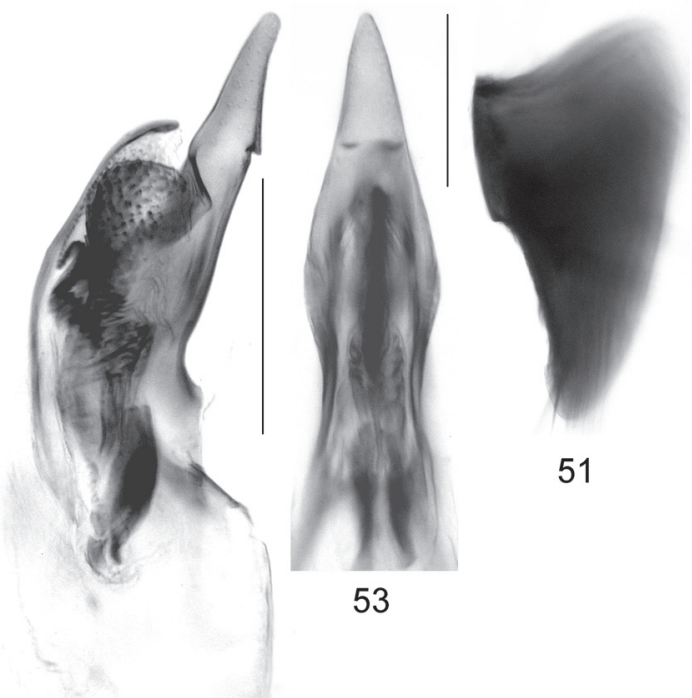

51

Figs 46-53: Neosclerus barbatulus sp. n. (46) and N. rougemonti sp. n. (47-53): male sternite VIII in ventral view (46, 50); habitus (47); forebody (48); male sternite VII (49); male sternite VIII in lateral view (51); aedeagus in lateral view (52); apical portion of aedeagus in ventral view (52). Scale bars: $47: 1.0 \mathrm{~mm}$; 48: $0.5 \mathrm{~mm}$; 46, 49-53: $0.2 \mathrm{~mm}$.

\section{Description:}

Body length 3.0-3.5 mm. Habitus as in Fig. 47. Coloration: head blackish; pronotum blackishbrown; elytra dark-brown, with the humeral angles and the posterior margin indistinctly paler; abdomen blackish-brown; legs and antennae yellowish.

Head across eyes approximately 1.2 times as wide as long; eyes large, postocular region extremely short, almost obsolete; punctation moderately coarse and dense in anterior portion, sparse and finer in posterior portion of dorsal surface (Fig. 48); interstices without distinct microreticulation and glossy; antenna approximately $0.9-1.0 \mathrm{~mm}$ long.

Pronotum approximately as wide as long or indistinctly transverse, and approximately 0.85 times as wide as head (Fig. 48); punctation similar to that of anterior portion of head, but somewhat sparser; impunctate midline of variable width, narrow and ill-defined to broad and well-defined; interstices without microsculpture and glossy. 
Elytra long and large, 1.10-1.15 times as long and approximately 1.25 times as wide as pronotum; humeral angles marked (Fig. 48); punctation dense and moderately fine; interstices glossy. Hind wings fully developed.

Abdomen distinctly narrower than elytra; punctation fine and moderately dense; interstices with shallow microsculpture; posterior margin of tergite VII with palisade fringe.

$\sigma^{*}$ : sternite VII with posterior margin broadly and shallowly concave in the middle, near this concavity with transverse cluster of short and stout dark setae (Fig. 49); sternite VIII relatively short, approximately as wide as long, anteriorly with elevation (best visible in lateral view), median portion extensively without pubescence, posterior excision V-shaped and acute, its depth approximately $1 / 5$ the length of sternite (Figs 50-51); aedeagus with long, apically acute and laterally compressed ventral process, internal sac basally with pair of distinctly sclerotized structures (Fig. 52-53).

\section{Etymology:}

The species is dedicated to Guillaume de Rougemont, who collected the type material of this and several other species treated in the present paper and to whom I am thankful for his continuous and most helpful assistance in my work on Eastern Palaearctic and Oriental paederines.

\section{Comparative notes:}

Based on the morphology of the aedeagus (laterally compressed and apically acute ventral process, shape of internal structures), the synapomorphically derived shape and chaetotaxy of the male sternites VII (posterior margin concave in the middle; presence of median cluster of dark setae near posterior margin) and VIII (anteriorly with median elevation, posterior median portion extensively without pubescence), this species is closely allied to $N$. barbatulus, $N$. inarmatus, and $N$. brevipennis (posterior cluster of setae on the male sternite VII not pronounced). From the former two species, it is separated by the absence of distinct microsculpture on the head, from the latter by distinctly longer, larger, and darker elytra. It is distinguished from all its congeners by the shape of the ventral process and the internal structures of the aedeagus.

\section{Distribution and bionomics:}

The species is currently known from two localities in Thailand, where it was collected in January and March.

\section{Neosclerus rimatus sp. n. (Figs 54-59)}

\section{Type material:}

Holotype $\sigma^{*}$ [teneral]: "China, Guangxi, Cengwanglaoshan, 1300 m, 3.VIII.99, J.R. Fellowes / leaf litter / Holotypus o Neosclerus rimatus sp. n. det. V. Assing 2010" (cRou). Paratype $\sigma^{\star}$ [teneral]: same data as holotype (cAss).

\section{Description:}

Body length 3.0-3.2 mm. Habitus as in Fig. 54. Coloration [note that both type specimens are teneral]: head blackish; pronotum dark-brown; elytra yellowish-brown; abdomen brown; legs and antennae yellowish.

Head strongly transverse, across eyes 1.25-1.30 times as wide as long; eyes large, postocular region extremely short, almost obsolete (Fig. 55); punctation coarse and dense, in posterior portion of 
dorsal surface as dense as in anterior portion, or nearly so; interstices with distinct microreticulation and almost matt; antenna approximately $1.0 \mathrm{~mm}$ long.

Pronotum distinctly convex in cross-section, approximately as wide as long, and approximately 0.85 times as wide as head (Fig. 55); punctation similar to that of head; midline very narrowly impunctate and with fine longitudinal furrow at least in posterior 3/4; interstices without microsculpture and glossy.

Elytra short, approximately 0.65 times as long as, and about as wide as pronotum; humeral angles weakly marked (Fig. 55); punctation very dense, moderately fine, and rather ill-defined; surface with subdued shine. Hind wings absent.

Abdomen slightly broader than elytra; punctation fine and moderately dense, sparser on tergite VII than on anterior tergites; interstices with shallow microsculpture; posterior margin of tergite VII without palisade fringe.

$\sigma^{\star}$ : sternite VII with posterior margin broadly and shallowly concave in the middle, near this concavity with transverse cluster of approximately 15 rather weakly modified dark setae (Fig. 59); sternite VIII weakly oblong, anteriorly with elevation (best visible in lateral view) with median cluster of few short setae, median portion depressed and extensively devoid of pubescence, posterior excision V-shaped, its depth approximately 1/5-1/6 the length of sternite (Figs 56-57); aedeagus with short, relatively stout, laterally compressed, subapically dentate ventral process and with a pair of sclerotized structures in internal sac (Fig. 58).

\section{Etymology:}

The specific epithet is an adjective derived from the noun rima (Latin: scratch) and alludes to the distinctive median furrow on the pronotum.

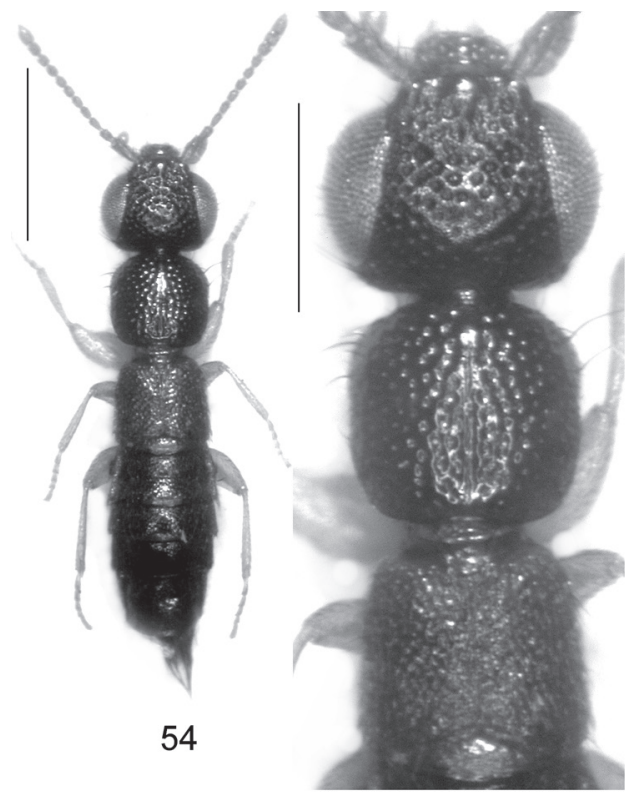

55

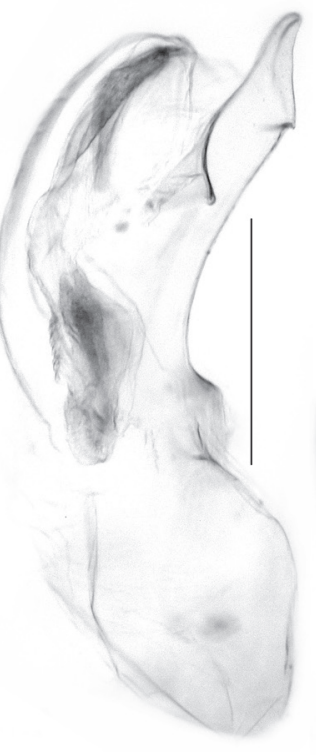

58
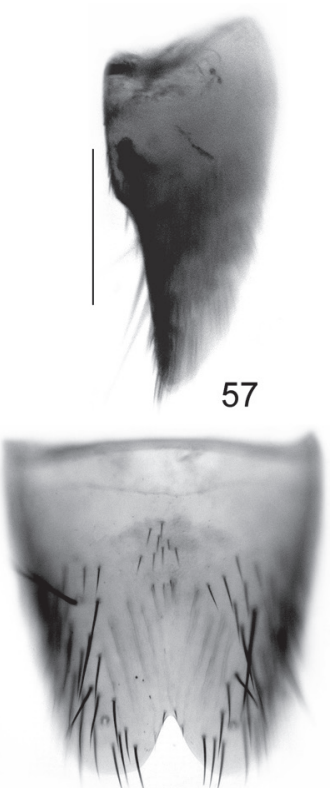

56

Figs 54-58: Neosclerus rimatus sp. n.: habitus (54); forebody (55); male sternite VIII in ventral view (56); male sternite VIII in lateral view (57); aedeagus in lateral view (58). Scale bars: $54: 1.0 \mathrm{~mm}$; 55: $0.5 \mathrm{~mm}$; 56-58: $0.2 \mathrm{~mm}$. 


\section{Comparative notes:}

Based on the morphology of the aedeagus (internal structures, shape of the apex of the ventral process), the shape and chaetotaxy of the male sternites VII and VIII, as well as on the punctation and microsculpture of the head, $N$. rimatus is closely related to $N$. barbatulus and its allies. It is distinguished from all its congeners by the shape of the ventral process of the aedeagus, the shape and chaetotaxy of the male sternite VIII, as well as by the presence of a median furrow on the pronotum. It is separated from many of its congeners also by the short wings and the absence of a palisade fringe at the posterior margin of tergite VII.

\section{Distribution and bionomics:}

The type locality is situated in Guangxi province, southern China. Morphological evidence (adaptive reductions of elytral length, hind wings, and palisade fringe at the posterior margin of the abdominal tergite VII) suggests that the distribution this species is restricted. The two teneral specimens were collected from leaf litter at an altitude of $1300 \mathrm{~m}$ in August.

Neosclerus incisus sp. n. (Figs 60-65)

\section{Type material:}

Holotype ơ [slightly teneral]: "China, Guangxi, Nongxin, 1020 m, 12.VIII.1998, J.R. Fellowes / Holotypus ơ Neosclerus incisus sp. n. det. V. Assing 2010" (cAss).

\section{Description:}

Body length $3.0 \mathrm{~mm}$. Habitus as in Fig. 60. Coloration: head blackish; pronotum dark-brown; elytra and abdomen brown; legs yellowish; antennae reddish-yellow.

Head strongly transverse, across eyes approximately 1.25 times as wide as long; eyes large, postocular region practically obsolete (Fig. 61); punctation coarse and dense, in posterior portion of dorsal surface only slightly sparser than in anterior portion; interstices with very shallow microreticulation (distinctly visible only in posterior portion of head); antenna approximately $0.95 \mathrm{~mm}$ long.

Pronotum distinctly convex in cross-section, approximately as wide as long, and approximately 0.8 times as wide as head (Fig. 61); punctation moderately dense and somewhat less coarse than that of head; midline very narrowly impunctate; interstices without microsculpture and glossy.

Elytra short, approximately 0.65 times as long as, and at posterior margin about as wide as pronotum; humeral angles weakly marked (Fig. 61); punctation very dense, moderately fine, and rather ill-defined; surface with subdued shine. Hind wings absent.

Abdomen approximately 1.1 times as broad as elytra; punctation fine and moderately dense, sparser on tergite VII than on anterior tergites; interstices with shallow microsculpture; posterior margin of tergite VII without palisade fringe.

$0^{*}$ : sternite VII with posterior margin broadly and very shallowly concave in the middle, near this concavity with approximately 10 rather weakly modified dark setae (Fig. 62); sternite VIII weakly oblong, anteriorly with short elevation (best visible in lateral view) without setae, median portion extensively devoid of pubescence, posterior excision conspicuously narrow, its depth approximately 1/7 the length of sternite (Figs 63-64); aedeagus with short, relatively stout, laterally compressed, subapically dentate ventral process and with pair of sclerotized structures in internal sac (Fig. 65). 


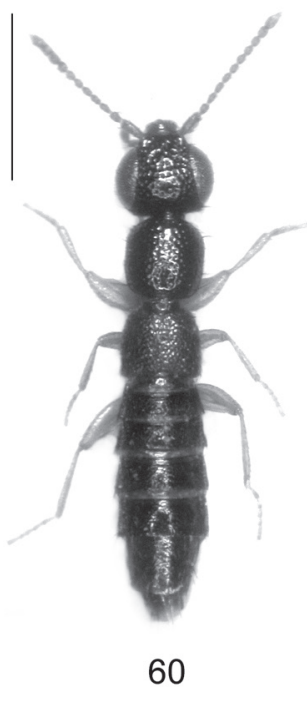

60

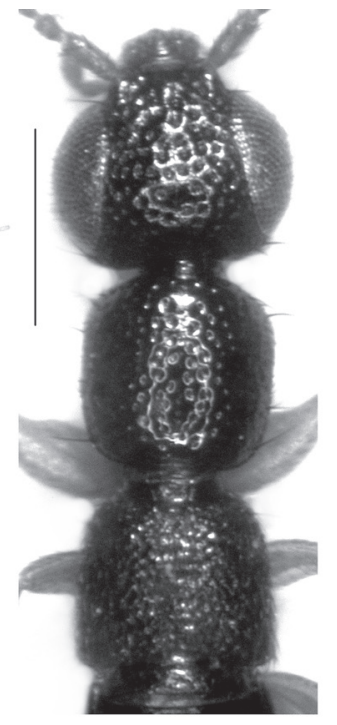

61

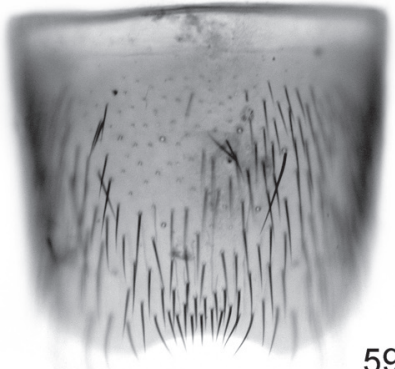

59

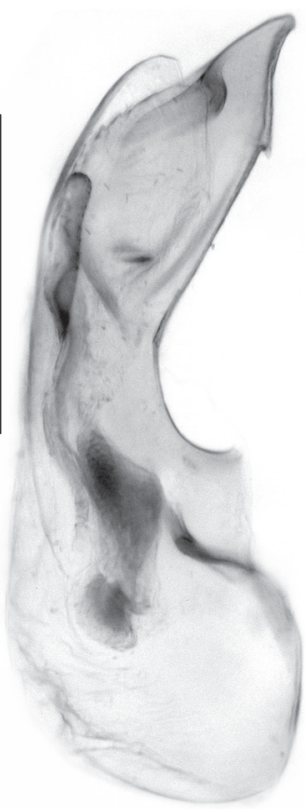

65

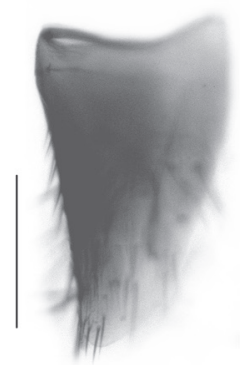

64

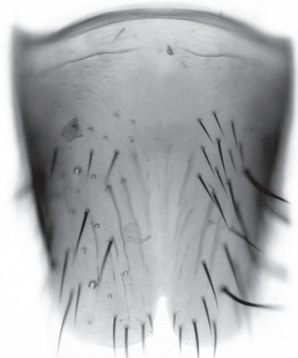

63

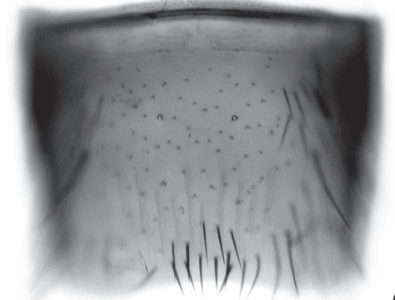

62

Figs 59-65: Neosclerus rimatus sp. n. (59) and N. incisus sp. n. (60-65): male sternite VII (59, 62); habitus (60); forebody (61); male sternite VIII in ventral view (63); male sternite VIII in lateral view (64); aedeagus in lateral view (65). Scale bars: 60: $1.0 \mathrm{~mm}$; 61: 0.5 mm; 59, 62-65: $0.2 \mathrm{~mm}$.

\section{Etymology:}

The specific epithet (Latin, adjective: incised) alludes to the narrow posterior excision of the male sternite VIII.

\section{Comparative notes:}

Based on the morphology of the aedeagus (internal structures, shape of the apex of the ventral process), the shape and chaetotaxy of the male sternites VII and VIII, as well as on the punctation and microsculpture of the head, $N$. rimatus is closely related to $N$. barbatulus and its allies. It is distinguished from all its congeners by the shape of the ventral process of the aedeagus, as well as by the shape and chaetotaxy of the male sternite VIII, particularly the narrow posterior excision. It is separated from many of its congeners also by the short wings and the absence of a palisade fringe at the posterior margin of tergite VII. From the similar and geographically close micropterous $N$. rimatus, it is additionally distinguished by the absence of a median furrow on the pronotum, and the much less pronounced microsculpture on the head. 


\section{Distribution and bionomics:}

The type locality is situated in Guangxi province, southern China. As can be inferred from the adaptive reductions of elytral length, hind wings, and the palisade fringe at the posterior margin of the abdominal tergite VII, the species probably has a restricted distribution. The slightly teneral holotype was collected at an altitude of $1020 \mathrm{~m}$ in August.

Neosclerus schuelkei sp. n. (Figs 66-72)

\section{Type material:}

Holotype ơ: "China: Yunnan, Baoshan Pref., mount. range $22 \mathrm{~km} \mathrm{~S}$ Tengchong, $1800 \mathrm{~m}$, $24^{\circ} 49^{\prime} 29^{\prime \prime} \mathrm{N}, 98^{\circ} 29^{\prime} 30^{\prime \prime E}$, devast. primary forest, litter \& mushr. sifted, 30.VIII.2009, leg. M. Schülke [CH09-19] / Holotypus ơ Neosclerus schuelkei sp. n. det. V. Assing 2010" (cAss). Paratypes: 3 우 $q$ : same data as holotype (cSch).

\section{Description:}

Relatively large species of broad habitus (Fig. 66). Body length 3.4-4.0 mm. Coloration: body blackish, except for the reddish-yellow posterior margins of the elytra; legs yellowish; antennae reddish-yellow.

Head across eyes approximately 1.25-1.30 times as wide as long; eyes large, postocular region obsolete (Fig. 67); punctation areolate, coarse and extremely dense, also in posterior portion of dorsal surface; interstices reduced to narrow ridges, with shallow microreticulation; dorsal surface matt; antenna approximately $1.2 \mathrm{~mm}$ long.

Pronotum weakly transverse, 1.05-1.10 times as wide as long and approximately 0.9 times as wide as head (Fig. 67); punctation areolate, coarse, and dense, similar to that of head; impunctate midline very narrow; interstices without microsculpture and glossy.

Elytra 0.95-1.00 times as long and approximately 1.1 times as wide as pronotum; humeral angles marked (Fig. 67); punctation very dense and moderately fine; interstices glossy. Hind wings present.

Abdomen approximately as wide as elytra or slightly narrower; punctation fine and moderately dense, slightly sparser on tergite VII than on anterior tergites; interstices with shallow microsculpture; posterior margin of tergite VII with palisade fringe.

$\sigma^{*}$ : sternite VII with posterior margin indistinctly concave in the middle, near middle of posterior margin with slightly denser and very weakly modified setae (Fig. 68); sternite VIII anteriorly with median elevation, in posterior half with extensive impression without pubescence, posterior excision conspicuouly deep and distinctly $\mathrm{V}$-shaped, its depth almost $1 / 3$ the length of sternite (Figs 69-70); aedeagus with subapically distinctly dentate and apically acute (lateral view) ventral process, internal sac with pair of sclerotized structures (Figs 71-72).

\section{Etymology:}

The species is dedicated to my colleague and friend Michael Schülke, who not only collected the type series of this species, but also type material of various other species treated in the present paper.

\section{Comparative notes:}

Neosclerus schuelkei is the largest species of the genus. It is characterized not only by its size and 


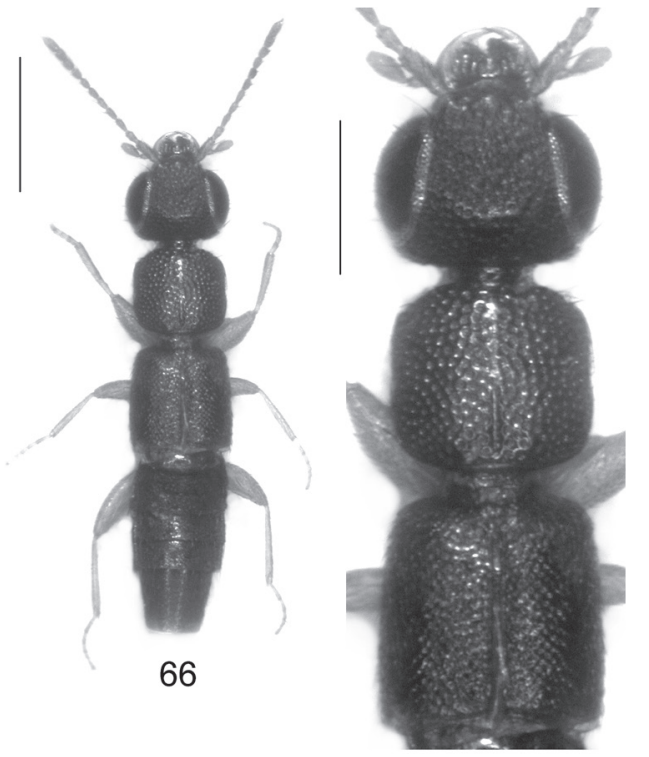

67
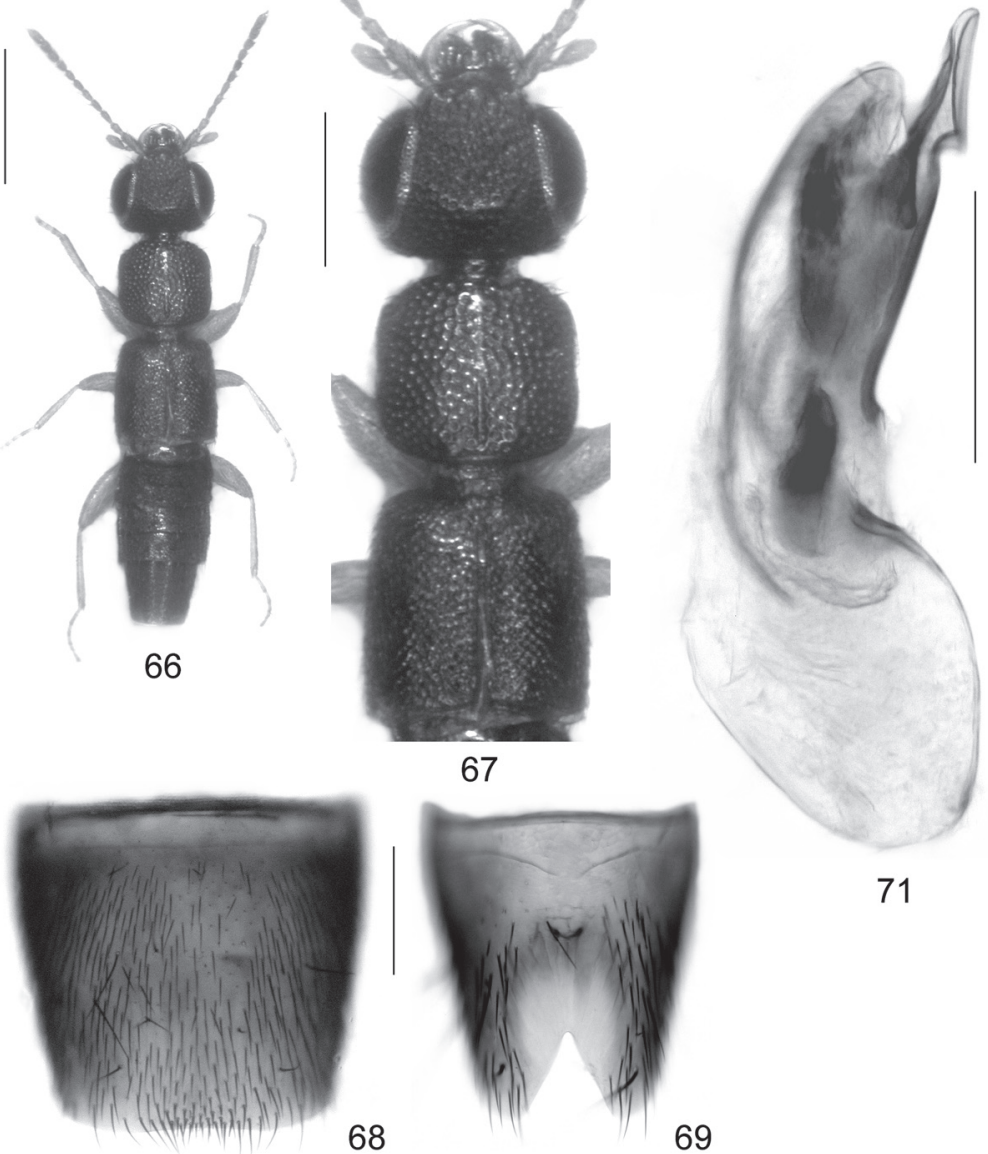

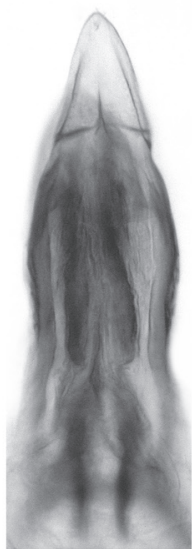

72

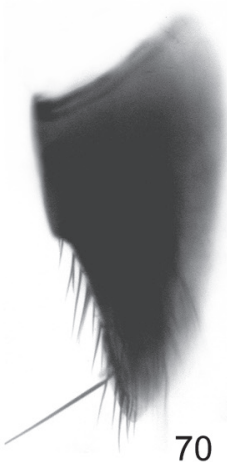

Figs 66-72: Neosclerus schuelkei sp. n.: habitus (66); forebody (67); male sternite VII (68); male sternite VIII in ventral view (69); male sternite VIII in lateral view (70); aedeagus in lateral view (71); apical portion of aedeagus in ventral view (72). Scale bars: $66: 1.0 \mathrm{~mm}$; 67: $0.5 \mathrm{~mm}$; 68-72: $0.2 \mathrm{~mm}$.

broad habitus, but also by the areolate and dense punctation of the head and pronotum, the shape and chaetotaxy of the male sternites VII and VIII, and particularly by the shape of the ventral process of the aedeagus.

\section{Distribution and bionomics:}

The species is known only from the type locality to the south of Tengchong, Yunnan, China. The specimens were sifted from leaf litter in a degraded primary forest at an altitude of $1800 \mathrm{~m}$ in August.

Neosclerus inarmatus sp. n. (Figs 73-79)

\section{Type material:}

Holotype $0^{\star}$ : "Taiwan - Hsinchu Co., Wufeng, Rd. 122, km 19, 1200 m, mountain forest litter, 26.III.2008, leg. Vít [12] / Holotypus ơ Neosclerus inarmatus sp. n. det. V. Assing 2009" (cAss). 


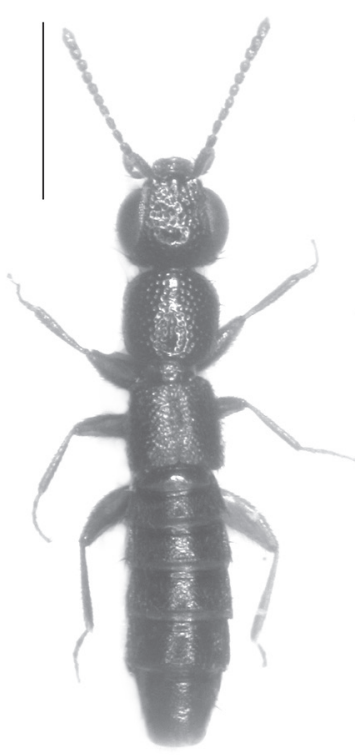

73

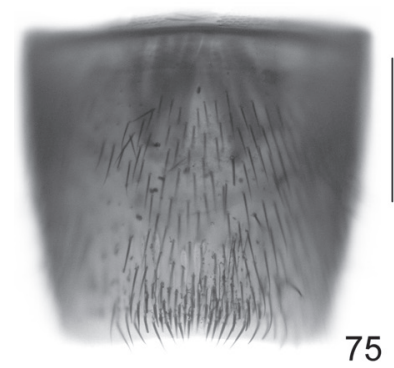

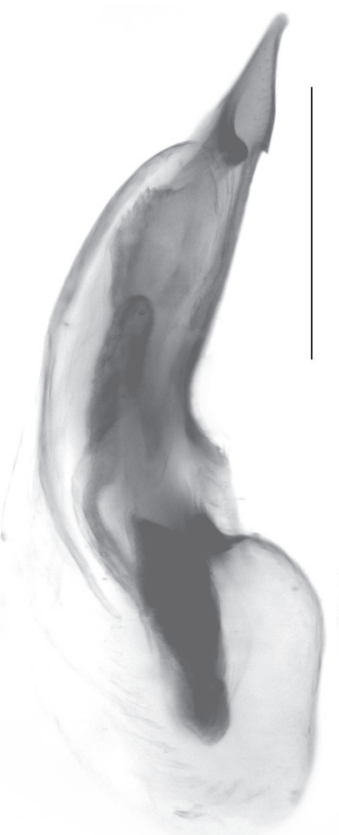

78

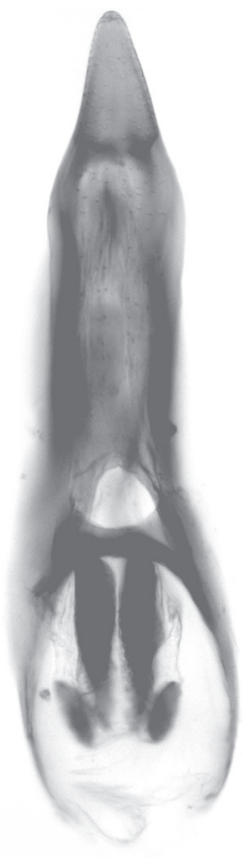

79

Figs 73-79: Neosclerus inarmatus sp. n.: habitus (73); forebody (74); male sternite VII (75); male sternite VIII in ventral view (76); male sternite VIII in lateral view (77); aedeagus in lateral view (78); aedeagus in ventral view (79). Scale bars: 73: $1.0 \mathrm{~mm}$; 74: $0.5 \mathrm{~mm}$; 75-79: $0.2 \mathrm{~mm}$.

\section{Description:}

Body length $3.4 \mathrm{~mm}$. Habitus as in Fig. 73. External morphology as in N. configens (see below), except as follows:

Head with denser puntation; postocular region shorter, almost obsolete. Elytra slightly longer, approximately 0.75 times as long as pronotum (Fig. 74).

$\sigma^{\star}$ : sternite VII with very weakly concave posterior margin, in posterior median portion with somewhat denser, but otherwise unmodified pubescence (Fig. 75); sternite VIII with broadly $\mathrm{V}$-shaped posterior excision, its depth approximately 1/6 the length of sternite, in anterior half with median elevation, this elevation without posterior spinose extension (Figs 76-77); aedeagus of distinctive morphology, ventral process subapically weakly dentate in lateral view (Figs 78-79).

\section{Etymology:}

The name (Latin, adjective: unarmed) refers to the absence of a posterior spinose extension of the 
median elevation of the male sternite VIII, a character distinguishing $N$. inarmatus from other micropterous species known from Taiwan.

\section{Comparative notes:}

This species is distinguished from other micropterous congeners distributed in Taiwan by the denser punctation of the head, the practically obsolete postocular region, the longer elytra, the morphology of the aedeagus, and by the absence of an anterior carina with posterior process on the male sternite VIII.

\section{Distribution and bionomics:}

The type locality is situated in Hsinchu Hsien, northwestern Taiwan, where the holotype was sifted from mountain forest litter at an altitude of $1200 \mathrm{~m}$ in March.

\section{Neosclerus hlavaci sp. n. (Figs 80-91)}

\section{Type material:}

Holotype $0^{\star}$ : "China, Fujian prov., Wuyi Shan Nat. Res., Masu (1100 m), 6.vi.2001, Hlaváč \& Cooter lgt. / Holotypus ơ Neosclerus hlavaci sp. n. det. V. Assing 2009" (cAss). Paratypes: 1 q : same data as holotype (cAss); 1 on, 2 ㅇ ㅇ: "China, Fujian prov., Wuyi Shan Nat. Res., Gadun hill, (9001300 m), 1.-2.vi.2001, Hlaváč \& Cooter lgt." (cAss); 4 ㅇ ㅇ: "China, Fujian prov., Wuyi Shan Nat. Res., Sangan env. (900 m), 30.v.-12.vi.2001, Hlaváč \& Cooter lgt." (cAss); 8 exs.: "China: Fujian Province, Wuyi Shan, ca. 1300 m, 27 $73^{\prime} \mathrm{N}$ [sic], 11764'E [sic], ca. 5 km E Guadun / 1.vi.2001, Leg. J. Cooter + P. Hlaváč, Mixed forest litter" (cRou, cAss); 1 ex.: "China: Fujian Province, Wuyi Shan, ca. $820 \mathrm{~m}, 27^{\circ} 75^{\prime} \mathrm{N}$ [sic], 117 66' E [sic] / ca. $2 \mathrm{~km}$ NE Tongmu village, 30.v.2001, Mixed forest litter, leg. J. Cooter \& P. Hlaváć" (cRou); 3 exs.: "China: Fujian Province, Wuyi Shan. $1200 \mathrm{~m}, 27^{\circ} 75^{\prime} \mathrm{N}$ [sic], 117 $64^{\prime} \mathrm{E}$ [sic] / Quiliquao-Guadun road, 1.vi.2001, Mixed forest litter, Leg. J. Cooter + P. Hlaváč" (cRou); 3 exs.: "China: Fujian Province, Wuyi Shan. 1150 m, 27070'N [sic], 117 $64^{\prime} \mathrm{E}$ [sic] / Quiliquao-Guadun road, 1.vi.2001, Mixed forest litter, Leg. J. Cooter + P. Hlaváć" (cRou); 1 ex.: "China: Fujian Province, Wuyi Shan, ca. 800 m, 277 $74^{\prime} \mathrm{N}$ [sic], 11767'E [sic] / Sangan, 2.vi.2001, Leg. J. Cooter + P. Hlaváč, Sieved mixed forest litter" (cRou); 2 exs.: "China: Fujian Province, Wuyi Shan, ca. 800 m, 27 $74^{\prime} \mathrm{N}$ [sic], 11767'E [sic] / Sangan, 30.v.2001, Leg. J. Cooter + P. Hlaváč" (cRou); 1 ex.: "China: Fujian Province, Wuyi Shan, 1000 m, 3 km NE Tongmu vill. / $27^{\circ} 75^{\prime} \mathrm{N}$ [sic], $117^{\circ} 68^{\prime} \mathrm{E}$ [sic], 7.vi.2001, Mixed litter, Leg. J. Cooter + P. Hlaváč" (cAss); 1 ex.: "China: Jiangxi Province, Wuyi Shan, Huangganshan, $27^{\circ} 83^{\prime} \mathrm{N}$ [sic], $117^{\circ} 76^{\prime} \mathrm{E}$ [sic], / ca. 2000 m, 5.vi.2001, Mixed forest litter, Leg. J. Cooter + P. Hlaváć" (cRou).

\section{Description:}

Body length 3.0-3.6 mm. Habitus as in Fig. 80. Coloration: head and abdomen blackish; pronotum and elytra dark-brown to blackish-brown, usually at least slightly paler than head and abdomen; anterior margin of elytra and scutellum reddish; posterior elytral margin and pronotal margins usually narrowly reddish-brown; legs and antennae yellowish to reddish-yellow.

Head across eyes 1.20-1.25 times as wide as long; postocular region moderately short, approximately as long as width of antennomere I (Fig. 81); punctation coarse and dense, sparser in posterior median area; interstices with very shallow to pronounced microsculpture (always clearly visible in posterior dorsal portion of head); antenna 1.0-1.1 mm long. Mouthparts as in Figs 82-84. Pronotum approximately as wide as long and 0.80-0.85 times as wide as head (Fig. 81); punctation coarse and dense; midline impunctate; interstices without microsculpture and glossy. 


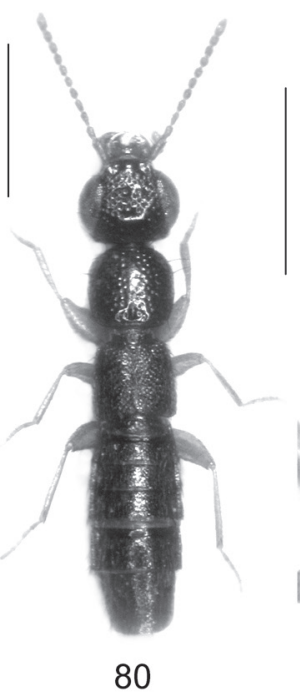

80

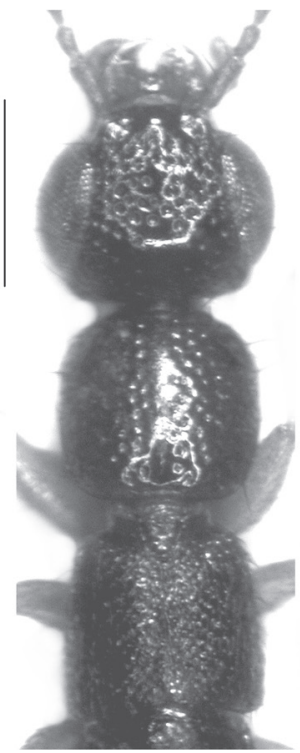

81

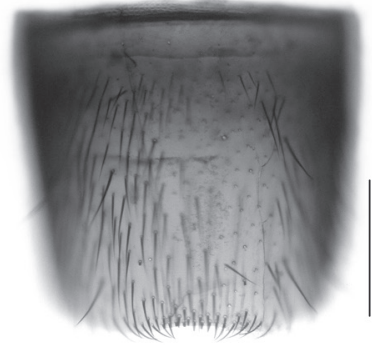

85

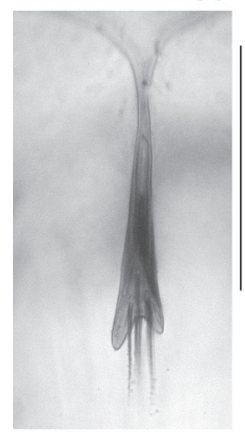

88

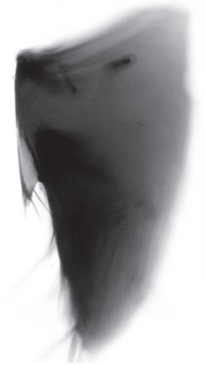

87

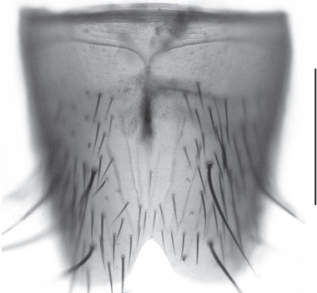

86

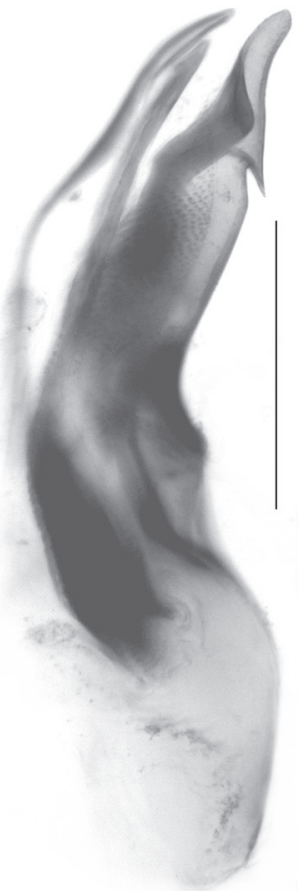

89

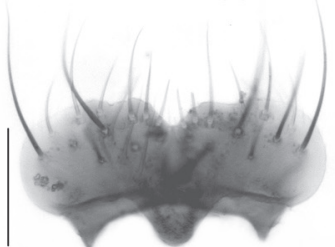

83

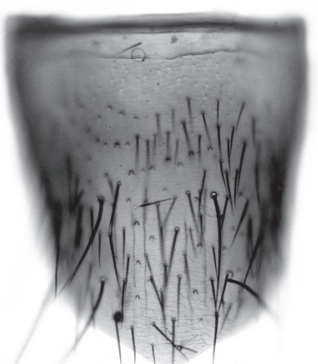

91

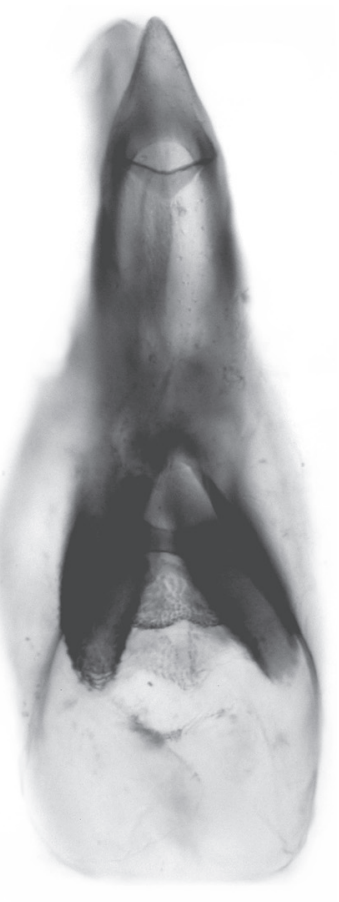

90

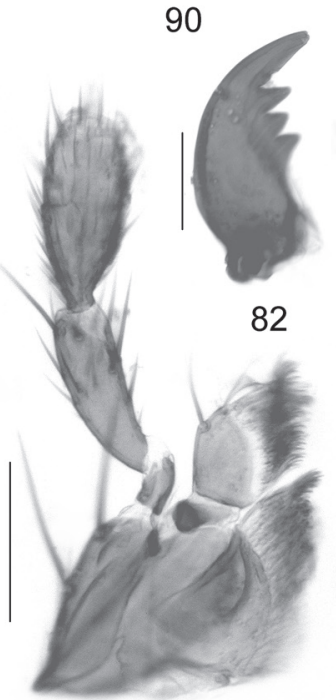

84

Figs 80-91: Neosclerus hlavaci sp. n.: habitus (80); forebody (81); mandible (82); labrum (83); maxilla (84); male sternite VII (85); male sternite VIII in ventral view (86); male sternite VIII in lateral view (87); process of male sternite VIII (88); aedeagus in lateral and in ventral view (89-90); female tergite VIII (91). Scale bars: $80: 1.0 \mathrm{~mm}$; 81: $0.5 \mathrm{~mm}$; 85-87, 89-91: $0.2 \mathrm{~mm}$; 82-84, 88: $0.1 \mathrm{~mm}$. 
Elytra short, approximately 0.7 times as long and approximately as wide as pronotum; humeral angles weakly pronounced (Fig. 81); punctation dense and rather fine, surface only with subdued shine. Hind wings reduced.

Abdomen 1.05-1.15 times as wide as elytra; punctation fine and dense; interstices with very shallow microsculpture; posterior margin of tergite VII without palisade fringe.

$\mathrm{O}^{\mathrm{A}}$ : posterior margin of sternite VII weakly concave in the middle, near this concavity with cluster of approximately 15 short modified setae, on either side of this cluster with longer setae directed diagonally medio-caudad (Fig. 85); sternite VIII with almost V-shaped posterior excision, its depth approximately $1 / 5$ the length of sternite, in anterior half with median carina, this carina extended into spinose process posteriorly (Figs 86-87), apex of spinose process with few setae (Fig. 88); aedeagus of distinctive morphology, ventral process subapically with pronounced tooth in lateral view (Figs 89-90).

ㅇ: sternite VIII posteriorly obtusely angled in the middle (Fig. 91).

\section{Etymology:}

The species is dedicated to my friend and colleague Peter Hlaváč, Košice, who collected the type series, also in gratitude for the generous gift of the Neoclerus material he collected in China.

\section{Comparative notes:}

This species is best distinguished from other micropterous congeners by the morphology of the aedeagus. It is readily separated from the sympatric and syntopic $N$. glaber additionally by the presence of microsculpture on the head, the less coarse and dense punctation of the head, the distinctly shorter and anteriorly more distinctly reddish elytra, the absence of a palisade fringe at the posterior margin of the abdominal tergite VII, as well as by the shape and chaetotaxy of the male sternites VII and VIII.

\section{Distribution and bionomics:}

The known distribution is confined to three localities in Fujian province, southeastern China, where the type specimens were collected at altitudes of 900-1300 m. In two localities, $N$. hlavaci was collected together with $N$. glaber.

\section{Neosclerus configens sp. n. (Figs 92-100)}

\section{Type material:}

Holotype o': "Taiwan, Taoyuan Hsien, Takuanshan For, 17.IV.90, 1650 m, A. Smetana [T5] / Holotypus ơ Neosclerus configens sp. n. det. V. Assing 2010" (cSme). Paratypes: 4 exs.: same data

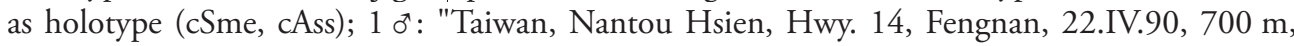
A. Smetana [T17] (cAss).

\section{Description:}

Body length 3.3-4.0 mm. Habitus as in Fig. 92. Coloration: head blackish; pronotum dark-brown to blackish-brown; elytra brown to dark-brown, with the anterior and posterior margins reddish; abdomen dark-brown to blackish-brown, with the apex reddish to reddish-brown; legs yellowish to yellowish-brown; antennae reddish-yellow.

Head across eyes approximately 1.2 times as wide as long; postocular region approximately as long as width of antennomere I (Fig. 93); punctation coarse, moderately dense in anterior and sparse 


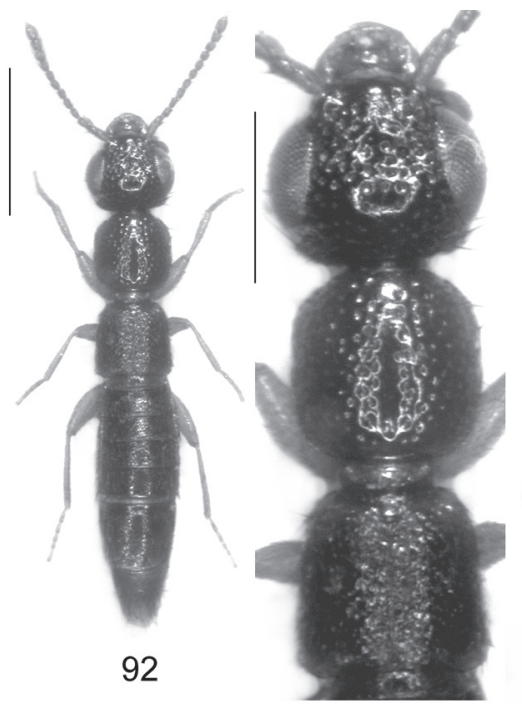

93
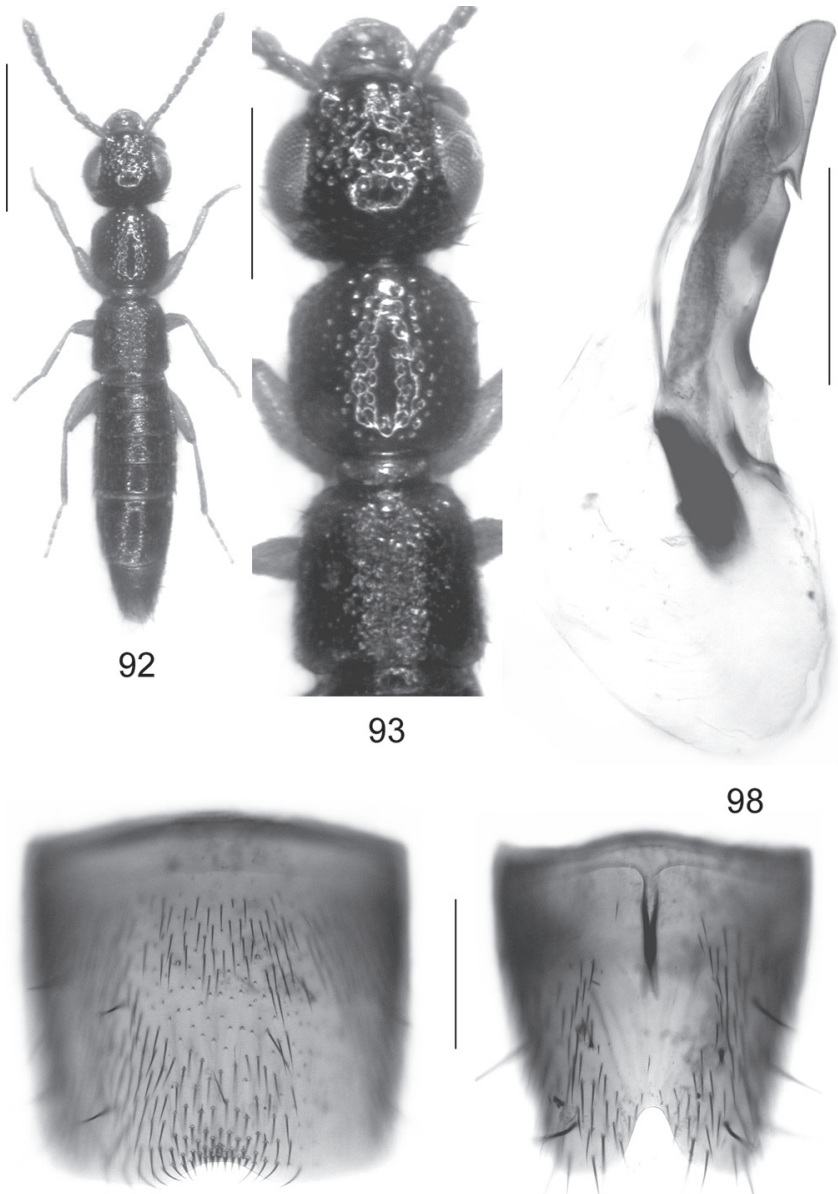

94
98

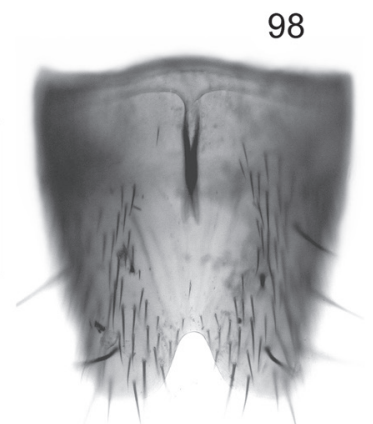

95
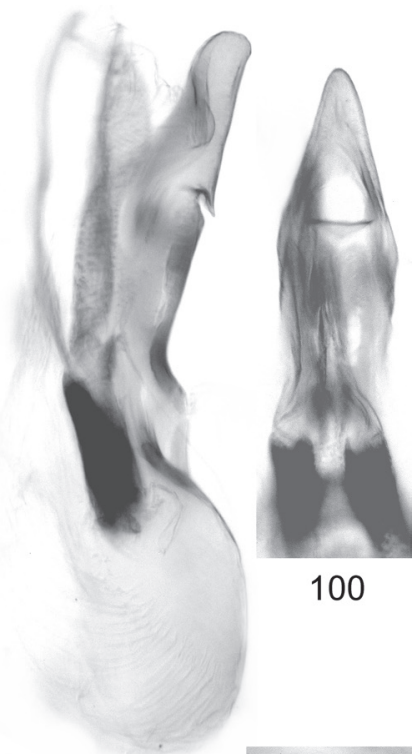

100

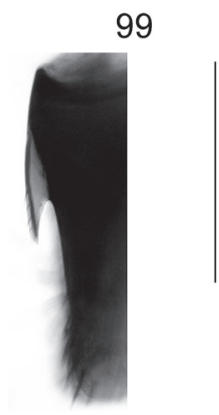

96

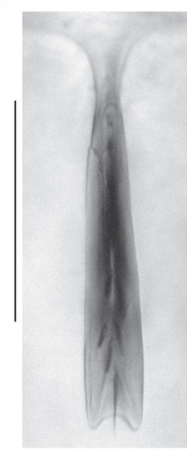

97

Figs 92-100: Neosclerus configens sp. n.: habitus (92); forebody (93); male sternite VII (94); male sternite VIII in ventral view (95); male sternite VIII in lateral view (96); process of male sternite VIII (97); aedeagus in lateral view (98-99; 98: male from Nantou, 99: male from Taoyuan); apical portion of aedeagus in ventral view (100). Scale bars: 92: $1.0 \mathrm{~mm}$; 93: $0.5 \mathrm{~mm}$; 94-96, 98-100: $0.2 \mathrm{~mm}$; 97: $0.1 \mathrm{~mm}$.

in posterior portion of dorsal surface; interstices in anterior and median area with very shallow traces of microsculpture, in posterior area with distinct microreticulation; antenna approximately $1.1 \mathrm{~mm}$ long.

Pronotum approximately as long as wide and approximately 0.9 times as wide as head (Fig. 93); punctation as coarse as that of head or nearly so, and moderately dense; interstices on average distinctly narrower than diameter of punctures; impunctate midline usually moderately broad and well defined.

Elytra short and widened posteriad, approximately 0.65 times as long and at posterior margin about as wide as pronotum; humeral angles weakly marked (Fig. 93); punctation relatively fine, dense, and rather ill-defined. Hind wings absent.

Abdomen 1.05-1.10 times as wide as elytra; punctation fine, dense on anterior tergites and somewhat less dense on posterior tergites; microsculpture shallow, but distinct; posterior margin of tergite VII without palisade fringe. 
$\mathrm{O}^{\mathrm{A}}$ : sternite VII with posterior margin shallowly concave in the middle, at the margin of this concavity with transverse cluster of moderately dense, short and dark setae (Fig. 94); sternite VIII in anterior half with pronounced carina posteriorly extending into an acute process with some setae, median portion without pubescence, posterior excision almost U-shaped, its depth approximately $1 / 5$ the length of tergite (Figs 95-97); aedeagus with ventral process notched and dentate approximately in the middle (lateral view), internal sac with pair of dark basal structures (Figs 98-100).

\section{Etymology:}

The specific epithet is the present participle of the Latin verb configere (to pierce) and refers to the acute process of the male sternite VIII.

\section{Comparative notes:}

Based on the male primary and secondary sexual characters (particularly modifications of male sternite VIII, shape of ventral process and of internal structures of aedeagus), as well as on the similar external morphology, N. configens is closely related to $N$. hlavaci from Fujian. It is best distinguished from this species by the shape of the ventral process of the aedeagus (much more acute in $N$. hlavaci).

\section{Distribution and bionomics:}

The adaptive reductions of the elytra, the hind wings, and the palisade fringe at the posterior margin of the abdominal tergite VII suggest that $N$. configens is endemic to Taiwan, where it has been recorded from Nantou Hsien (central Taiwan) and from Taoyuan (northwest). The type material was sifted from moist to wet debris and humus among lush vegetation and from dead, slightly mouldy plum twigs in a plum orchard at altitudes of 1650 and $700 \mathrm{~m}$, respectively (SMETANA pers. comm.).

\section{Neosclerus smetanai sp. n. (Figs 101-108)}

\section{Type material:}

Holotype $0^{*}$ : "Taiwan, Ilan Hsien, Taipingshan, 1950 m, 13.VII.93, A. Smetana [T150] / Holotypus o Neosclerus smetanai sp. n. det. V. Assing 2010" (cAss). Paratypes: 2 ㅇ 오 : same data as holotype (cSme); 1 : "Taiwan, Ilan Hsien, Taipingshan, 1895 m, 13.VII.93, A. Smetana [T149]" (Sme).

\section{Description:}

Body length 3.2-3.8 mm. Habitus as in Fig. 101. External morphology as in N. configens (Fig. 102), distinguished only by the male sexual characters:

$\sigma^{*}$ : posterior margin of sternite VII very indistinctly concave in the middle, near this concavity with cluster of approximately 20 short modified setae, on either side of this cluster with longer setae directed diagonally medio-caudad (Fig. 103); sternite VIII anteriorly with narrow carina posteriorly extending into a long, acute, and apically distinctly bifid process, posterior excision broad and deep, its depth approximately $1 / 4$ the length of sternite (Figs 104-106); aedeagus with ventral process of similar morphology as in N. configens, but more slender apically (Figs 107-108).

\section{Etymology:}

The species is dedicated to Aleš Smetana, Ottawa, who contributed a considerable proportion of the material treated in the present study and who collected the type material of this species. 

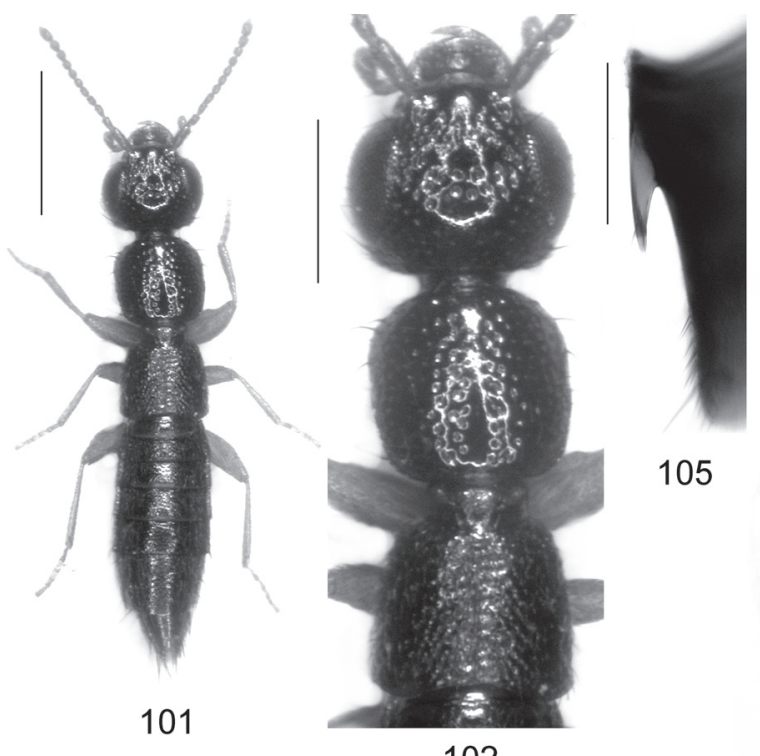

105

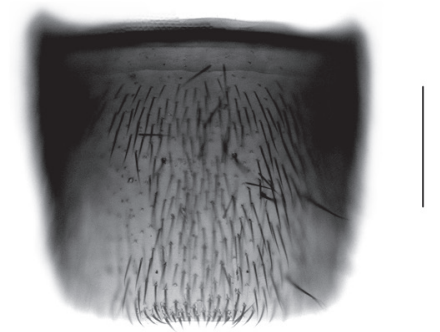

103

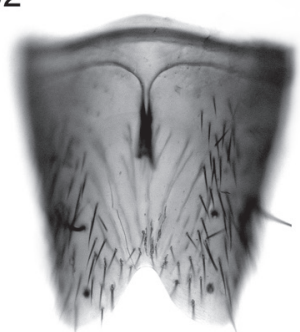

104
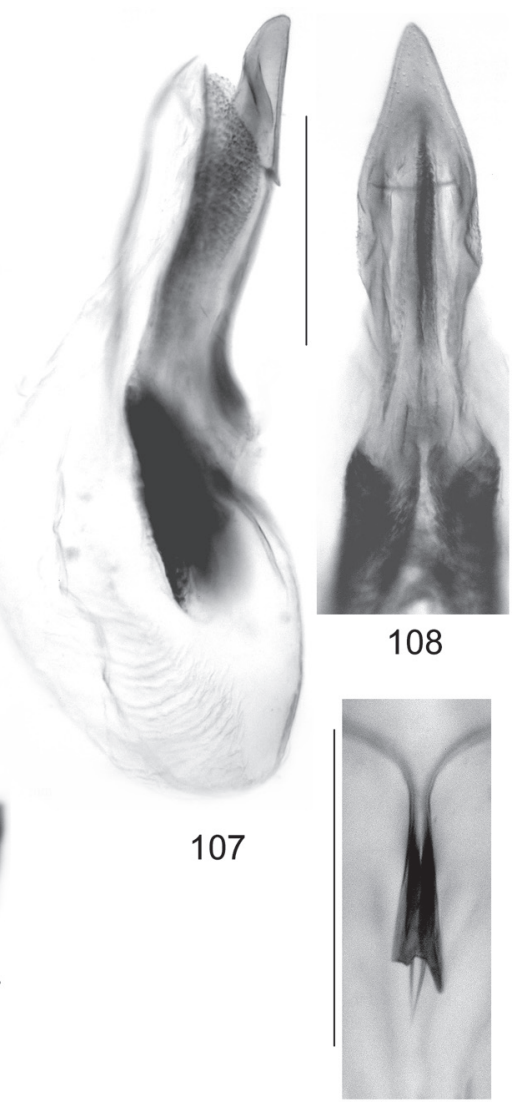

108

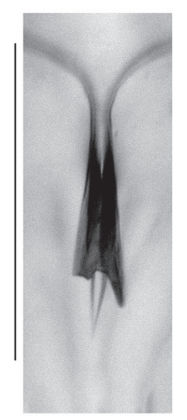

106

Figs 101-108: Neosclerus smetanai sp. n.: habitus (101); forebody (102); male sternite VII (103); male sternite VIII in ventral view (104); male sternite VIII in lateral view (105); process of male sternite VIII (106); aedeagus in lateral view (107); apical portion of aedeagus in ventral view (108). Scale bars: 101: $1.0 \mathrm{~mm}$; 102: $0.5 \mathrm{~mm}$; 103-108: $0.2 \mathrm{~mm}$.

\section{Comparative notes:}

Based on the synapomorphically derived morphology of the male sternites VII-VIII and of the aedeagus, as well as on the similar external morphology, this species is undoubtedly closely allied to $N$. hlavaci and $N$. configens, from which it is best distinguished by the deeper posterior excision and the shape of the anterior carina of the male sternite VIII, as well as by the shape of the apex of the ventral process of the aedeagus.

\section{Distribution and bionomics:}

The type locality is situated in Yilan province, northeastern Taiwan. The specimens were sifted from leaf litter and other debris among rhododendron and from moss in a coniferous forest (mainly Chamaecyparis) with the forest floor full of decaying wood covered with lush moss at altitudes of approximately 1900 and $1950 \mathrm{~m}$ in July (SMETANA pers. comm.). 
Neosclerus armatus sp. n. (Figs 109-115)

\section{Type material:}

Holotype $0^{\star}$ : "Taiwan - Hsinchu Co., envs. Yulao Scen. View, Rd. 60, Jienshih Twnsh., 1400 m, roadside litter, 25.III.2008, leg. Vít [7] / Holotypus ơ Neosclerus armatus sp. n. det. V. Assing 2009" (cAss). Paratype + : same data as holotype (cAss).

\section{Description:}

Body length 3.5-3.7 mm. Habitus as in Fig. 109. External morphology as in N. smetanai (Fig. 110), distinguished only by the male sexual characters:

$\sigma^{t}$ : posterior margin of sternite VII distinctly concave in the middle (Fig. 111); sternite VIII with narrower posterior excision, anterior median carina less slender and posteriorly with shorter process (Figs 112-113); aedeagus with ventral process apically in lateral view more slender and in ventral view more acute (Figs 114-115).
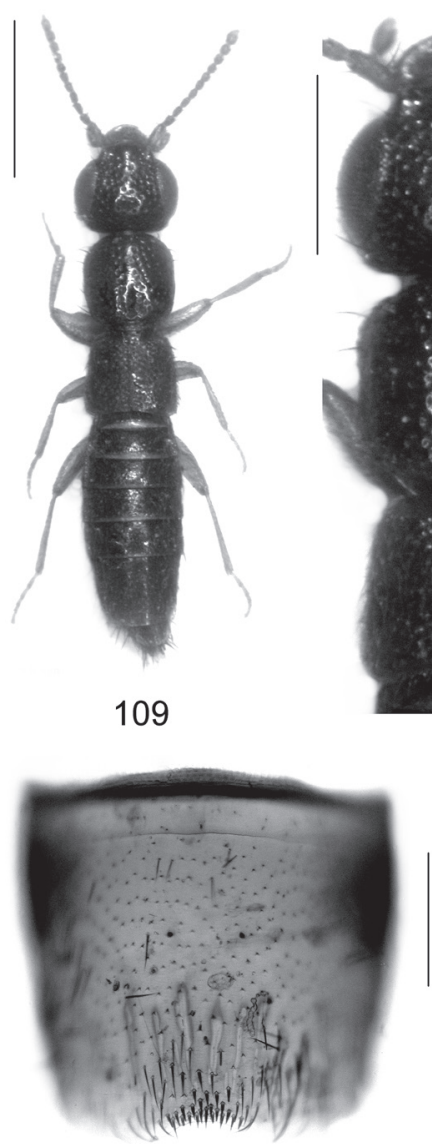

111
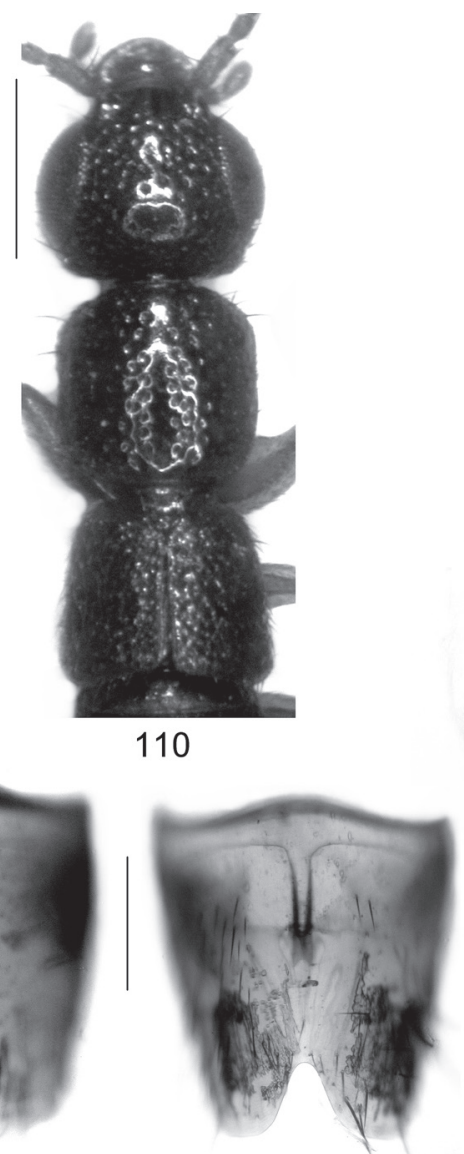

112
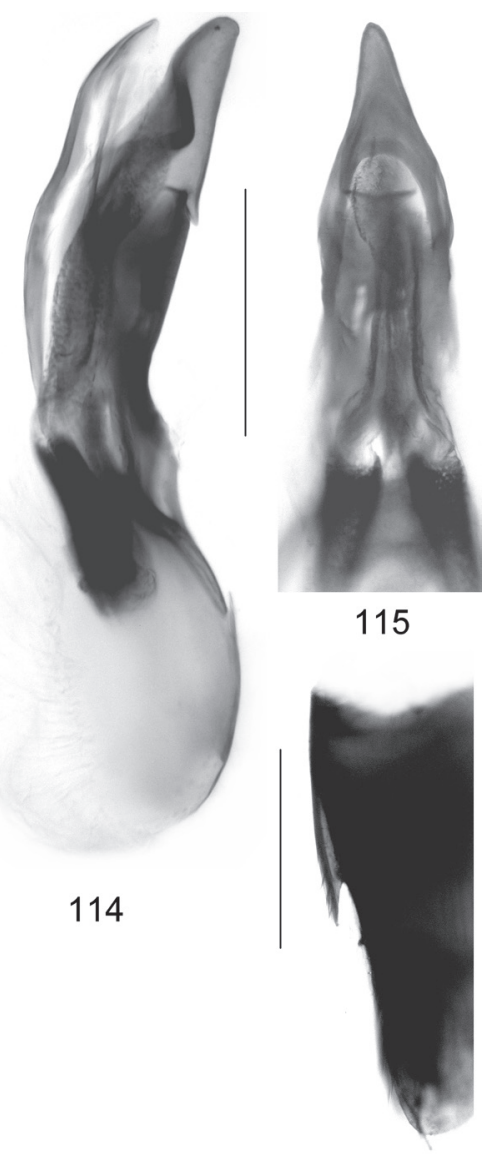

115

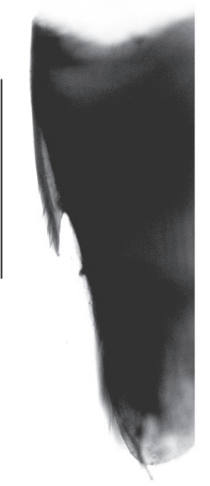

113

Figs 109-115: Neosclerus armatus sp. n.: habitus (109); forebody (110); male sternite VII (111); male sternite VIII in ventral view (112); male sternite VIII in lateral view (113); aedeagus in lateral view (114); apical portion of aedeagus in ventral view (115). Scale bars: 109: $1.0 \mathrm{~mm} ; 110: 0.5 \mathrm{~mm} ; 111-115: 0.2 \mathrm{~mm}$. 


\section{Etymology:}

The specific epithet (Latin, adjective: armed) alludes to the sharp spine-like process on the male sternite VIII.

\section{Comparative notes:}

Like the preceding species, $N$. armatus is closely allied to $N$. configens and $N$. hlavaci, from which it is reliably distinguished only by the male sexual characters. For characters separating it from the extremely similar $N$. smetanai see the description above.

\section{Distribution and bionomics:}

The type locality is situated in Hsinchu County, northwestern Taiwan, where the holotype was sifted from roadside leaf litter at an altitude of $1400 \mathrm{~m}$ in March.

Neosclerus bifidus sp. n. (Figs 116-124, 134)

\section{Type material:}

Holotype $0^{\star}$ : "Taiwan, Kaohsiung Hsien, Peinantashan trail, 2020 m, 7.VII.93, A. Smetana [T143] / Holotypus ơ Neosclerus bifidus sp. n. det. V. Assing 2010" (cAss). Paratypes: $2 o^{\star} o^{\star}, 2$ o $~+$ : same data as holotype (cSme, cAss); 1 : "Taiwan, Kaohsiung Hsien, Peinantashan trail, 2000 m, 7.VII.93, A. Smetana [T144]" (cSme); 13 exs. [1 o $^{\star}$ with teratologically deformed aedeagus]: "Taiwan, Kaohsiung Hsien, Tengchin, 1610 m, 24.IV.1990, A. Smetana [T20]" (cSme, cAss); 1 q "Taiwan, Kaohsiung Hsien, Tengchin, 1565 m, 23.IV.1990, A. Smetana [T18]" (cSme).

\section{Description:}

Body length 3.5-3.7 mm. Habitus as in Fig. 116. External morphology as in N. configens (Fig. 117), except for the (on average) less distinct microsculpture of the head, reliably distinguished only by the male sexual characters:

$0^{t}$ : posterior margin of sternite VII distinctly concave in the middle, near this concavity with cluster of numerous slender setae (Fig. 118); sternite VIII anteriorly with longitudinally bifid carina posteriorly extending into a bifid process with two long setae in the middle, posterior excision almost V-shaped, its depth barely 1/4 the length of sternite (Figs 119-121); aedeagus with ventral process of characteristic shape (Figs 122-124, 134).

\section{Etymology:}

The specific epithet (Latin, adjective: bifid) alludes to the shape of the anterior carina on the male sternite VIII.

\section{Comparative notes:}

Neosclerus bifidus is closely related to $N$. configens and allied species, from which it is reliably distinguished only by the male sexual characters.

\section{Distribution and bionomics:}

The species was collected in several localities in Kaohsiung Hsien, southern Taiwan, at altitudes of 1565-2020 $\mathrm{m}$ in April and July. The specimens were sifted from debris in a Taiwania cryptomeroides forest, from bark, humus, and other debris around bases of standing dead trees in a forest clearing, from moss and bark on a large fallen tree in a mature broadleaved evergreen forest, and 

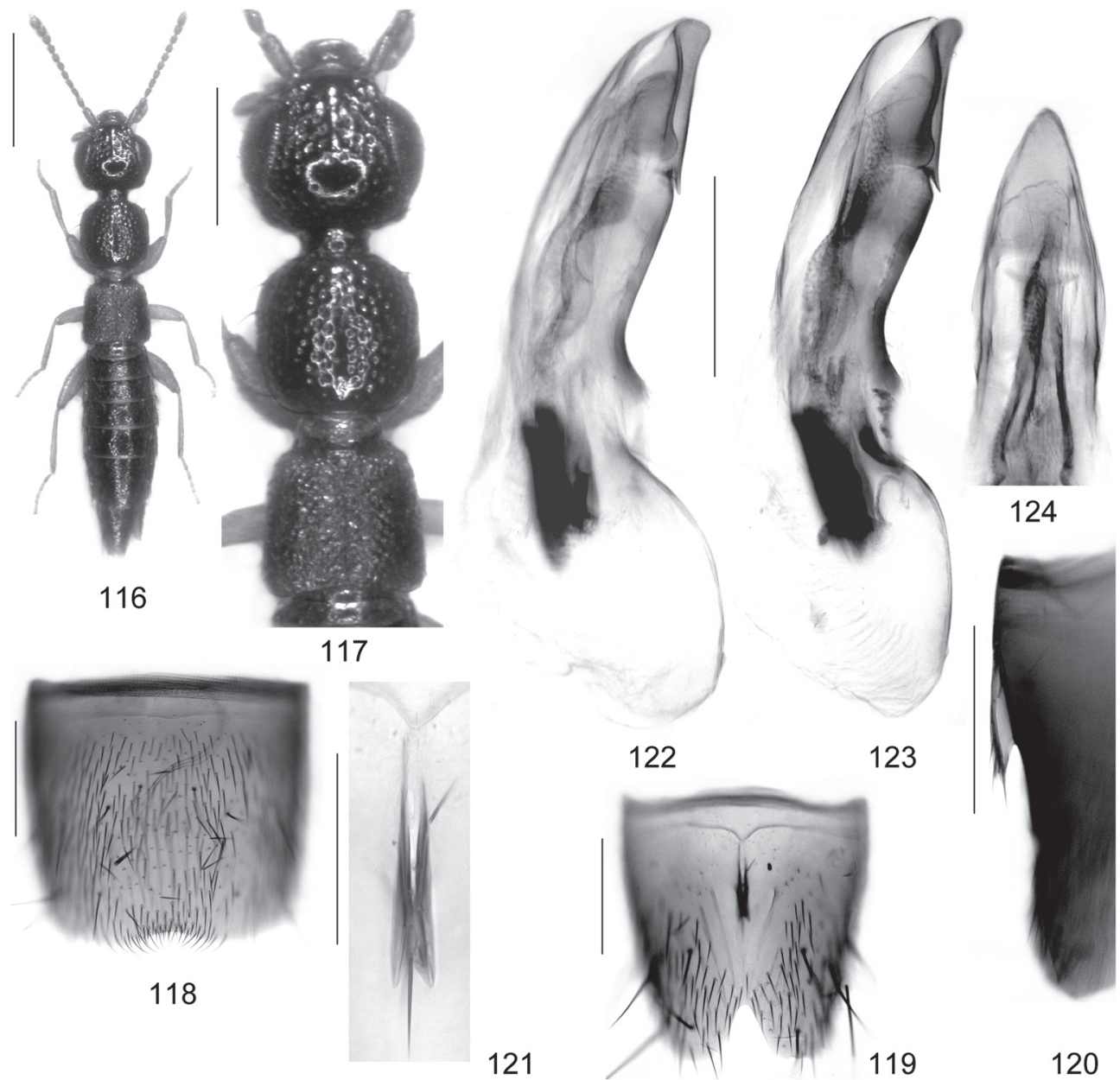

Figs 116-124: Neosclerus bifidus sp. n.: habitus (116); forebody (117); male sternite VII (118); male sternite VIII in ventral view (119); male sternite VIII in lateral view (120); process of male sternite VIII (121); aedeagus in lateral view (122-123); apical portion of aedeagus in ventral view (124). Scale bars: 116: $1.0 \mathrm{~mm}$; 117: $0.5 \mathrm{~mm}$; 118-120, 122-124: $0.2 \mathrm{~mm}$; 121: $0.1 \mathrm{~mm}$.

from moist fallen leaves and various debris along edges of an abandoned forest road in an evergreen broadleaved forest (SMETANA pers. comm.). One of the males has a teratologically deformed aedeagus.

\section{Neosclerus atsushii ShiBata, 1992 (Figs 125-133)}

Neosclerus atsushii Shibata, 1992: $184 \mathrm{ff}$.

\section{Type material examined:}

Paratypes: $1 \sigma^{\star}, 1$ ㅇ: "(Lushan Wenchuan), Nantou Hsien, Taiwan (1200 m), July 28th, 1983, Y. Shibata leg. / [Paratype] Neosclerus atsushii, ơ, Y. Shibata 1992." (cShi, cAss). 


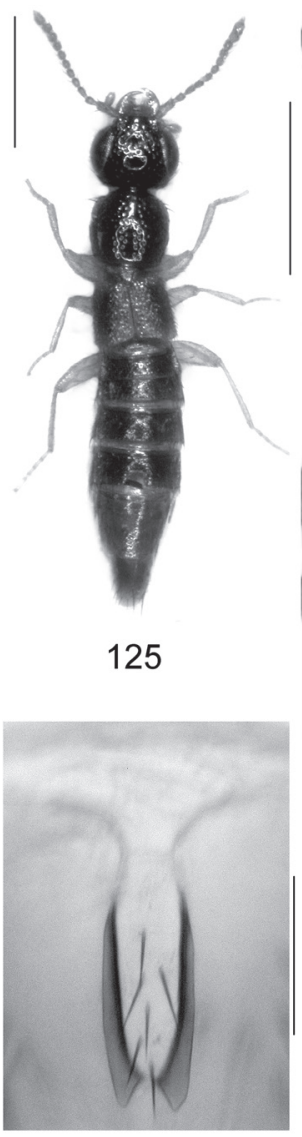

130

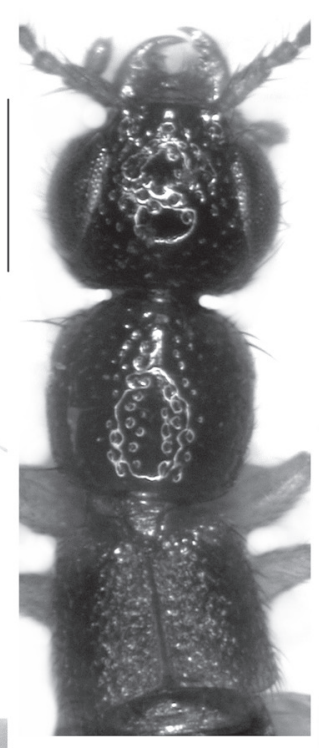

126

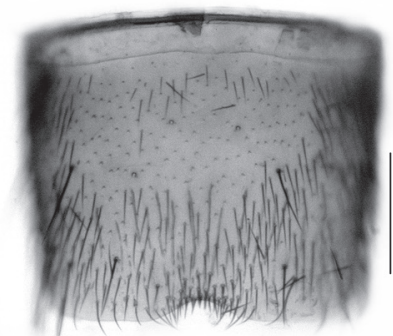

127
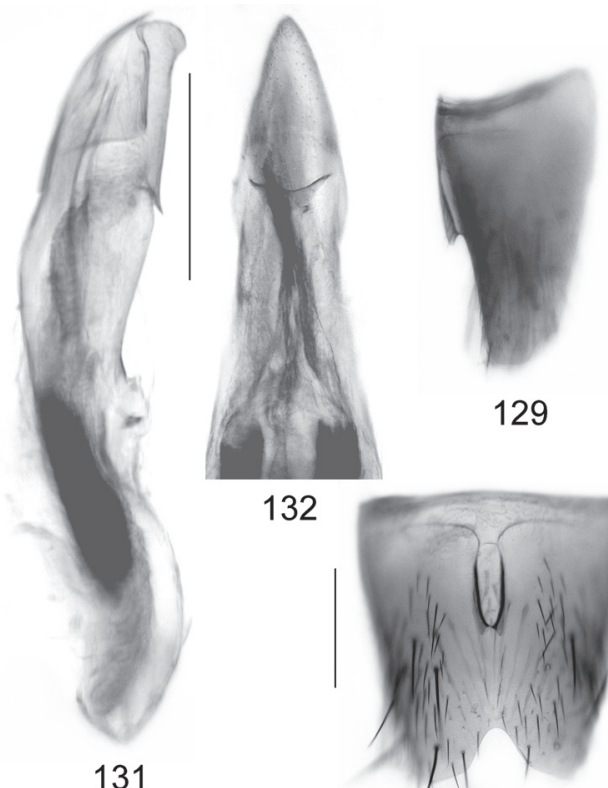

132

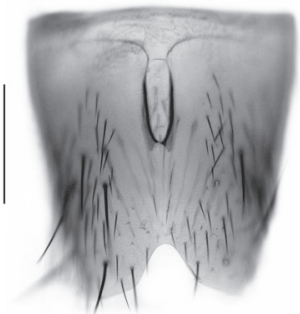

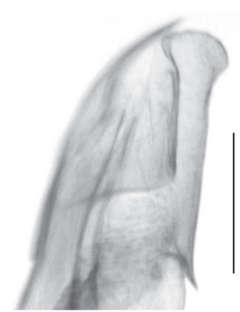

133

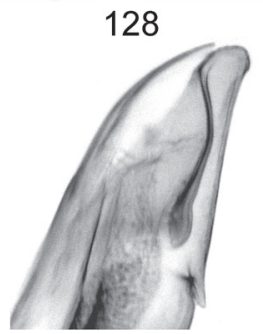

134

Figs 125-134: Neosclerus atsushii SHIBATA, paratype (125-133) and N. bifidus sp. n. (134): habitus (125); forebody (126); male sternite VII (127); male sternite VIII in ventral view (128); male sternite VIII in lateral view (129); process of male sternite VIII (130); aedeagus in lateral view (131); apical portion of aedeagus in ventral view (132); apical portion of aedeagus in lateral view (133-134). Scale bars: 125: $1.0 \mathrm{~mm}$; 126: $0.5 \mathrm{~mm}$; 127-129, 131-132: $0.2 \mathrm{~mm}$; 130, 133-134: $0.1 \mathrm{~mm}$.

\section{Comment:}

The original description is based on a male holotype, a female allotype, and seven paratypes from "Lushan Wenchuan, about 1,200 alt., Nantou Hsien, Taiwan" (Shibata 1992).

\section{Redescription:}

Body length 3.5-4.0 mm. Habitus and forebody as in Figs 125-126. External characters as in N. bifidus.

$\sigma^{*}$ : posterior margin of sternite VII distinctly concave in the middle, near this concavity with cluster of numerous slender setae (Fig. 127); sternite VIII anteriorly with relatively broad and short carina with several setae, posteriorly extending into a short bifid process, posterior excision not distinctly V-shaped, its depth approximately $1 / 5$ the length of sternite (Figs 128-130); aedeagus with ventral process similar to that of $N$. bifidus, but apical portion in lateral view shorter and broader, and in ventral view more slender (Figs 131-133). 


\section{Comparative notes:}

The similar external characters and the similarly derived shape of the ventral process of the aedeagus suggest that $N$. atsushii is the adelphotaxon of $N$. bifidus, from which it is distinguished by the shape and chaetotaxy of the anterior carina of the male sternite VIII (broader, shorter, presence of several setae in the middle, posteriorly less strongly extended), the less deep posterior excision of the male sternite VIII, and the slightly differently shaped apex of the ventral process of the aedeagus (Figs 133-134).

\section{Distribution and bionomics:}

This species is known only from the type locality in Nantou Hsien, Taiwan, where the type specimens were collected at an altitude of $1200 \mathrm{~m}$ (Shibata 1992).

Neosclerus carinatus sp. n. (Figs 135-142)

\section{Type material:}

Holotype $0^{*}$ : "Taiwan, Pingtung Hsien, Pietawushan [sic] Trail at 2000 m, 23.V.1991, A. Smetana [T91] / Holotypus ơ Neosclerus carinatus sp. n. det. V. Assing 2010" (cAss).

\section{Description:}

Pronotum and elytra uniformly reddish-brown, other external characters as in $N$. configens (Figs 135-136).

$\sigma^{\star}$ : posterior margin of sternite VII weakly concave in the middle, near this concavity with cluster of numerous weakly modified setae (Fig. 137); sternite VIII anteriorly with rather broad and long carina with few long setae and posteriorly extending into a short bifid process, posterior excision broad and V-shaped, its depth approximately $1 / 5$ the length of sternite (Figs 138-140); aedeagus of highly distinctive morphology, $0.83 \mathrm{~mm}$ long, ventral process very slender, apically with median carina (ventral view), internal sac with rather long and massive dark structures in apical portion (Figs 141-142).

\section{Etymology:}

The specific epithet (Latin, adjective) alludes to the apically carinate ventral process of the aedeagus.

\section{Comparative notes:}

As can be inferred from the similar modifications of the male sternites VII and VIII, the general morphology of the aedeagus (ventral process notched and dentate, internal sac with pair of large, dark basal structures), as well as from the similar external characters, $N$. carinatus is closely related to $N$. configens and allied species. It is readily distinguished from them by the chaetotaxy of the male sternite VIII, the broader anterior carina with shorter posterior processes, the distinctly longer aedeagus ( $N$. configens: approx. $0.7 \mathrm{~mm}$ ), the much longer, more slender, and differently shaped ventral process, and the massive apical internal structures.

\section{Distribution and bionomics:}

The holotype was collected in the Peitawushan, Pingtung Hsien, southern Taiwan, at an altitude of $2000 \mathrm{~m}$ in May, by sifting humus, debris, and fallen leaves along fallen trees in an old broadleaved evergreen forest (SMETANA pers. comm.). 


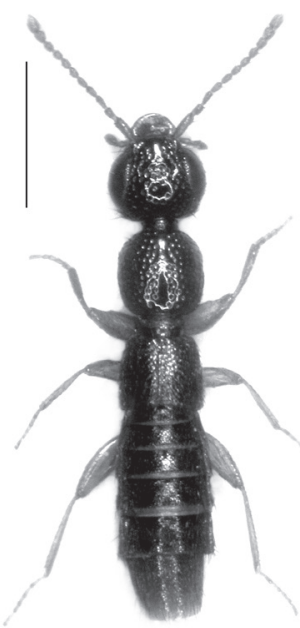

135

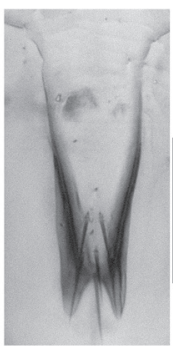

140

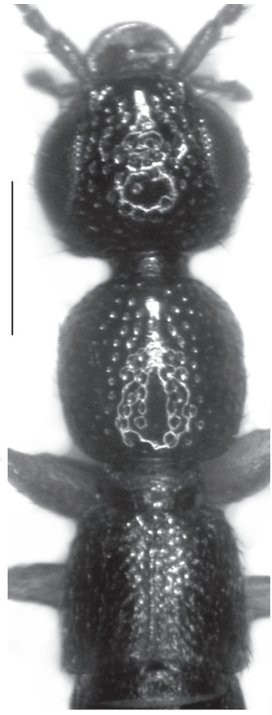

136

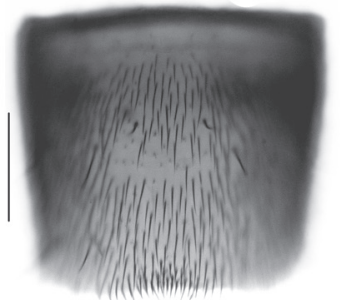

137

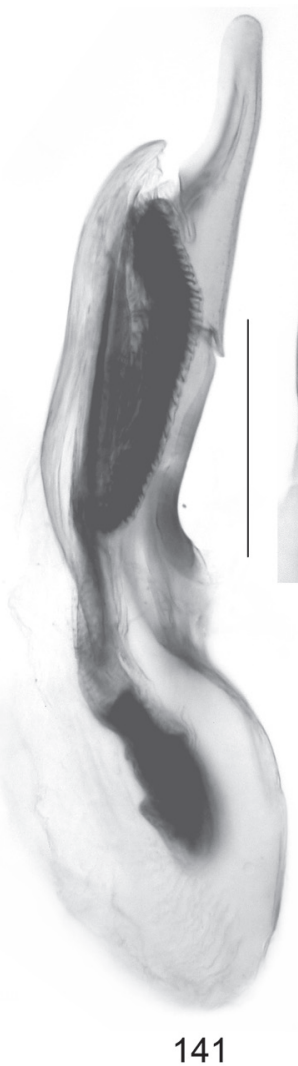

141
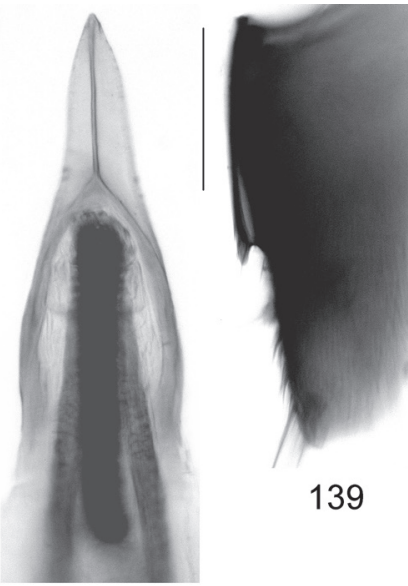

139

\section{2}

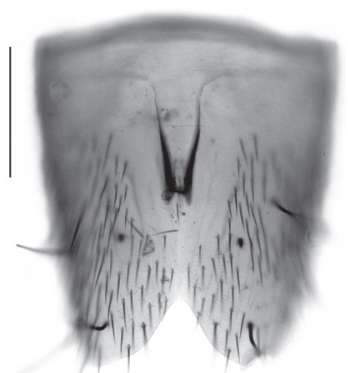

138

Figs 135-142: Neosclerus carinatus sp. n.: habitus (135); forebody (136); male sternite VII (137); male sternite VIII in ventral view (138); male sternite VIII in lateral view (139); process of male sternite VIII (140); aedeagus in lateral view (141); apical portion of aedeagus in ventral view (142). Scale bars: $135: 1.0 \mathrm{~mm}$; 136: $0.5 \mathrm{~mm}$; 137-139, 141-142: $0.2 \mathrm{~mm}$; 140: $0.1 \mathrm{~mm}$.

Neosclerus glaber sp. n. (Figs 143-150)

\section{Type material:}

Holotype ơ: "China, Fujian prov., Wuyi Shan Nat. Res., Sangan env. (900 m), 30.v.-12.vi.2001, Hlaváč \& Cooter lgt. / Holotypus ơ Neosclerus glaber sp. n. det. V. Assing 2009" (cAss). Paratypes: 9 exs.: same data as holotype (cAss, cShi); 1 q : "China, Fujian prov., Wuyi Shan Nat. Res., Gadun hill, (900-1300 m), 1.-2.vi.2001, Hlaváč \& Cooter lgt." (cAss); 3 exs.: "China: Fujian Province, Wuyi Shan, ca. $820 \mathrm{~m}, 27^{\circ} 75^{\prime} \mathrm{N}$ [sic], 117 $66^{\prime} \mathrm{E}$ [sic] / ca. $2 \mathrm{~km} \mathrm{NE}$ Tongmu village, 30.v.2001, Mixed forest litter, leg. J. Cooter \& P. Hlaváć" (cRou, cAss); 1 ex.: "China: Fujian Province, Wuyi Shan. $1200 \mathrm{~m}, 27^{\circ} 75^{\prime} \mathrm{N}$ [sic], 11764'E [sic] / Quiliquao-Guadun road, 1.vi.2001, Mixed forest litter, Leg. J. Cooter + P. Hlaváč" (cRou); 3 exs.: "China: Fujian Province, Wuyi Shan, ca. 800 m, $27^{\circ} 75^{\prime} \mathrm{N}$ [sic], $117^{\circ} 68^{\prime} \mathrm{E}$ [sic], ca. 2 km NE Tongmu village, 8.vi.2001, Leg. J. Cooter + P. Hlaváć, Sieved Taxus/Phyllostachys pubescens (bamboo) litter" (cRou, cAss); 7 exs.: "China: Yunnan, Dali Bai Aut. Pref., $36 \mathrm{~km}$ N Dali, ruderal pasture with pines and shrubs, $26^{\circ} 01^{\prime} 20^{\prime \prime} \mathrm{N}, 100^{\circ} 08^{\prime} 14^{\prime \prime} \mathrm{E}$, $2158 \mathrm{~m}$, litter sifted under pines and shrubs, 24.VIII.2009, leg. M. Schülke [CH09-04]" (cSch, 
cAss); 1 \%: "China: Yunnan, Baoshan Pref., 10 km SE Kambaiti pass, 45 km NW Tengchong, 1700-1800 m, 2521'13-29"N, 98 13'39-54'"E, primary forest, litter and mushrooms sifted, 29.VIII.2009, leg. M. Schülke [CH09-15]" (cSch); 1 \%: "China (Yunnan), Nujiang Lisu Aut. Pref., Salween side valley $5 \mathrm{~km} \mathrm{~S}$ Fugong, road SS $228 \mathrm{~km} 223$ (creek bank, litter sifted), 8.VI.2007, D.W. Wrase [25]" (cSch); 1 + : "Honkong, N.T., Kadoori Farm, 570 m, 6.IX.1999, J.R. Fellows" (cRou); $2 \sigma^{\top} \sigma^{*}$ [macropterous]: "N-Thailand, Chiang Mai, Doi Suthep, $1580 \mathrm{~m}$ NN, Laubstreu, 13.11.1995, P. Wunderle (cWun, cAss); 1 o, 1 ㅇ: "Malaysia, 19.-23.iii.2008, P.M. Hammond / Pahang, Cameron Hlds., Tanah Rata / rotten log / BMNH \{E\} 2008-42, P.M. Hammond" (BMNH, cAss).

\section{Description:}

Body length 3.0-3.6 mm. Habitus as in Fig. 143. Coloration: body usually almost uniformly blackish, elytra rarely brown with yellowish margins; legs yellowish; antennae usually yellowish with antennomere I weakly infuscate, rarely darker.

Head across eyes 1.15-1.20 times as wide as long; postocular region very short or obsolete; punctation coarse and of variable density, moderately dense to very dense, in posterior portion of dorsal surface sparser (Figs 144-145); interstices without microsculpture and glossy; antenna 0.9$1.0 \mathrm{~mm}$ long.

Pronotum approximately as long as wide and 0.8-0.9 times as wide as head (Figs 144-145); punctation coarse and moderately dense; impunctate midline ill-defined or indistinct.

Elytra of very variable length and width, 0.85-1.10 times as long and 1.05-1.20 times as wide as pronotum (morph with long and broad elytra much rarer than morph with short and narrow elytra); humeral angles marked (Figs 144-145); punctation moderately fine and very dense; interstices without microsculpture. Hind wings present, but possibly dimorphic and of reduced length in specimens with short elytra.

Abdomen slightly to distinctly narrower than elytra; punctation fine and moderately dense, somewhat sparser on tergite VII than on anterior tergites; interstices usually with very shallow microsculpture; posterior margin of tergite VII with palisade fringe.

$\sigma^{*}$ : sternite VII with weakly convex posterior margin, posteriorly without modified setae (Fig. 146); sternite VIII with almost V-shaped posterior excision, its depth approximately $1 / 5$ the length of sternite, in anterior half unmodified (Fig. 147); aedeagus of distinctive morphology, ventral process very slender in lateral view, subapically without a tooth in lateral view; internal sac with two slender sclerotized structures in apical portion (Figs 148-150).

\section{Etymology:}

The name (Latin, adjective: glabrous) refers to the glossy appearance of this species.

\section{Comparative notes:}

This species is best distinguished from other macropterous congeners by the morphology of the aedeagus, from most species also by the unmodified male sternite VII and the shape and chaetotaxy of the male sternite VIII.

\section{Distribution and bionomics:}

Neosclerus glaber is known from Fujian and Yunnan provinces (southern China), Hongkong, Thailand, and Malaysia, suggesting that it is widespread in the Oriental and the southern East Palaearctic regions. The type specimens from Fujian were collected at altitudes of $900-1300 \mathrm{~m}$ in March, June, August, and September, partly together with $N$. hlavaci; those from Yunnan 


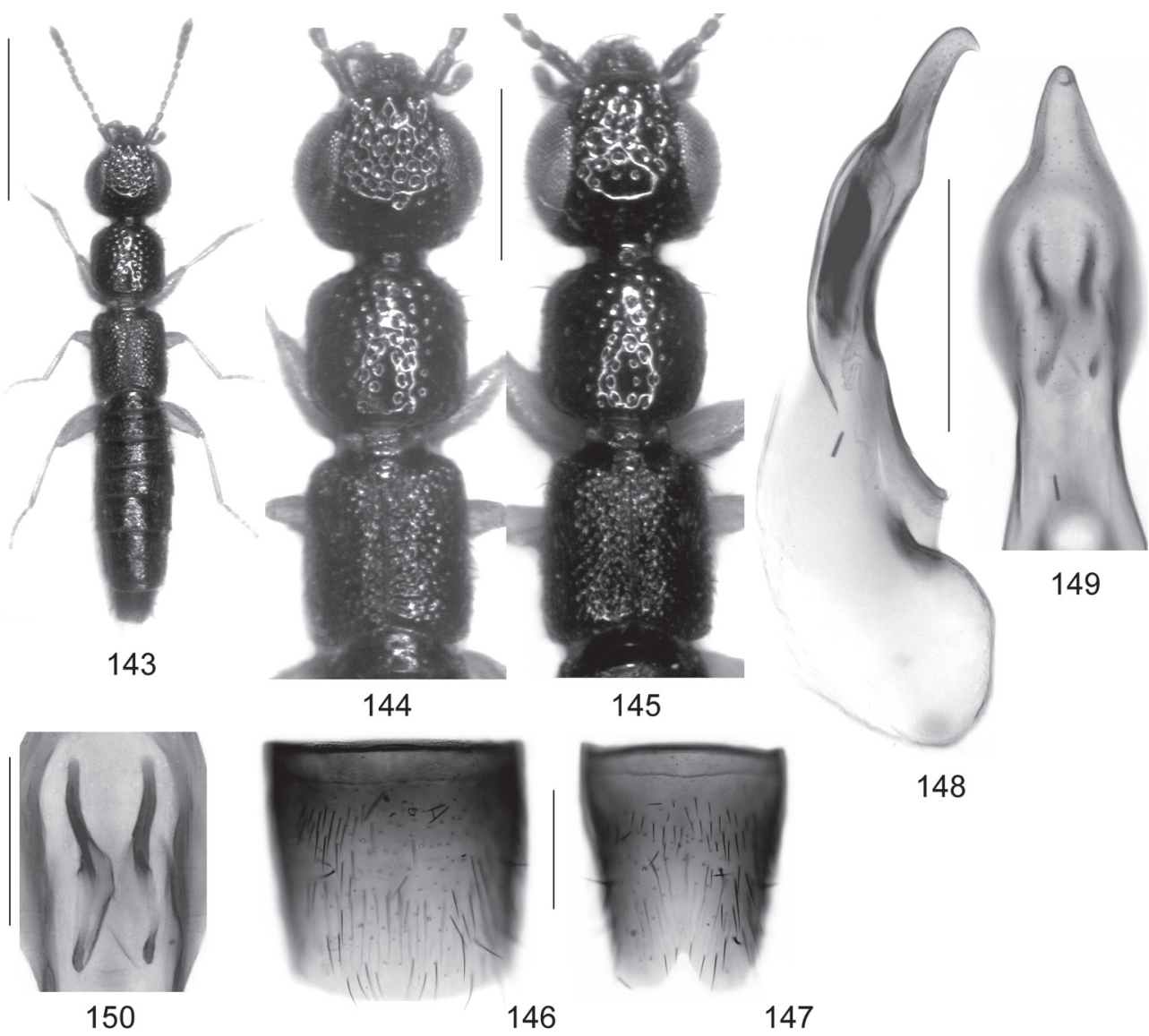

Figs 143-150: Neosclerus glaber sp. n.: habitus (143); forebody of specimens from Fujian (144) and Malaysia (145); male sternite VII (146); male sternite VIII (147); aedeagus in lateral view (148); apical portion of aedeagus in ventral view (149); internal structures of aedeagus in ventral view (150). Scale bars: 143: $1.0 \mathrm{~mm}$; 144-145: $0.5 \mathrm{~mm}$; 146-149: $0.2 \mathrm{~mm}$; 150: $0.1 \mathrm{~mm}$.

were sifted from leaf litter under shrubs, in a forest, and on a stream bank at altitudes of 1700$2160 \mathrm{~m}$. The material from Malaysia was found in a rotten log, the female from Hongkong at an altitude of $570 \mathrm{~m}$. The specimens from Thailand were sifted from leaf litter at an altitude of $1580 \mathrm{~m}$ in November.

Neosclerus bicarinatus sp. n. (Figs 151-156)

\section{Type material:}

Holotype ơ : "Vietnam: Hatinh Pr., Raò An, 13 km W Huang Son, rt. 8, 7 km S Nuòc Sôt village, $18^{\circ} 21^{\prime} \mathrm{N} ; 105^{\circ} 15^{\prime} \mathrm{E}, 300 \mathrm{~m}$, V/9-22/1998, L. Herman, flight intercept trap / Holotypus $0^{\top}$ Neosclerus bicarinatus sp. n. det. V. Assing 2010" (AMNH). Paratypes: 5 exs.: same data as holotype (AMNH, cAss). 


\section{Description:}

Body length 2.7-3.2 mm. Habitus as in Fig. 151. Coloration: head blackish; pronotum darkbrown to blackish; elytra dark-brown, with the humeral angles and the posterior margin rather extensively reddish; abdomen brown to dark-brown; legs and antennae yellowish.

Head across eyes 1.15-1.20 times as wide as long; postocular region approximately as long as width of antennomere II (Fig. 152); punctation moderately coarse and moderately dense in anterior portion, sparser in posterior portion of dorsal surface; interstices without distinct microreticulation and glossy (traces of microsculpture may be visible in posterior portion of dorsal surface); antenna approximately 0.9-1.0 $\mathrm{mm}$ long.

Pronotum weakly transverse, approximately 1.05 times as wide as long and approximately 0.85 times as wide as head (Fig. 152); punctation similar to that of anterior portion of head or slightly less coarse; impunctate midline of variable width, narrow to moderately broad; interstices without microsculpture and glossy.

Elytra of variable length, 0.95-1.10 times as long as pronotum; humeral angles marked (Fig. 152); punctation dense and moderately fine; interstices glossy. Hind wings apparently fully developed.

Abdomen slightly to distinctly narrower than elytra; punctation fine and moderately dense; interstices with very shallow, sometimes barely noticeable microsculpture; posterior margin of tergite VII with palisade fringe.

$\sigma^{\star}$ : sternite VII very distinctive, posterior margin broadly and shallowly concave in the middle, on either side of this concavity with pronounced tooth-like process, pubescence not distinctly modified (Fig. 153); sternite VIII highly distinctive, anteriorly not distinctly elevated, but with pair of carinae of approximately $1 / 3$ the length of sternite, median portion extensively without pubescence, posterior excision with approximately 10 marginal setae, not very acute, its depth approximately $1 / 5$ the length of sternite (Fig. 154); aedeagus with curved, subapically not dentate, and apically acute ventral process, internal sac in apical portion with pair of long sclerotized structures (Figs 155-156).

\section{Etymology:}

The specific epithet (Latin, adjective: with two carinae) alludes to the distinctive modifications of the male sternite VIII.

\section{Comparative notes:}

Neosclerus bicarinatus is apparently most closely related to $N$. glaber, as can be inferred from the similarly derived morphology of the aedeagus (shape of ventral process; pair of oblong sclerotized structures in apical portion of internal sac), the unmodified pubescence of the male sternite VII, and the similar external characters (punctation of the head and pronotum, absence of microsculpture on the head). The species is readily distinguished from its congeners by the coloration of the elytra (similar only to $N$. rougemonti) and the male sexual characters, particularly the dentate processes of the abdominal sternite VII (unique), the presence of a pair of carinae in the anterior portion of sternite VIII, and the shape of the ventral process of the aedeagus.

\section{Distribution and bionomics:}

The species is currently known only from one locality (altitude: $300 \mathrm{~m}$ ) in Vietnam, but may be widespread in the Oriental region, as is suggested by the fact that the type specimens were collected on the wing (flight interception trap in May). 


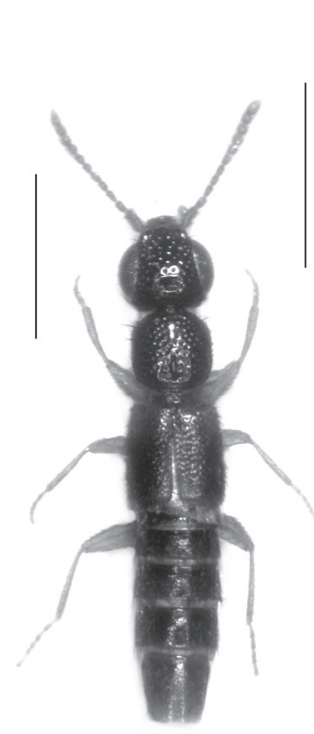

151

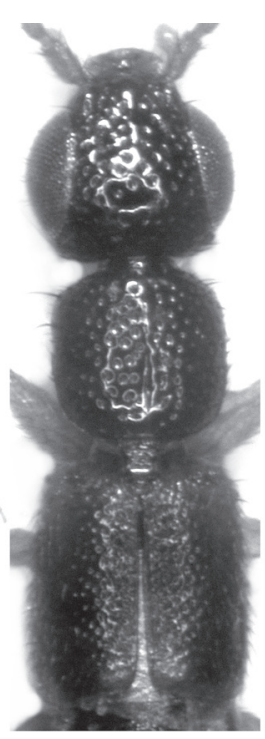

152

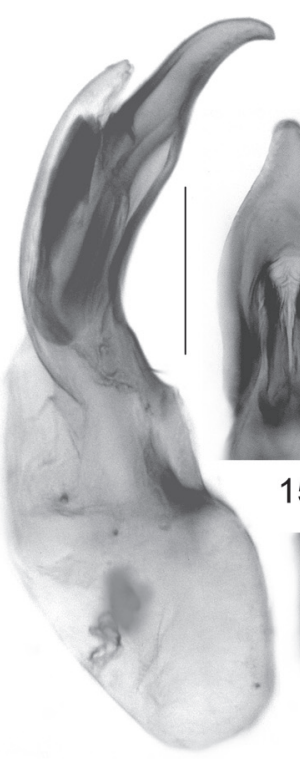

155

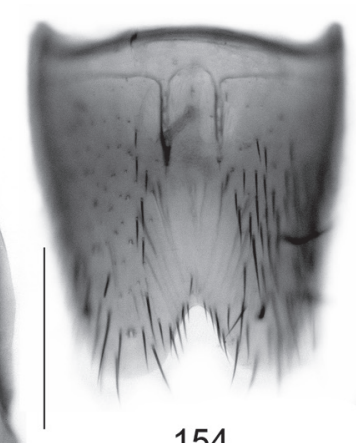

154

156

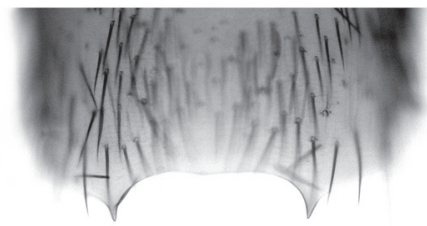

153

Figs 151-156: Neosclerus bicarinatus sp. n.: habitus (151); forebody (152); posterior portion of male sternite VII (153); male sternite VIII (154); aedeagus in lateral view (155); apical portion of aedeagus in ventral view (156). Scale bars: 151: $1.0 \mathrm{~mm}$; 152: $0.5 \mathrm{~mm}$; 153-154: $0.2 \mathrm{~mm}$; 155-156: $0.1 \mathrm{~mm}$.

Neosclerus nigerrimus (KraATZ, 1859); comb. n. (Figs 157-161)

Lithocharis nigerrima KRAATZ, 1859: $141 \mathrm{f}$.

Medon (Lithocharis) nigerrimus: BeRnHAUER \& SCHUBERT (1912: 242).

Lobochilus nigerrimus: CAMERON (1931: 124).

\section{Type material:}

Lectotype ơ: "Ceylon / coll. Kraatz / Syntypus / coll. DEI Müncheberg / Lectotypus ơ Lithocharis nigerrima Kraatz, desig. V. Assing 2009 / Neosclerus nigerrimus (Kraatz), det. V. Assing 2009"

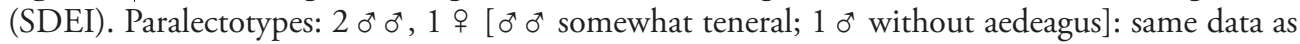
lectotype (SDEI).

\section{Comment:}

The original description is based on an unspecified number of syntypes from "Ceylan" (KRAATZ 1859). Four syntypes, three males (two of them somewhat teneral) and a female, were located in the collections of the SDEI. The mature male is designated as the lectotype.

\section{Redescription:}

Body length 2.7-3.2 mm. Coloration of mature specimens: body blackish, with the elytra and the abdominal apex indistinctly paler; legs and antennae brown.

Head across eyes approximately 1.15 times as wide as long; postocular region moderately short, approximately as long as width of antennomere I (Fig. 157); punctation coarse, moderately sparse in anterior half and very sparse in posterior half of dorsal surface; interstices without microsculpture and glossy; antenna not distinctive. 


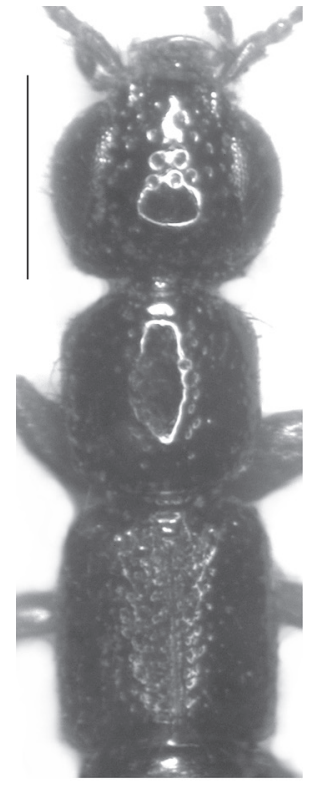

157

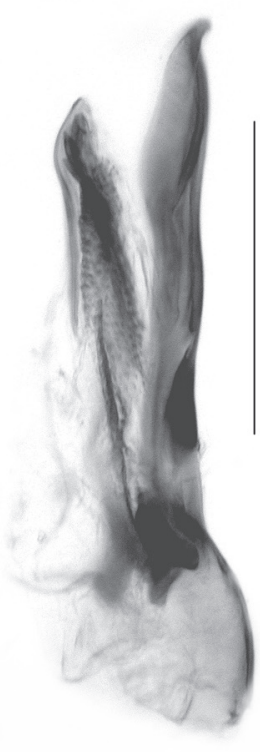

160

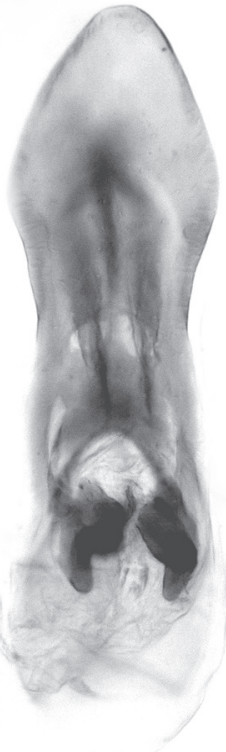

161

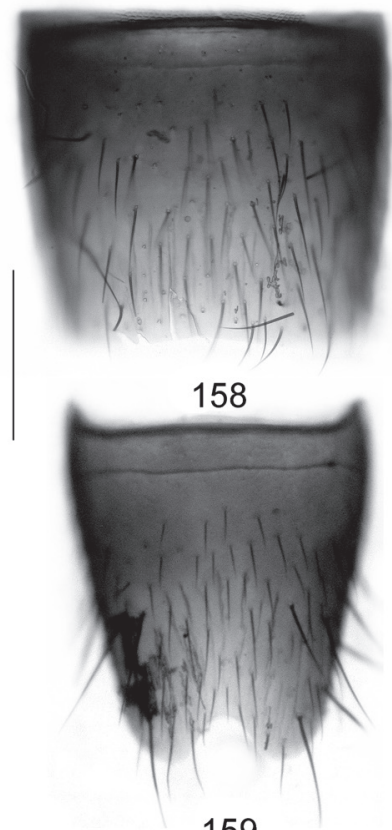

159

Figs 157-161: Neosclerus nigerrimus (KRAATZ): forebody (157); male sternite VII (158); male sternite VIII (159); aedeagus in lateral view (160); aedeagus in ventral view (161). Scale bars: 157: $0.5 \mathrm{~mm}$; 158-161: $0.2 \mathrm{~mm}$.

Pronotum approximately as long as wide or indistinctly oblong, approximately 0.85 times as wide as head (Fig. 157); punctation coarse and not very dense; midline broadly impunctate; interstices without microsculpture and glossy.

Elytra moderately long, 0.94-0.97 times as long and 1.10-1.15 times as wide as pronotum; humeral angles marked (Fig. 157); punctation moderately coarse and moderately dense. Hind wings present.

Abdomen approximately as wide as elytra; punctation moderately fine, rather dense on anterior tergites and very sparse on posterior tergites; interstices with shallow microsculpture; posterior margin of tergite VII with palisade fringe.

$\mathrm{O}^{\star}$ : sternite VII unmodified (Fig. 158); sternite VIII with broadly V-shaped and not very deep posterior excision, its depth approximately $1 / 6-1 / 5$ the length of sternite, otherwise unmodified (Fig. 159); aedeagus of distinctive morphology (Figs 160-161).

\section{Comparative notes:}

This species is readily distinguished from all its congeners particularly by the shape of the aedeagus, from most species also by the unmodified male sternite VII.

\section{Distribution and bionomics:}

Confirmed records of this species are known only from Sri Lanka. In view of the more or less restricted distributions and external similarity of Neosclerus species, as well as of the fact that the male sexual characters of this species were previously unknown, the record from Sikkim by BIswas (2003: 265) appears highly doubtful and is most likely based on a misidentification. Bionomic data are not available. 
Neosclerus javanus (BERNHAUER, 1920); comb. n. (Figs 162-163)

Lobochilus javanus BernHAUER, 1920: 180.

\section{Type material:}

Holotype + : "J. B. Corporaal, Java - Preanger, Tjigembong, 6.45 / Lobochilus javanus Brh., Typus unic. / Chicago NHMus. M.Bernhauer Collection / Holotypus o Lobochilus javanus Bernhauer, rev. V. Assing 2010 / Neosclerus javanus (Bernhauer), det. V. Assing 2010" (FMNH).

\section{Comment:}

The original description is based on a single specimen ("Das bisher einzige Stück") from "Java: Preanger (Tjigembong)" collected by "Herrn J. B. Corporaal ... im Juni 1915" (Bernhauer 1920). The holotype, a female, was located in the Bernhauer collection at the FMNH.

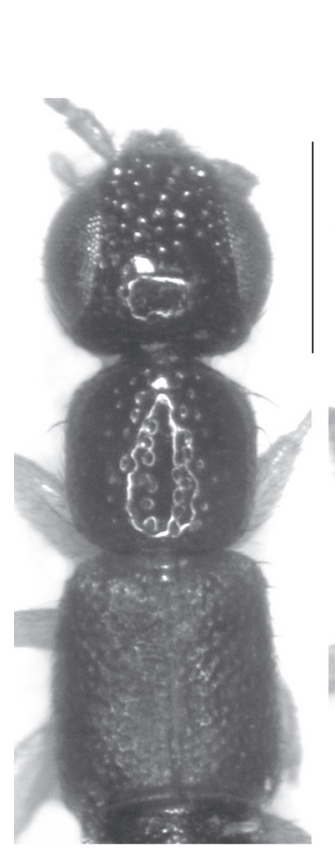

162

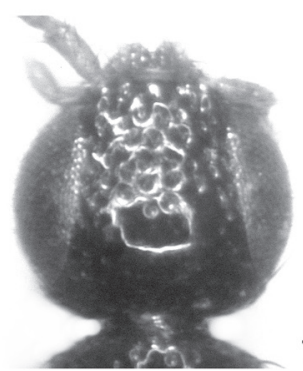

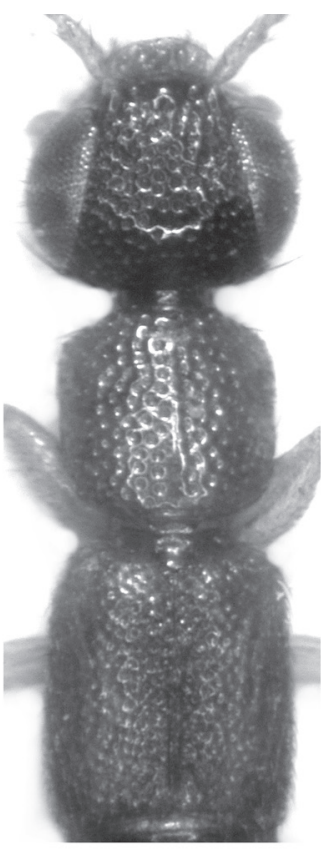

165

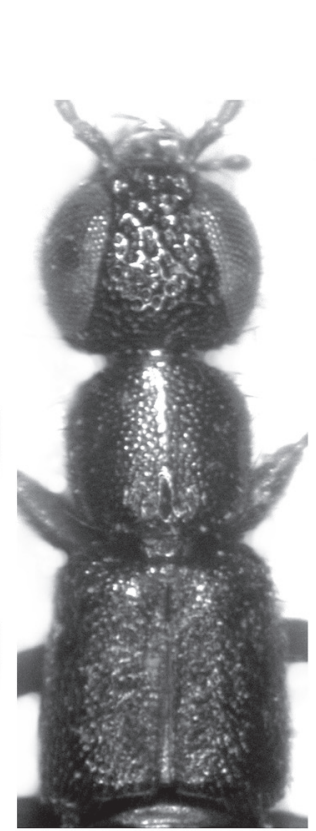

167

\section{3}
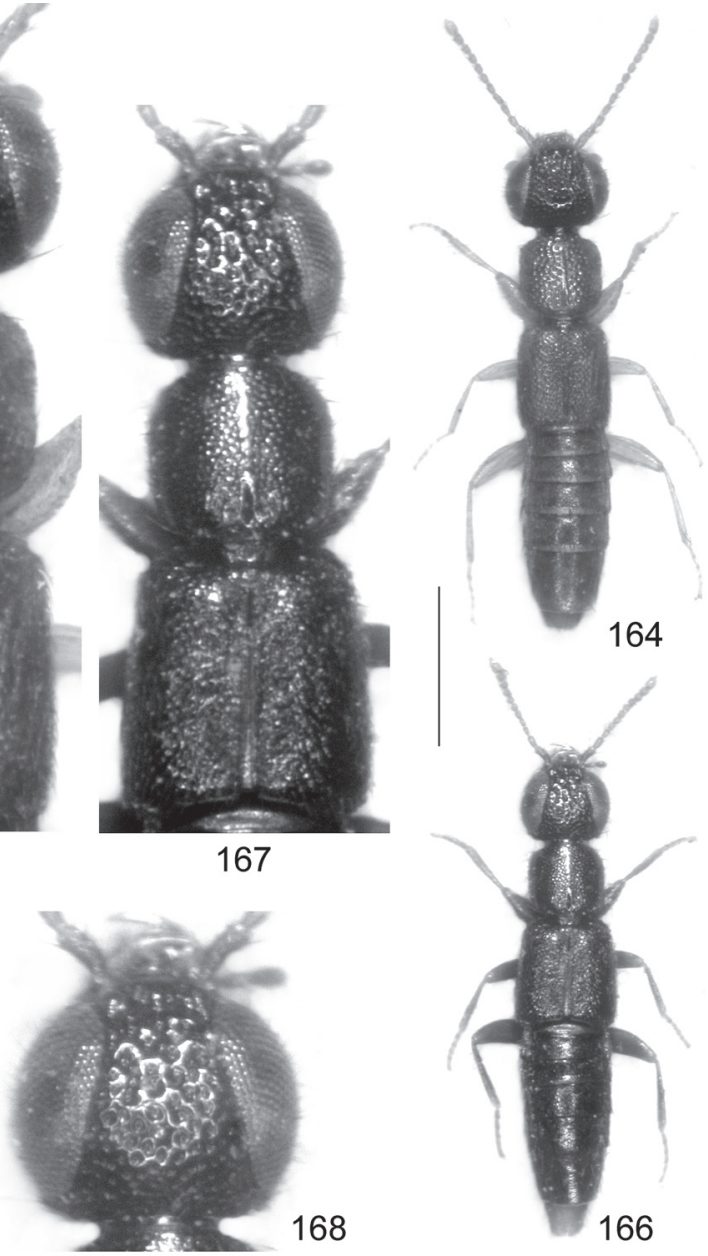

Figs 162-168: Neosclerus javanus (Bernhauer), holotype (162-163), N. assamensis (Cameron), holotype (164-165), and N. granulicollis CAMERoN, lectotype (166-168): forebody (162, 165, 167); head (163, 168); habitus (164, 166). Scale bars: 164, 166: $1.0 \mathrm{~mm}$; 162-163, 165, 167-168: $0.5 \mathrm{~mm}$. 


\section{Redescription:}

Body length $3.0 \mathrm{~mm}$. Coloration: head blackish brown; pronotum brown; elytra yellowishbrown; abdomen dark-brown with reddish-brown apex; legs and antennae yellowish.

Head across eyes 1.18 times as wide as long; eyes very large, postocular region practically obsolete (Fig. 162); punctation of dorsal surface coarse and dense, except for the sparsely punctate posterior portion (Fig. 163); interstices without microsculpture and glossy; antenna approximately $0.9 \mathrm{~mm}$ long.

Pronotum approximately as long as wide, approximately 0.85 times as wide as head (Fig. 162); punctation slightly less coarse and sparser than that of head; midline broadly impunctate; interstices without microsculpture and glossy.

Elytra relatively long, almost 1.05 times as long and 1.15 times as wide as pronotum; humeral angles marked (Fig. 162); punctation moderately coarse, dense, and rather shallow. Hind wings present.

Abdomen somewhat narrower than elytra; punctation fine, moderately dense on anterior tergites and sparse on posterior tergites; microsculpture almost obsolete on anterior tergites and slightly more distinct on posterior tergites; posterior margin of tergite VII with palisade fringe.

$o^{\star}$ : unknown.

\section{Comparative notes:}

Among other macropterus Neosclerus species, $N$. javanus is characterized particularly by the coarse punctation of the head and pronotum, as well as by the large eyes. Since the male sexual characters are unknown, the phylogenetic affiliations are unclear.

\section{Distribution and bionomics:}

This species has not been recorded again since its original description, which is based on a single specimen from Java collected in June.

Neosclerus assamensis (CAMERON, 1931); comb. n. (Figs 164-165)

Lobochilus assamensis CAMERON, 1931: 126.

\section{Type material:}

Holotype + : "Laimatak, Naga Hills (20) / Type / M. Cameron. Bequest. B.M. 1955-147. /

L. assamensis Cam. Type / Lectotypus o Lobochilus assamensis Cameron, desig. V. Assing 2010 / Neosclerus assamensis (Cameron), det. V. Assing 2010" (BMNH).

\section{Comment:}

The original description is based on an unspecified number of specimens from "Assam: Naga Hills, Laimatak" (CAMERON 1931). A single syntype, a female and probably the only syntype seen by Cameron, was found at the BMNH. It is designated as the lectotype.

\section{Redescription:}

Body length $3.2 \mathrm{~mm}$. Habitus as in Fig. 164. Coloration conspicuous: head black, remainder of body reddish-yellow; legs and antennae yellowish. 
Head strongly transverse, across eyes 1.28 times as wide as long; eyes very large, postocular region practically obsolete (Fig. 165); dorsal surface, except for posterior region, with very coarse and very dense punctation; interstices reduced to narrow ridges, without microsculpture and glossy; antenna approximately $1 \mathrm{~mm}$ long.

Pronotum approximately as long as wide, approximately 0.8 times as wide as head; punctation as coarse and dense as that of head; midline very narrowly impunctate (Fig. 165); interstices without microsculpture and glossy.

Elytra rather long, almost 1.1 times as long and 1.1 times as wide as pronotum; humeral angles marked (Fig. 165); punctation relatively coarse, dense, and well-defined. Hind wings present.

Abdomen slightly narrower than elytra; punctation fine, moderately dense on anterior tergites and very sparse on posterior tergites; interstices with shallow microsculpture; posterior margin of tergite VII with palisade fringe.

$o^{\star}$ : unknown.

\section{Comparative notes:}

Among other macropterous Neoclerus species, N. assamensis is characterized particularly by the conspicuously bicoloured body, the very large eyes, as well as by the coarse and dense punctation of the head and pronotum. Its phylogenetic affiliations are unclear, since the male characters are unknown.

\section{Distribution and bionomics:}

The type locality is situated in Nagaland, northeastern India. Bionomic data are not available.

\section{Neosclerus granulicollis CAMERON, 1924 (Figs 166-168)}

Neosclerus granulicollis CAMERON, 1924: 190.

Lobochilus granulicollis: CAMERON (1931: 125).

Neosclerus granulicollis: SMETANa (2004: 622).

Neosclerus frater CAMERon, 1924: 190 f.; syn. n.

\section{Type material:}

N. granulicollis: Lectotype + : "Type H.T. / Kaligad, Dehra Dun. 10.VII.21 / Neosclerus granulicollis Cam. / Syntype / M. Cameron. Bequest. B.M. 1955-147. / Lectotypus \& Neosclerus granulicollis Cameron, desig. V. Assing 2010 / Neosclerus granulicollis Cameron, det. V. Assing 2010" (BMNH).

N. frater: Lectotype $9:$ "Kaligad, Dehra Dnn. [sic] / Dr. Cameron, 19.VI.21 / Syntype / M. Cameron. Bequest. B.M. 1955-147. / Lectotypus i Neosclerus frater Cameron, desig. V. Assing 2010 / Neosclerus granulicollis Cameron, det. V. Assing 2010" (BMNH). Paralectotype ㅇ [severely damaged, whole thorax missing]: "Type H.T. / Kaligad, Dehra Dnn. [sic], Dr. Cameron, 19.VI.21 / Neosclerus frater Cam. / Syntype / M. Cameron. Bequest. B.M. 1955$147 "(\mathrm{BMNH})$.

Additional material examined:

India: $1 \sigma^{*}$ [with teratological aedeagus and without posterior excision of sternite VIII], 1 \% , West Bengal, Ghum district, Mangpo, V.1931, leg. Cameron (BMNH, FMNH). 


\section{Comment:}

The original description of $N$. granulicollis is based on an unspecified number of specimens from "Mussorie District; Kaligad" (Cameron 1924). A single syntype, a female and probably the only syntype seen by Cameron, was found at the BMNH. It is designated as the lectotype.

Neosclerus frater was described from an unspecified number of specimens collected in "Mussorie District; Kaligad" (CAMERon 1924). Two female syntypes were located at the BMNH, one of them severely damaged. The specimen in good condition is designated as the lectotype.

According to Cameron $(1924,1931), N$. frater is distinguished from $N$. granulicollis by the more densely punctate and, consequently, less shiny dorsal surface of the head and by the less distinct impuncte midline of the pronotum. These characters, however, are also subject to intraspecific variation in other Neosclerus species. Moreover, the type material of both names is extremely similar in other characters, including the conspicuous punctation of the pronotum, and both the type localities and the circumstances of collection are identical. Thus, even though the male sexual characters remain unknown, is seems reasonable to assume that the type material of both species is conspecific. Hence the synonymy proposed above.

\section{Redescription:}

Body length 3.0-3.3 mm. Habitus as in Fig. 166. Coloration: body blackish-brown to blackish; legs yellowish-brown to brown, with the femora somewhat darker; antennae uniformly yellowish or with antennomere weakly infuscate.

Head across eyes approximately 1.15 times as wide as long; eyes very large, postocular region practically obsolete; punctation of dorsal surface characteristic, anteriorly very coarse and very dense, posteriorly also dense, but somewhat finer (Fig. 168); antenna short, only approximately 0.7-0.8 mm long.

Pronotum approximately as long as wide, approximately 0.85 times as wide as head; punctation characteristic: fine, very dense, and weakly granulose; midline very narrowly impunctate (Fig. 167); interstices without microsculpture and glossy.

Elytra rather long and broad, 1.00-1.05 times as long and 1.2-1.3 times as wide as pronotum; humeral angles marked (Fig. 167); punctation dense and fine. Hind wings present.

Abdomen slightly to distinctly narrower than elytra; punctation fine, moderately dense on anterior tergites and sparse on posterior tergites; interstices with shallow microsculpture; posterior margin of tergite VII with palisade fringe.

$o^{\star}$ : unknown.

\section{Comparative notes:}

This species is readily distinguished from other macropterous Neosclerus species by the characteristic punctation of head and pronotum. The male characters, which would be essential for assessing its phylogenetic affiliations, are unknown.

\section{Distribution and bionomics:}

If the two specimens listed as additional material from West Bengal, northeastern India, and the type specimens from Uttar Pradesh, northwestern India, are indeed conspecific, this species is rather widespread. According to CAMERon (1924, 1931), the type material of N. granulicollis and $N$. frater was collected from stream moss. The only male available has a teratologically deformed aedeagus and a sternite VIII without posterior excision. 

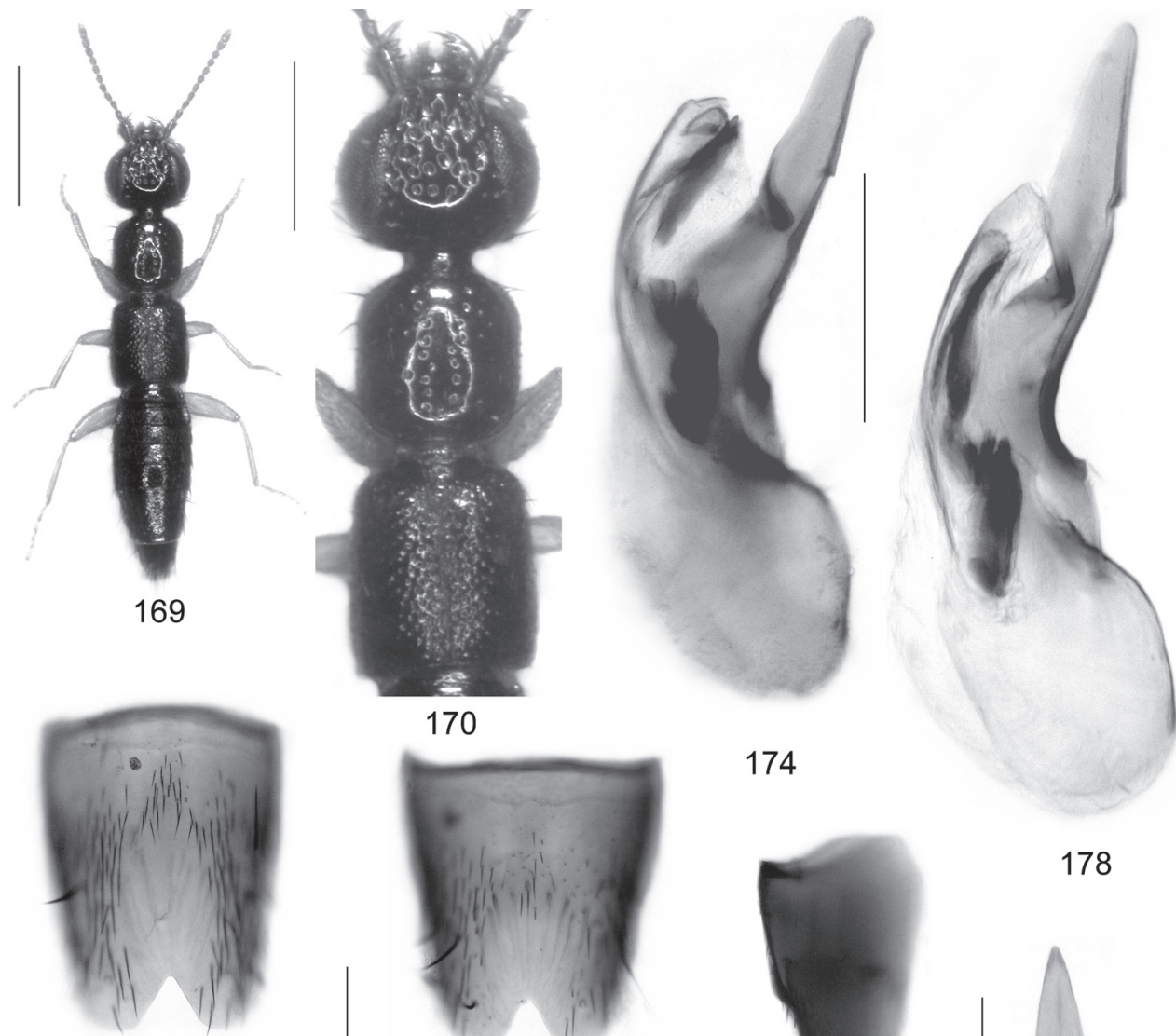

170

177
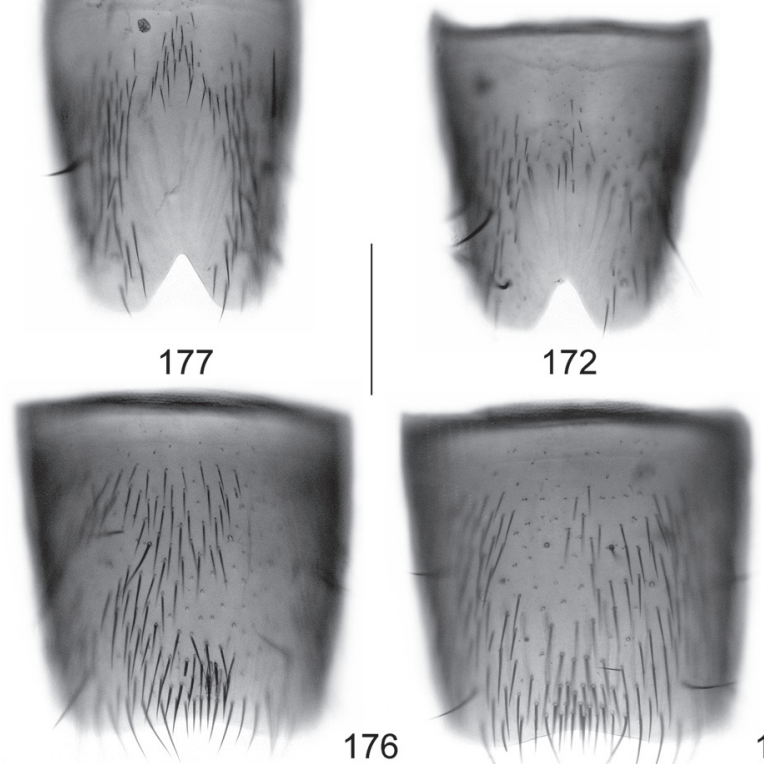

174

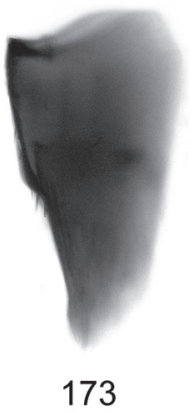

178

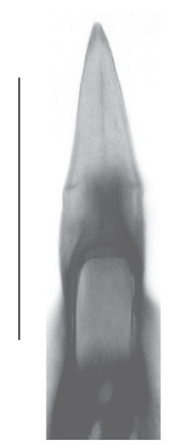

175

Figs 169-178: Neosclerus schillhammeri sp. n. (169-175) and N. brevipennis (CAMERON) from Arunachal Pradesh (176-178): habitus (169); forebody (170); male sternite VII $(171,176)$; male sternite VIII in ventral view $(172,177)$; male sternite VIII in lateral view (173); aedeagus in lateral view $(174,178)$; apical portion of aedeagus in ventral view (175). Scale bars: $169: 1.0 \mathrm{~mm}$; 170: $0.5 \mathrm{~mm}$; 171-178: $0.2 \mathrm{~mm}$. 


\section{Undescribed species}

Several additional, most likely unnamed species were examined, but are not described, since males are not available:

Neosclerus sp. 1: 1 ㅇ: India, Meghalaya, SW Cherrafunjee, 25ำ13-14'N, 91²4'E, 900 m, 5.-24.V.2005, leg. Pacholatko (BMNH).

Neosclerus sp. 2: 1 9 : [India, Meghalaya?], "Da-laen-saen nr. Nong-po. Walker Coll. 93.-18." (BMNH).

Neosclerus sp. 3: 3 우 ㅇ: S-Indien, 15.XI.1993, Tamil Nadu, Nilgiri hills, 15 km SE Kotagiri (3), Kunchappanai, $900 \mathrm{~m} / 76^{\circ} 56^{\prime} \mathrm{E}, 11^{\circ} 22^{\prime} \mathrm{N}$, leg. Boukal \& Kejval" (NHMW).

Neosclerus sp. 4: 1 ㅇ: China, Guangxi, Dayaoshan, 18.IX.1998, leg. J. R. Fellowes (cRou).

Neosclerus sp. 5: 1 i : China, Guangxi, Hongdon, Mulun, 22.VII.1998, leg. J. R. Fellowes (cRou).

Neosclerus sp. 6: 3 우: China, S-Sichuan, Ya'an pref., Shimian Co., Xiaoxiang Ling, side valley above Nanya Cun near Caluo, 11 km S Shimian, 1250 m, 7.VII.1999, leg. Pütz, Schülke (cPüt, cSch).

Neosclerus sp. 7: 3 우: Taiwan, Taitung Hsien, Hsinkangshan above Chengkang, 900 m, 19.IV.1998, A. Smetana [184] (cSme).

\section{Key to the species of Neosclerus}

1. Posterior margin of abdominal tergite VII without palisade fringe. Elytra short, at most approximately 0.75 times as long as pronotum. Hind wings completely reduced. Species from southern China and Taiwan.

2

Posterior margin of abdominal tergite VII with palisade fringe. Elytra at least approximately 0.85 times as long as pronotum. Hind wings not completely reduced, but sometimes of reduced length. 11

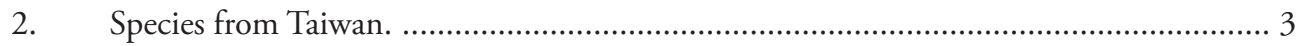

Species from southern China. ......................................................................... 9

3. Elytra approximately 0.75 times as long as pronotum (Fig. 74). Head with denser punctation (Fig. 74). $0^{*}$ : sternite VIII posteriorly without distinct cluster of modified setae (Fig. 75); sternite VIII anteriorly without spinose process (Figs 76-77); aedeagus as in Figs 78-79. Hsinchu Hsien. N. inarmatus sp. n.

- Elytra shorter, approximately 0.60-0.65 times as long as pronotum. Head with less dense punctation. $\sigma^{7}$ : sternite VII posteriorly with distinct cluster of modified setae; sternite VIII anteriorly with spinose process (best visible in lateral view); aedeagus of different morphology. 4

4. $\sigma^{\star}$ : aedeagus long and slender (length $>0.83 \mathrm{~mm}$ ), ventral process slender and with median carina in ventral view, internal sac with long and massive dark structures in apical portion (Figs 141-142); sternite VIII shaped as in Figs 128-129, anteriorly with broad and long carina (Fig. 140). Pingtung Hsien. N. carinatus $\mathrm{sp} . \mathrm{n}$. $\mathrm{o}^{\star}$ : aedeagus shorter $(<0.74 \mathrm{~mm})$ and less slender, ventral process of completely different shape and without apical carina, internal sac with the usual basal pair of sclerotized structures, but without large dark structures in apical portion; sternite VII of different shape and anteriorly with narrower carina. 
5. $\sigma^{*}$ : aedeagus with apex of ventral process in lateral view slender, shaped as in Figs 133134.

$0^{t}$ : aedeagus with ventral process of different shape.

6. $\sigma^{\star}$ : sternite VIII with anterior carina very slender, longer, and more strongly extended posteriorly (Figs 120-121); posterior excision of sternite VIII deeper, its depth approximately $1 / 4$ the length of sternite (Fig. 119); aedeagus with ventral process apically more slender in lateral view (Figs 122-124, 134). Kaohsiung Hsien. N. bifidus sp. n. $0^{*}$ : sternite VIII with anterior carina broader, shorter, and less strongly extended posteriorly (Figs 129-130); posterior excision of sternite VIII less deep, its depth approximately $1 / 5$ the length of sternite (Fig. 128); aedeagus with ventral process apically less slender in lateral view (Figs 131-133). Nantou Hsien.

N. atsushii SнIBATA

7. $\sigma^{*}$ : ventral process of aedeagus apically broader in lateral view (Figs 98-100); posterior margin of sternite VII distinctly concave in the middle (Fig. 94); sternite VIII as in Figs 95-97. Nantou and Taoyuan Hsien.

N. configens sp. n.

$\sigma^{*}$ : ventral process of aedeagus apically more slender in lateral view; posterior margin of sternite VII weakly concave in the middle. 8

8. $\sigma^{\text {t }}$ : ventral process apically more slender in lateral view and less abruptly narrowed in ventral view (Figs 107-108); sternite VIII anteriorly with longer process (Figs 104-106). Yilan Hsien. N. smetanai sp. n.

$\sigma^{\star}$ : ventral process apically less slender in lateral view and more abruptly narrowed in ventral view (Figs 114-115); sternite VIII anteriorly with shorter and less erect process (Figs 112-113). Hsinchu Hsien. N. armatus sp. n.

9. Punctation of head distinctly sparser in posterior than in anterior portion of dorsal surface; postocular region moderately short, approximately as long as width of antennomere I (Fig. 81). $0^{\text {* }}$ : aedeagus with ventral process subapically notched and acutely dentate (Figs 89-90); sternite VIII anteriorly with median carina posteriorly extending into a bifid process (Figs 86-88). Wuyi Shan (Fujian and Jiangxi provinces). N. hlavaci sp. $\mathrm{n}$.

- Punctation of head posteriorly as dense as, or only slightly less dense than that of anterior portion of dorsal surface; postocular region indistinct, almost obsolete. $\sigma^{\star}$ : aedeagus with ventral process of different shape; sternite VIII anteriorly without carina and without process. 10

10. Head with indistinct microreticulation in anterior portion of dorsal surface. Impunctate midline of pronotum not sulcate (Fig. 61). $0^{\star}$ : sternite VII strongly transverse and with weakly concave posterior margin (Fig. 62); sternite VIII with very narrow posterior excision and without anterior elevation (Figs 63-64); aedeagus shaped as in Fig. 65. Guangxi province.

N. incisus sp. n.

Head with distinct microreticulation everywhere and matt. Midline of pronotum narrowly sulcate (Fig. 55). o`: sternite VII weakly transverse (Fig. 59); sternite VIII anteriorly elevated and posteriorly with V-shaped excision (Figs 56-57); aedeagus shaped as in Fig. 58. Guangxi province.

N. rimatus sp. $\mathrm{n}$.

11. Pronotum and elytra reddish.

At least the pronotum darker, dark-brown to blackish. 
12. Whole body of uniformly reddish coloration. Head with extremely dense punctation and matt, interstices reduced to narrow ridges and with microreticulation (Fig. 22). $\sigma^{\text {* }}$ : sternite VII with posterior margin broadly and very weakly concave, with row of long submarginal setae, otherwise unmodified (Fig. 23); sternite VIII slender, with dense pubescence and broadly $\mathrm{V}$-shaped posterior excision, otherwise unmodified (Fig. 24); aedeagus of characteristic morphology (Figs 25-26). Borneo: Sabah.

N. erubescens sp. n.

Head blackish, distinctly contrasting with the reddish pronotum. Head with very dense and coarse punctation, but interstices without microsculpture (Fig. 165). $\sigma^{\top}$ : unknown. NE-India.

N. assamensis (CAMERON)

13. Punctation of pronotum fine, dense, and somewhat granulose, much finer than that of head (Fig. 167). Head with very dense and coarse punctation (Fig. 168). $\sigma^{*}$ : sexual characters unknown. N-India, Nepal. N. granulicollis CAMERON Punctation of pronotum coarse and not granulose, at most slightly finer than that of head.

14. Species known only from Java. Head with postocular region obsolete.

N. javanus (BERNHAUER)

Unknown from Java. Head often with short, but noticeable postocular region.

15. $0^{\top}$ : ventral process of aedeagus dorso-ventrally somewhat flattened, curved and subapically not dentate in lateral view, apically abruptly narrowed and acute in ventral view; internal sac with pair of slender and long sclerotized structures in apical portion. 16

$\mathrm{o}^{\mathrm{t}}$ : ventral process of aedeagus dorso-ventrally in most species not flattened, usually straight and subapically or apically dentate in lateral view, apically gradually narrowed in ventral view; internal structures of different shape and in different position.

16. Elytra (almost) uniformly blackish-brown to blackish. ơ : sternite VII unmodified (Fig. 146); sternite VIII anteriorly unmodified (Fig. 147); aedeagus shaped as in Figs 148-150. Widespread: S-China, Hongkong, Thailand, Malaysia. N. glaber sp. n. Elytra dark-brown, with the humeral angles and the posterior margins broadly reddish. $\sigma^{*}$ : sternite VII posteriorly with pair of tooth-like processes (Fig. 153); sternite VIII anteriorly with pair of carinae (Fig. 154); aedeagus shaped as in Figs 155-156. Vietnam.

N. bicarinatus sp. $\mathrm{n}$.

17. $0^{\top}$ : sternite VII unmodified, pubescence sparse (Fig. 158); sternite VIII unmodified, except for the posterior excision (Fig. 159); aedeagus of distinctive shape (Figs 160-161). Sri Lanka. N. nigerrimus (KRAATZ)

$\sigma^{\star}$ : sternite VII with pubescence denser and posteriorly modified; aedeagus of completely different morphology. Unknown from Sri Lanka.

18. Largest species of the genus of broad habitus (Fig. 66), body length 3.4-4.0 mm. Head and pronotum with conspicuously dense and areolate punctation, head matt (Fig. 67). $0^{\star}$ : sternite VII posteriorly very indistinctly concave in the middle (Fig. 68); sternite VIII anteriorly with elevation, in posterior median portion depressed and without pubescence, and with deep V-shaped posterior excision (Figs 69-70); aedeagus shaped as in Figs 71-72. S-China: Yunnan. N. schuelkei sp. n.

Body smaller and more slender. Punctation of head and pronotum less dense and not areolate; head not completely matt. $0^{\star}$ : sexual characters different. 
19. $\sigma^{\pi}$ : internal sac of aedeagus with two long series of small spines; ventral process of aedeagus slender, apically not spear-shaped. 20

$\sigma^{*}$ : internal sac of aedeagus with pair of sclerotized structures, but without long series of small spines; ventral process of aedeagus apically spear-shaped, acute and subapically dentate.

20. $0^{*}$ : aedeagus with apex of ventral process of distinctive shape, not hooked (Figs 19-20); sternites VII and VIII as in Figs 17-18. Thailand. N. barbatus sp. n. $\sigma^{\star}$ : aedeagus with ventral process apically weakly to distinctly hooked. N-India, Nepal.

21. $\mathrm{O}^{\star}$ : sternite VII posteriorly with more extensive cluster of long dark setae, posterior margin distinctly concave in the middle (Fig. 10); sternite VIII with deeper posterior excision, its depth about $1 / 4$ the length of sternite (Fig. 11); aedeagus with ventral process stouter, apically more distinctly hooked in lateral view and apically less slender in ventral view, internal sac with more massive series of spines (Figs 12-14). N. dupleseriatus sp. $\mathrm{n}$. $\sigma^{\text {t }}$ : sternite VII posteriorly with less conspicuous cluster of long setae, posterior margin only very indistincty concave in the middle (Fig. 3); posterior excision of sternite VIII less deep, its depth approximately $1 / 5$ the length of sternite (Fig. 4); aedeagus with ventral process very slender, apically weakly hooked in lateral view and more slender in ventral view (Figs 5-6). N. fortepunctatus CAMERON

22. Elytra shorter, 0.85-0.95 times as long as pronotum. $\sigma^{*}$ : aedeagus with ventral process apically conspicuously slender and acute.

Elytra longer, 1.10-1.15 times as long as prontoum. $0^{7}$ : aedeagus with ventral process apically less slender and acute.

23. $\sigma^{*}$ : sternite VIII anteriorly not elevated and without carinae, posterior excision less deep, its depth approximately $1 / 6$ the length of sternite; ventral process of aedeagus apically dorsoventrally compressed, in lateral view extremely slender (Figs 38-39). S-China: Yunnan; Thailand. N. praeacutus sp. $\mathrm{n}$.

$\sigma^{*}$ : sternite VIII anteriorly with pair of short carinae, in lateral view elevated, posteriorly depressed and extensively devoid of pubescence (Figs 31, 173), posterior excision deeper, its depth approximately $1 / 5$ the length of sternite; ventral process of aedeagus apically laterally compressed (Figs 32-33, 178). 24

24. Elytra usually more or less distinctly paler than head and pronotum, reddish-brown to brown. $\sigma^{x}$ : sternite VIII longer and more slender, posteriorly more extensively devoid of pubescence (Figs 30-31, 176); aedeagus with ventral process on ventral side angled and on dorsal side distinctly incised in the middle (lateral view), apex of ventral process more acute (lateral view), apical internal structures longer and more slender (Figs 32-33, 178). Southern Himalaya region (N-India, Bhutan, Nepal). N. brevipennis (CAMERON) Elytra dark-brown, of similar coloration as pronotum; $0^{\star}$ : sternite VIII shorter and less slender, posteriorly less extensively devoid of pubescence (Figs 172-173); aedeagus with ventral process on ventral side straight and on dorsal side not distinctly incised in the middle (lateral view), apex of ventral process rounded and slightly bent ventrad; apical internal structures shorter and stouter (Figs 174-175). Myanmar. N. schillhammeri sp. n. 
25. Head usually with distinct microsculpture, at least in posterior portion of dorsal surface

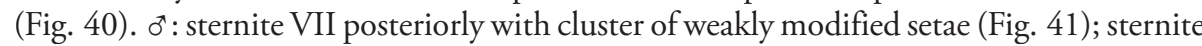
VIII more slender, with longer and more extensive depression without pubescence (Fig. 46); ventral process of aedeagus apically very acute in lateral view and less acute in ventral view (Figs 43-45). Widespread: Thailand, Myanmar, S-China. N. barbatulus sp. $\mathrm{n}$.

- Head without microsculpture (Fig. 48). $0^{\star}$ : sternite VII posteriorly with cluster of stout and short black setae (Fig. 49); sternite VIII less slender and with shorter, less oblong depression without pubescence; ventral process of aedeagus apically much less acute in lateral view and more acute in ventral view (Figs 52-53). Thailand.

N. rougemonti sp. $\mathrm{n}$.

\section{Catalogue of the species of Neosclerus}

\begin{tabular}{|c|c|}
\hline species & revised distribution \\
\hline armatus sp. $\mathbf{n}$. & Taiwan: Hsinchu \\
\hline assamensis (CAMERON, 1931); comb. $\mathbf{n}$. & NE-India \\
\hline atsushii Shibata, 1992 & Taiwan: Nantou \\
\hline barbatulus sp. $\mathrm{n}$. & Thailand, Myanmar, China: Yunnan \\
\hline barbatus sp. $\mathbf{n}$. & Thailand \\
\hline bicarinatus sp. $\mathbf{n}$. & Vietnam \\
\hline bifidus sp. $\mathrm{n}$. & Taiwan: Kaohsiung \\
\hline $\begin{array}{l}\text { brevipennis (CAMERON, 1943) } \\
=\text { brevipennis (COIFFAIT, 1978) } \\
=\text { houlberti (COIFFIT, 1987); syn. } \mathbf{n} .\end{array}$ & N-India, Bhutan, Nepal? \\
\hline carinatus sp. $\mathrm{n}$. & Taiwan: Pingtung \\
\hline configens sp. $\mathbf{n}$. & Taiwan: Nantou, Taoyuan \\
\hline dupleseriatus sp. $\mathbf{n}$. & N-India, Nepal \\
\hline erubescens sp. $\mathbf{n}$. & Malaysia: Borneo: Sabah \\
\hline fortepunctatus CAMERON, 1924 & N-India, Nepal \\
\hline $\begin{array}{l}\text { granulicollis CAMERON, } 1924 \\
=\text { frater } \text { CAMERON, 1924; syn. } \mathbf{n} .\end{array}$ & N-India, Nepal \\
\hline glaber sp. $\mathrm{n}$. & S-China, Hongkong, Thailand, Malaysia \\
\hline hlavaci sp. $\mathbf{n}$. & China: Fujian, Jiangxi \\
\hline inarmatus sp. $\mathrm{n}$. & Taiwan: Hsinchu \\
\hline incisus sp. $\mathrm{n}$. & China: Guangxi \\
\hline javanus (BERnhAUER, 1920); comb. $\mathbf{n}$. & Indonesia: Java \\
\hline nigerrimus (KRAATZ, 1859); comb. n. & Sri Lanka \\
\hline praeacutus sp. $\mathrm{n}$. & China: Yunnan, Thailand \\
\hline rimatus sp. $\mathbf{n}$. & China: Guangxi \\
\hline rougemonti sp. $\mathrm{n}$. & Thailand \\
\hline schillhammeri sp. n. & Myanmar \\
\hline schuelkei sp. n. & China: Yunnan \\
\hline smetanai sp. $\mathbf{n}$. & Taiwan: Yilan \\
\hline
\end{tabular}




\section{Species excluded from Neosclerus}

Sunius cameroni nom. n. (Figs 179-185)

Lobochilus brachypterus CAMERon, 1943: $33 \mathrm{f}$.

Neosclerus brachypterus: SMETANa (2004: 622).

Type material:

Holotype + : "Ghum dist. Tiger Hill, 8,500-10,000 ft., v-vi.31, Dr. Cameron / Syntype / Type / L. brachypterus Cam. Type / M. Cameron. Bequest. B.M. 1955-147. / Holotypus Lobochilus brachypterus Cameron, rev. V. Assing 2010 / Sunius cameroni nom. n., det. V. Assing 2010" (BMNH). Paratype $0^{*}$ : "Ghum dist. Tiger Hill, 8,500-10,000 ft., v-vi.31, Dr. Cameron / Syntype / M. Cameron. Bequest. B.M. 1955-147. / Syntype Lobochilus brachypterus Cameron, 1943: 33, det. R.G. Booth 2010 / Paratypus Lobochilus brachypterus Cameron, rev. V. Assing 2010 / Sunius cameroni nom. n., det. V. Assing 2010" (BMNH).

Additonal material examined:

1 ơ, 1 ㅇ, N-India, Ghum district, V.-VI.1931, leg. Cameron (BMNH).

\section{Comment:}

The original description is based on an unspecified number of specimens from "Ghum district: Tiger Hill, altitude 8000-10,000 feet" (CAMEron 1943). Two of them, a male and a female, were located in the collections of the BMNH. In referring to one of them as the type ("Type in my collection"), CAMERON (1943) designated a holotype. As can be inferred from the labels attached to the two specimens, the female must be regarded as the holotype.

The aedeagus of the male listed as additional material above is distinguished from that of the paratype by the slightly different shape of the apex of the ventral process, both in lateral and in ventral view (Figs 172-175), suggesting that it may represent a distinct species. However, since it is currently not known whether these differences are constant, they are provisionally attributed to intra- rather than interspecific variation.

An examination of the types and the additional material, particularly the morphology of the aedeagus, but also external characters such as the size of the eyes, the shape of the labrum, and the shape and punctation of the pronotum, revealed that the species is not particularly closely related to $N$. fortepunctatus and other Neosclerus species. Consequently, there is little doubt that an inclusion of this species in Neosclerus would render the genus polyphyletic. Instead, the characters examined are more similar to those of species currently attributed to the genus Sunius. The eyes are larger than is usually the case in Sunius - similarly large-eyed Sunius species are known only from the Himalaya and southern China (Assing 2010) -, but not near as large as in Neosclerus. Even in micropterous true Neosclerus, the eyes are not distinctly smaller than in macropterous species.

As the binomen Sunius brachypterus is preoccupied by S. brachypterus (GEMminger \& Harold, 1868), a species distributed in the western Pyrenees, the replacement name S. cameroni nom. n. is proposed for Lobochilus brachypterus CAMERON.

\section{Description:}

Body length 3.5-3.7 mm. Coloration: body blackish-brown; legs and antennae reddish.

Head across eyes 1.05-1.10 times as wide as long, tapering behind eyes; postocular region approximately half the length of eyes (Fig. 179); punctation coarse and dense in anterior half, sparse in posterior half of dorsal surface; interstices without microsculpture and glossy; antenna approximately $1.0 \mathrm{~mm}$ long. 


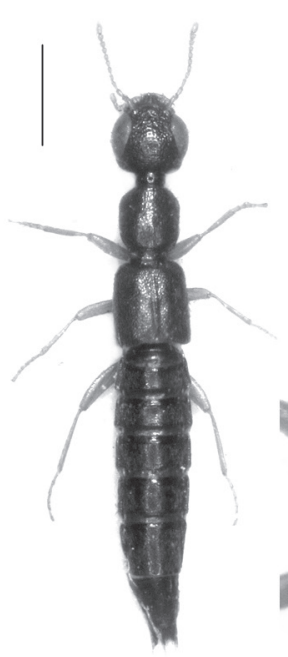

186
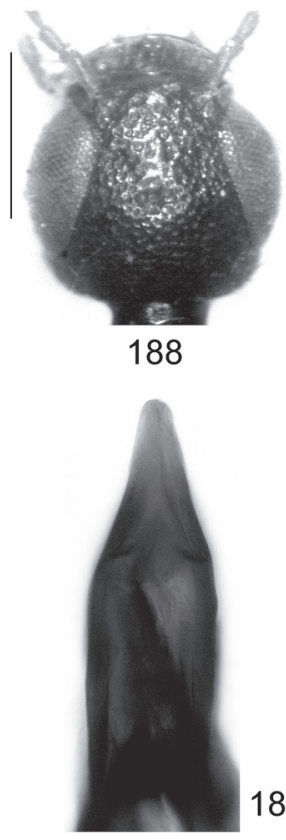

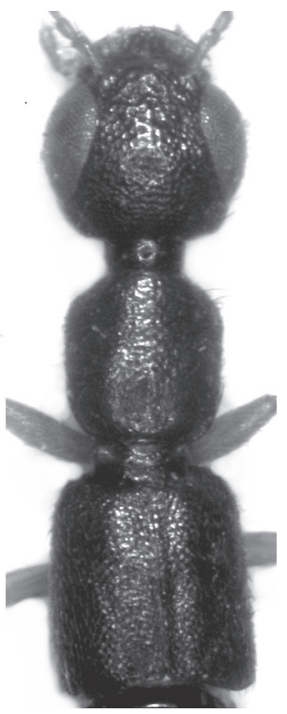

187

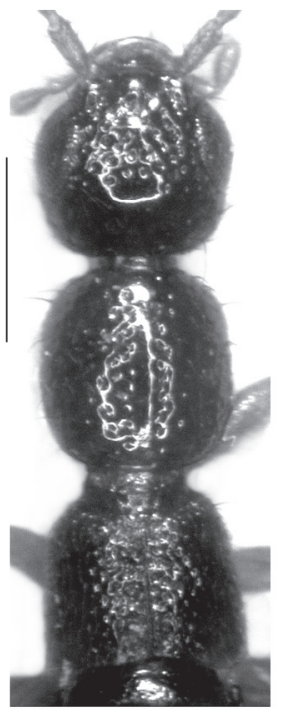

179

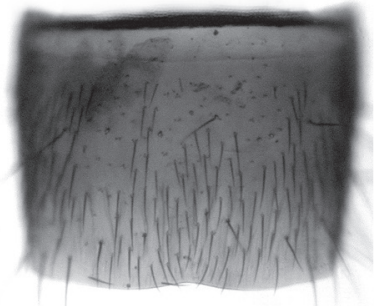

180

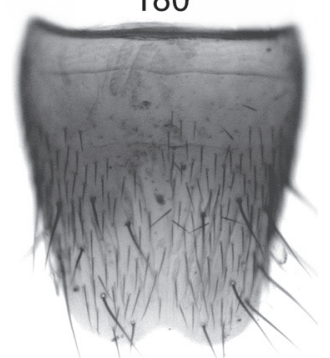

181

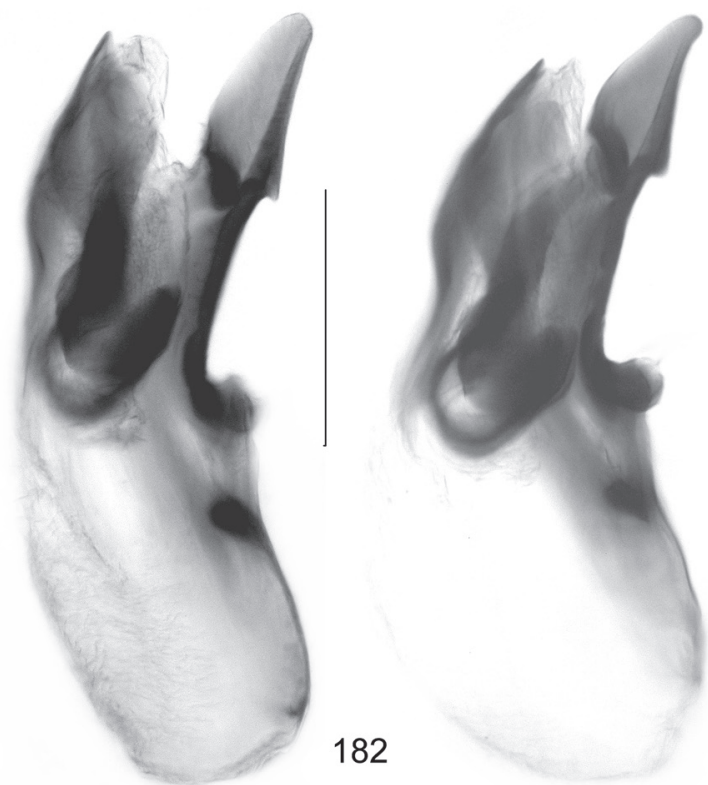

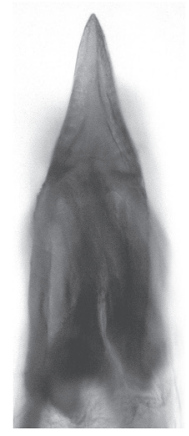

183

Figs 179-188: Sunius cameroni nom. n. (179-185; 179-183: paratype) and "Medon" labralis (CAMERON), holotype (186-188): forebody (179, 187); male sternite VII (180); male sternite VIII (181); aedeagus in lateral view $(182,184)$; apical portion of aedeagus in ventral view $(183,185)$; habitus (186); head (188). Scale bars: 186: $1.0 \mathrm{~mm}$; 179, 187-188: $0.5 \mathrm{~mm}$; 180-185: $0.2 \mathrm{~mm}$.

Pronotum 1.05-1.10 times as wide as long and approximately 0.97 times as wide as head; punctation coarse and dense; midline rather narrowly impunctate (Fig. 179); interstices without microsculpture and glossy. 
Elytra short, 0.60-0.65 times as long and at posterior margin approximately 1.05 times as wide as pronotum, noticeably widened posteriad; humeral angles weakly pronounced (Fig. 179); punctation rather dense and shallow. Hind wings reduced.

Abdomen approximately 1.1 times as wide as elytra; punctation fine and dense, moderately dense on tergites III-V and sparse on posterior tergites; interstices with shallow microsculpture; posterior margin of tergite VII without palisade fringe.

$0^{t}$ : sternite VII with posterior margin very weakly concave in the middle, otherwise unmodified (Fig. 180); sternite VIII with very shallow posterior excision, otherwise unmodified (Fig. 181); aedeagus with short, stout, subapically dentate (lateral view), and apically very acute (ventral view) ventral process and with U-shaped (lateral view) internal structures (Figs 182-185).

\section{Comparative notes:}

This species is readily distinguished from other Sunius species recorded from the Eastern Palaearctic region by the larger eyes, the shorter elytra, the reduced hind wings, the absence of a palisade fringe at the posterior margin of the abdominal tergite VII, and by the male sexual characters.

\section{Distribution and bionomics:}

The type locality is situated in Ghum district, near Darjiling, West Bengal, northern India. The adaptive reductions of the eyes and wings suggest that $N$. cameroni has a restricted distribution. Therefore, it seems very likely that the record from Meghalaya (as Neosclerus brachypterus) by BisWAS \& BisWAS (2000) refers to a different species. The type specimens were collected in moss at an altitude of $2400-3050 \mathrm{~m}$.

"Medon" labralis (CAMERon, 1943); comb. n. (Figs 186-188)

Lobochilus labralis CAMERon, 1943: 33.

Neosclerus labralis: SMETANA (2004: 622).

Type material:

Holotype + : "Holotype. / Ghum dist., Rongdong Valley, v-vi.1931, Dr. Cameron / L. labralis Cam. Type / M. Cameron. Bequest. B.M. 1955-147. / Holotype Lobochilus labralis Cameron, 1943, det. R.G. Booth 2010 / Holotypus Lobochilus labralis Cameron, rev. V. Assing 2010 / "Medon" labralis (Cameron), det. V. Assing 2010" (BMNH).

Additional material examined:

Nepal: 1 ㅇ, Ilam, Mai Pokhari, 2000 m, V.1987, leg. Morvan (cRou).

Comment:

The original description is based on a single specimen from "Ghum district: Rongdon Valley" (CAMERON 1943). The holotype shares the large and bulging eyes with species of Neosclerus, but is distinguished by so numerous and significant characters (shape of the labrum, broader and longer clypeus, conspicuously short antennae, punctation of forebody and abdomen, microsculpture of abdomen, slender habitus and legs, size, habitus, etc.) that, despite the fact that the male characters are unknown, it may safely be assumed that it is not congeneric with the type species of Neosclerus and that the large eyes are a result of convergent evolution. Therefore, it seems best to tentatively refer the species to the genus Medon STEPHENS, 1833, which already includes numerous species of unknown generic affiliations. 


\section{Redescription:}

Body length $5.5 \mathrm{~mm}$ (with abdomen fully extended). Habitus as in Fig. 186. Coloration: body blackish; legs pale reddish; antennae yellowish.

Head across eyes approximately 1.12 times as wide as long; eyes large, postocular region approximately as long as antennomere II; punctation on frons coarse and dense (Fig. 188), in posterior portion of dorsal surface much finer, shallow, dense, and confluent near neck; anterior margin of labrum with a long tooth on either side of the median incision; antenna short in relation to body size, only approximately $1 \mathrm{~mm}$ long.

Pronotum approximately 1.05 times as long as wide and approximately 0.8 times as wide as head (Fig. 187); punctation moderately fine, very shallow, partly ill-defined and confluent; midline only shortly impunctate in posterior half.

Elytra indistinctly longer than, and 1.35 times as wide as pronotum; humeral angles marked (Fig. 187); punctation dense and fine. Hind wings present.

Abdomen slightly narrower than elytra; punctation very fine and dense, barely noticeable in the pronounced microsculpture; posterior margin of tergite VII with palisade fringe.

$o^{\star}$ : unknown.

\section{Distribution and bionomics:}

The species was previously known only from the type locality in West Bengal, northeastern India. The specimen from Nepal represents a new country record. It was collected at an altitude of $2000 \mathrm{~m}$ in May.

\section{Acknowledgements}

My thanks are extended to the colleagues listed in the material section for the loan of material from their respective collections. In particular, I am grateful to Guillaume de Rougemont for very helpful comments and his generous permission to retain the holotypes of $N$. barbatus and $N$. incisus, to Michael Schülke for the gift of the holotypes of $N$. schuelkei and N. praeacutus, to Aleš Smetana for the gift of the holotypes of $N$. smetanai and $N$. carinatus, as well as for providing additional data for his material collected in Taiwan, to Giulio Cuccodoro (Genève) and Stanislav Vít (Genève) for permission to retain the holotypes of $N$. inarmatus and N. armatus, to Harald Schillhammer (NHMW) for the permission to retain the holotype of N. schillhammeri, to Peter Hlavač (Košice) for the generous gift of his Neosclerus material from China, and finally to Lee H. Herman for the Neosclerus section of his unpublished manuscript catalogue of the Paederinae. Benedikt Feldmann (Münster) proof-read the manuscript.

\section{References}

Assing, V. 2006: A revision of Western Palaearctic Medon: the species of the Atlantic Islands, the Western Mediterranean, and Europe, except for the southeast (Insecta: Coleoptera: Staphylinidae: Paederinae). - Bonner zoologische Beiträge 54 (2005): 25-95.

Assing, V. 2008a: A revision of the Sunius species of the Western Palaearctic region and Middle Asia (Coleoptera: Staphylinidae: Paederinae). - Linzer biologische Beiträge 40 (1): 5-135.

Assing, V. 2008b: Four new species and additional records of Palaearctic Sunius, with two new synonymies

(Coleoptera: Staphylinidae: Paederinae). - Beiträge zur Entomologie, Keltern 58 (2): 455-470.

Assing, V. 2010: A revision of Palaearctic Sunius. XII. New species, additional records, and a new synonymy (Coleoptera: Staphylinidae: Paederinae). - Linzer biologische Beiträge 42 (2): 1045-1061. 
Bernhauer, M. 1920: Neue Staphyliniden des indo-malayischen Gebietes. 16. Beitrag. - Archiv für Naturgeschichte (A) 84 (1918): 177-188.

Bernhauer, M. \& Schubert, K. 1912: Staphylinidae III. (Pars 40). - In: Junk, W. \& Schenkling, S. (eds.): Coleopterorum Catalogus. Volumen 5. Staphylinidae. - Junk, Berlin: 191-288.

Biswas, D. N. 2003: Insecta: Coleoptera: Staphylinidae. - Zoological Survey of India. State Fauna series 9, Fauna of Sikkim (Part 3): 237-281.

Biswas, D. N. \& Biswas, S. 1995: Insecta: Coleoptera: Staphylinidae. - Zoological Survey of India. State Fauna series 3, Fauna of West Bengal, Part 6 (A): 201-361.

Biswas, D. N. \& Biswas, S. 2000: Insecta: Coleoptera: Staphylinidae. pp. 115-160. - Zoological Survey of India. State Fauna series 4. Fauna of Meghalaya. Part 5: 115-160.

BLACKwelder, R. E. 1952: The generic names of the beetle family Staphylinidae, with an essay on genotypy. - United States National Museum Bulletin 200: i-iv + 1-483.

Cameron, M. 1924: New species of Staphylinidae from India. - The Transactions of the Entomological Society of London 1924: 160-198.

Cameron, M. 1931: The fauna of British India including Ceylon and Burma. Coleoptera. Staphylinidae. Vol. 2. - London, Taylor and Francis: i-viii + 1-257.

Cameron, M. 1943: Descriptions of new Staphylinidae (Coleopt.). - The Proceedings of the Royal Entomological Society of London (B) 12: 1-5, 32-36, 127-132.

Corffait, H. 1975: Xantholininae, Paederinae et Euaesthetinae récoltés au Népal par le professeur Franz (Coleoptera, Staphylinidae). - Nouvelle Revue d'Entomologie 5 (2): 153-186.

Coiffart, H. 1978: Ergebnisse der Bhutan-Expedition 1972 des Naturhistorischen Museums in Basel. Coleoptera: Fam. Staphylinidae Subfam. Paederinae, Euaesthetinae, Piestinae, Osoriinae et Omalinae [sic]. - Entomologica Basiliensia 3: 109-150.

Coiffait, H. 1982: Contribution à la connaissance des Staphylinides de l'Himalaya (Népal, Ladakh, Cachemire) (Insecta: Coleoptera: Staphylinidae). - Senckenbergiana biologica 62: 21-179.

Corffart, H. 1987: Nouvelles corrections homonymiques (Coleoptera, Staphylinidae). - Nouvelle Revue d'Entomologie (N. S.) 3 (1986): 497-498.

KraAtz, G. 1859: Die Staphylinen-Fauna von Ostindien, insbesondere der Insel Ceylan. - Archiv für Naturgeschichte 25: 1-196.

Shibata, Y. 1992: A new species of the genus Neosclerus (Coleoptera, Staphylinidae) from Taiwan. - Elytra 20: 183-187.

Smetana, A. 2004: Subfamily Paederinae Fleming, 1821. - In: Löbl, I. \& Smetana, A. (eds.): Catalogue of Palaearctic Coleoptera. Volume 2. Hydrophiloidea - Histeroidea - Staphylinoidea. - Stenstrup, Apollo Books: 579-624.

\section{Author's address:}

Dr. Volker Assing

Gabelsbergerstraße 2

30163 Hannover

Germany

e-mail: vassing.hann@t-online.de

\section{Subject Editor:}

B. Feldmann 